2012

\title{
THE PERFORMANCE AND MODIFICATION OF RECYCLED ELECTRONIC WASTE PLASTICS FOR THE IMPROVEMENT OF ASPHALT PAVEMENT MATERIALS
}

Baron W. Colbert

Michigan Technological University

Follow this and additional works at: https://digitalcommons.mtu.edu/etds

Part of the Civil Engineering Commons

Copyright 2012 Baron W. Colbert

Recommended Citation

Colbert, Baron W., "THE PERFORMANCE AND MODIFICATION OF RECYCLED ELECTRONIC WASTE PLASTICS FOR THE IMPROVEMENT OF ASPHALT PAVEMENT MATERIALS", Dissertation, Michigan Technological University, 2012.

https://doi.org/10.37099/mtu.dc.etds/472

Follow this and additional works at: https://digitalcommons.mtu.edu/etds

Part of the Civil Engineering Commons 


\title{
THE PERFORMANCE AND MODIFICATION OF RECYCLED ELECTRONIC WASTE PLASTICS FOR THE IMPROVEMENT OF ASPHALT PAVEMENT MATERIALS
}

\author{
By \\ Baron W. Colbert \\ A DISSERTATION \\ Submitted in partial fulfillment of the requirements for the degree of \\ DOCTOR OF PHILOSOPHY \\ In Civil Engineering \\ MICHIGAN TECHNOLOGICAL UNIVERSITY \\ 2012 \\ (C) Baron W. Colbert
}


This dissertation, "The Performance and Modification of Recycled Electronic Waste

Plastics for the Improvement of Asphalt Pavement Materials," is hereby approved in partial fulfillment of the requirements for the Degree of DOCTOR OF PHILOSOPHY IN CIVIL ENGINEERING.

Department of Civil and Environmental Engineering

Signatures:

Dissertation Advisor

Zhanping You

Department Chair

David Hand

Date 


\section{Table of Contents}

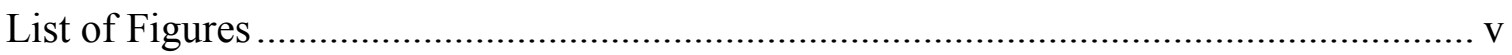

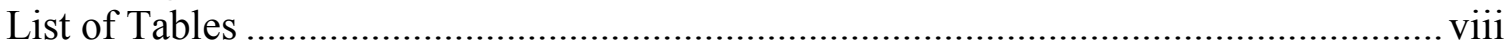

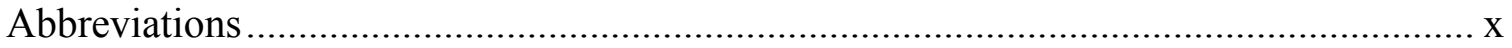

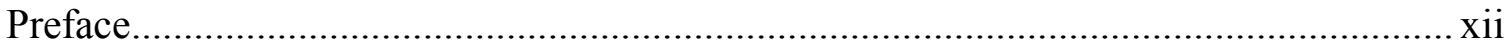

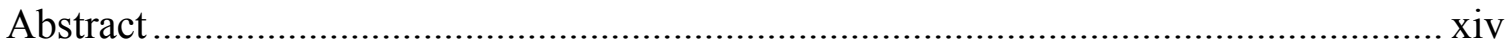

Electronic waste material background and research gaps.............................................. 1

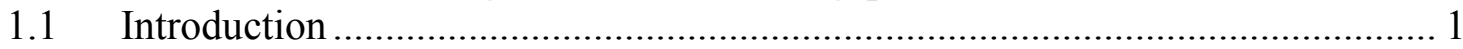

1.2 Bulk e-waste plastic properties considerations ………….................................. 2

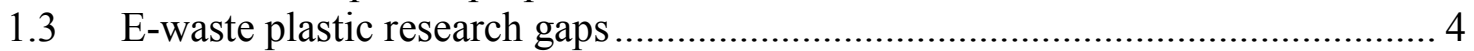

1.4 E-waste compatibility issues with aspahlt materials .......................................... 5

1.5 Electronic waste plastic applications for asphalt concrete research..................... 7

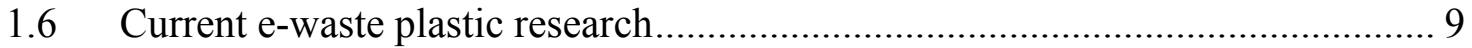

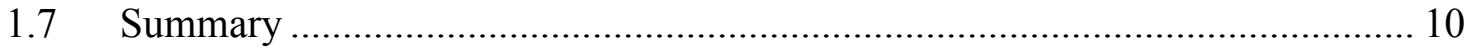

Dissertation hypothesis and objectives ................................................................... 11

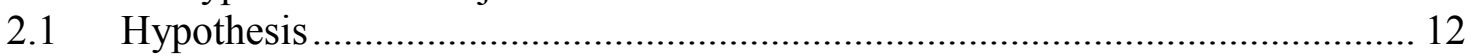

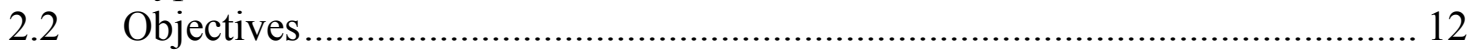

Chapter 3: Evaluation and performance of e-waste binders ............................................ 15

3.1 Asphalt binder performance characterization ……….................................. 15

3.2 Untreated e-waste binder results ................................................................ 16

3.3 Untreated e-waste binder summary .............................................................. 21

Chapter 4: The mechanical performance of asphalt binders modified with free radical

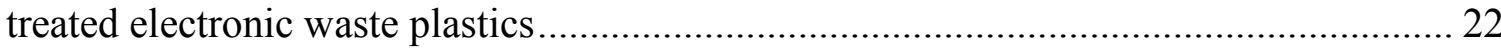

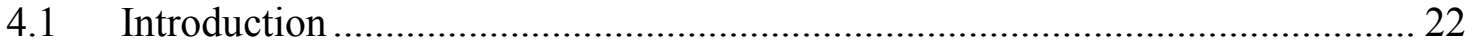

4.2 Treated e-waste asphalt binder research objectives ........................................... 22

4.3 Materials preparation and testing procedures.................................................. 23

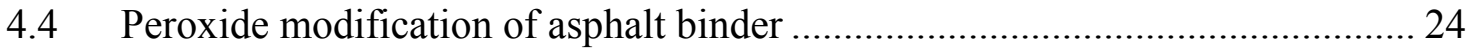

4.4.1 Asphalt binder viscosity characterization ................................................ 26

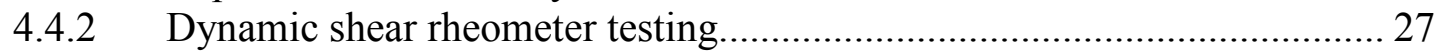

4.4.3 Asphalt binder artificial aging test procedures ………………………..... 27

4.4.4 Bending beam rheometer testing ......................................................... 28

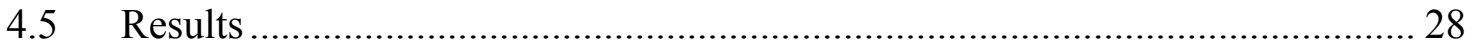

4.5.1 Viscosity results ........................................................................ 28

4.5.2 Complex moduli of e-waste modified asphalt binders ................................ 32

4.5.3 Low temperature asphalt binder performance results ................................. 35

4.5.4 Treated e-waste performance grade results................................................. 39

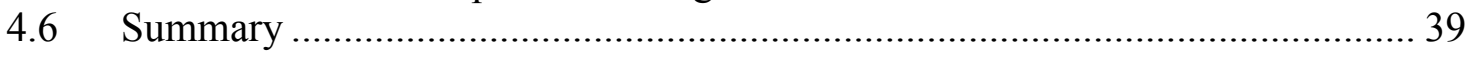

Chapter 5. E-waste binder aging susceptibility and chemical reaction verification......... 41

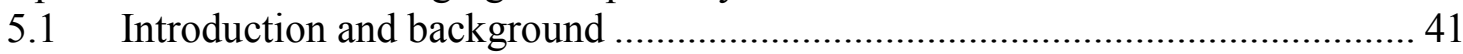

5.2 SEM procedures and analysis ...................................................................... 41

5.3 Differential scanning calorimeter procedures .................................................. 45 


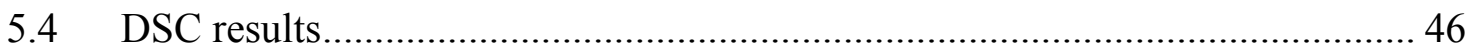

5.5 FTIR wavelength spectra analysis............................................................... 49

5.6 Aging susceptibility of electronic waste asphalt binders ………………….... 52

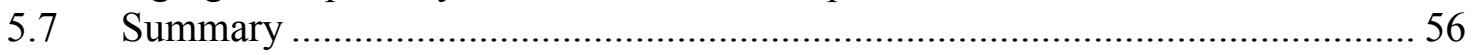

Chapter 6: The mechanical performance of asphalt mixtures modified with recycled e-

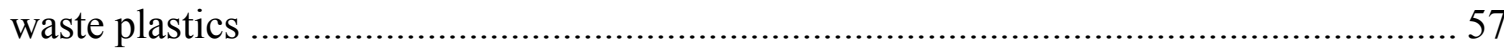

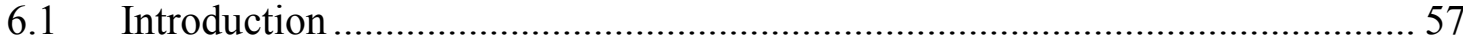

6.2 Characterization of e-waste modified HMA mixture........................................59

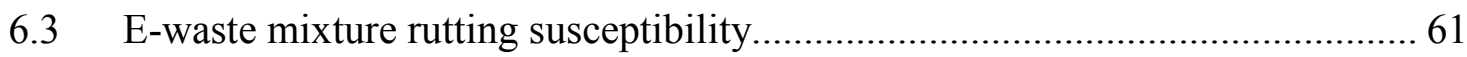

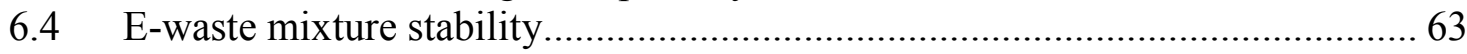

6.5 Dynamic moduli of e-waste modified asphalt mixtures ....................................... 66

6.6 E-waste mixture moisture susceptibility ............................................................ 70

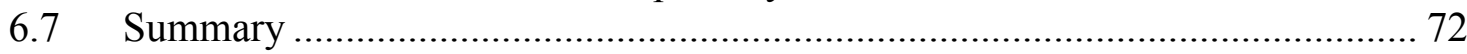

Chapter 7: A performance-emissions assessment for the comparison of e-waste modified

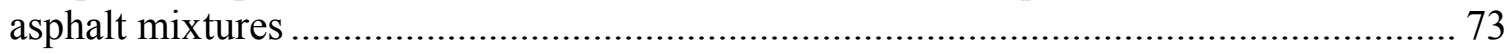

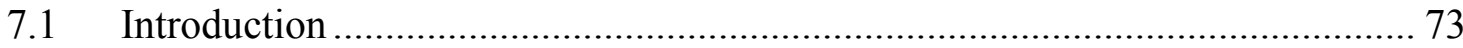

7.2 Emissions assessment model and assumptions …………………………..... 75

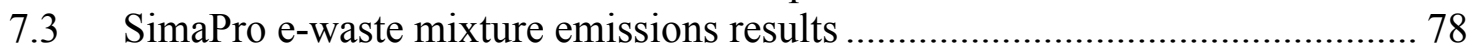

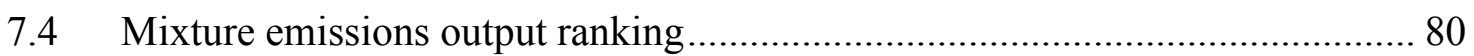

7.5 MEPDG rutting assessment of e-waste modified pavements ............................. 80

7.6 MEPDG mixture ranking based upon projected rutting ................................. 82

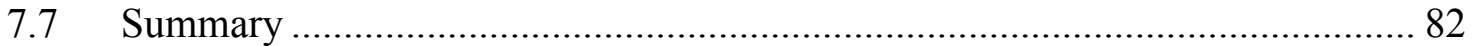

Chapter 8: Summary, conclusions, and recommendations .............................................. 84

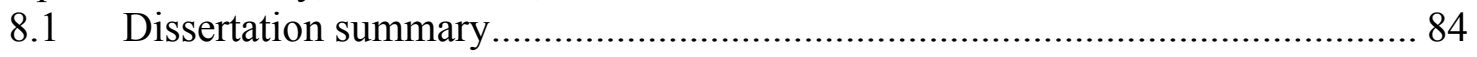

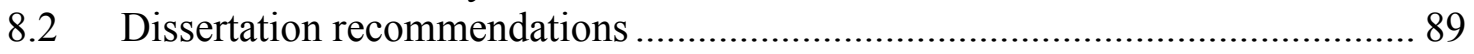

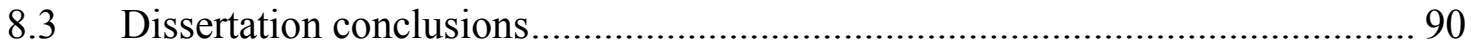

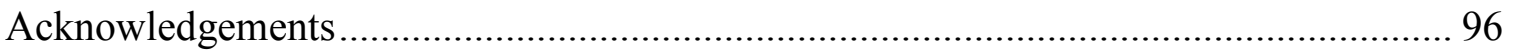

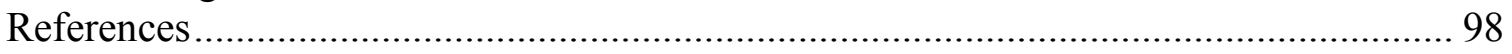

Appendix A: Copyright clearances ………………………................................... 104

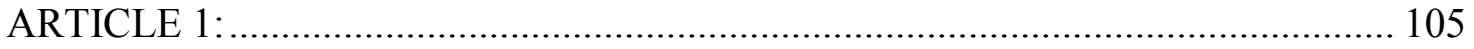




\section{List of Figures}

Figure 1.1 Electronic waste computer plastics used for the computer industry, (a) ABS,

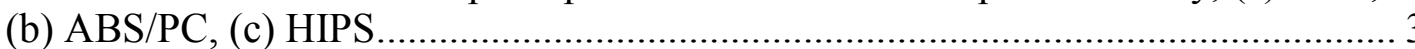

Figure 3.1 Viscosity results for untreated e-waste asphalt binders at $135^{\circ} \mathrm{C}$, taken from three replicates

Figure 3.2 E-waste modified binder viscosity for various sized e-waste plastic particlesviscosity test conducted using three replicates

Figure 3.3 BBR M-value comparisons between the control binder and e-waste modified asphalt binders based on three replicates.

Figure 4.1 Electronic waste materials size reduction equipment, industrial shredder and pulverizer on the left and the source ABS e-waste plastic samples on the right....... 24

Figure 4.2 Free radical initiation treatment process of e-waste plastics....................... 25

Figure 4.3 Electronic waste materials processing flowchart. 26

Figure 4.4 Viscosity of e-waste modified asphalt binder measured at $135^{\circ} \mathrm{C}(5 \% \mathrm{ABS}$ and $5 \%$ HIPS are the untreated ABS/HIPS modified binders, and the treated 5\% ABS/HIPS are the treated ABS/HIPS modified binders, percent differences between control binder in black HIPS, white ABS). Based on three replicates

Figure 4.5 HIPS modified asphalt binder rotational viscosity temperature curve based on three replicates

Figure 4.6 ABS modified rotational viscosity temperature curve. Based on three replicates

Figure 4.7 Five percent e-waste modified asphalt binder mastercurve results for unaged tank binders, mastercurve temperatures include reference temperature $40^{\circ} \mathrm{C}$. Based on three replicate DSR tests

Figure 4.8 E-waste modified asphalt binder mastercurve results for PAV aged asphalt binders, the complex modulus master curve reference temperature is $40^{\circ} \mathrm{C}$. Based on three replicate DSR tests.

Figure 4.9 Bending beam rheometer creep stiffness results for e-waste modified asphalt binders at BBR test temperature of $-18^{\circ} \mathrm{C}$. Based on three replicate DSR tests ....... 36 
Figure 4.10. Bending beam rheometer low temperature $\mathrm{m}$-value results for e-waste modified asphalt binders (specification for $-28^{\circ} \mathrm{C}$ ) BBR test temperature of $-18^{\circ} \mathrm{C}$. Based on three replicate DSR tests.

Figure 5.1 Hitachi S-4700 SEM photo of ABS particles at 250X magnification 42

Figure 5.2 ImageJ particle size distribution boundaries of ABS particles from SEM photograph.

Figure 5.3 ABS powder size distribution of particles less than $75 \mu \mathrm{m}$ based on SEM

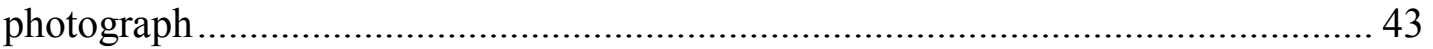

Figure 5.4 Hitachi S-4700 SEM photo of HIPS particles at 50X magnification 44

Figure 5.5 ImageJ particle size distribution boundaries of HIPS particles from SEM photograph.

Figure 5.6 HIPS powder size distribution of particles based on SEM photograph

Figure 5.7 DSC modified e-waste samples after quenching; the decreasing heat flow indicates an exothermic reaction, based on 1 replicate

Figure 5.8 DSC glass transition temperature change due to quenching for e-waste modified asphalt binders: A) using the extrapolated onset temperature $\left.\operatorname{Tf}\left({ }^{\circ} \mathrm{C}\right), \mathrm{B}\right)$ using the extrapolated end temperature $\mathrm{Te}, \mathrm{C}$ ) using the midpoint temperature $\mathrm{Tm}$, based on 1 replicate

Figure 5.9 FTIR qualitative analysis of 2.5\% ABS e-waste binders, based on 1 replicate

Figure 5.10 FTIR qualitative analysis of 5\% ABS e-waste binders, based on 1 replicate 50

Figure 5.11 FTIR qualitative analysis of 2.5\% HIPS e-waste binders, based on 1 replicate

Figure 5.12 FTIR qualitative analysis of 5\% HIPS e-waste binders, based on 1 replicate

Figure 5.13 FTIR spectra for control PG 58-28 asphalt binders at unaged tank binder (Control TB), rolling thin film aged (RTFO binder), and pressure aging vessel aged

(PAV Binder) conditions. , based on 1 replicate.

Figure 5.14 Bar chart of aging index for HIPS modified asphalt binder, based on 1 FTIR test replicate 
Figure 5.15 Bar chart of aging index for ABS modified asphalt binder, based on 1 FTIR

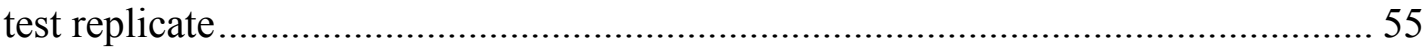

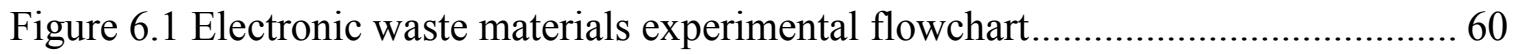

Figure 6.2 APA rutting depth after 8000 APA cycles, based on three replicates............ 62

Figure 6.3 E-waste modified asphalt mixture flow number results, based on three

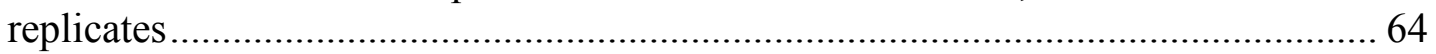

Figure 6.4 Dynamic modulus results for modified e-waste mixtures at -10 degrees Celsius

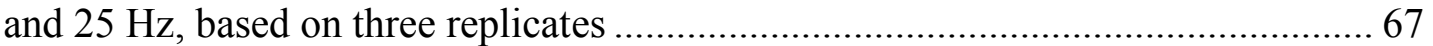

Figure $6.5 \mathrm{E}^{*} / \mathrm{sin}$ (delta) results for modified e-waste mixtures at 21.3 degrees Celsius

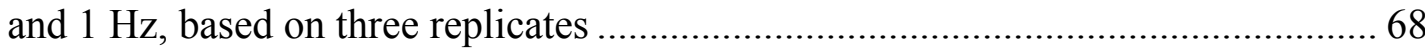

Figure 6.6 $\mathrm{E}^{*} / \mathrm{sin}$ (delta) results for modified e-waste mixtures at 39.2 degrees Celsius

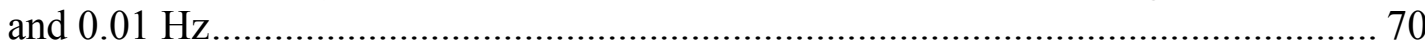

Figure 6.7 Moisture susceptibility performance of control PG 58-28 and e-waste modified HMA, based on three replicates .................................................................. 71

Figure 7.1 Schematic for the selection of sustainable materials by asphalt mixture

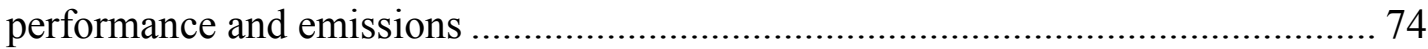

Figure 7.2 SimaPro emissions assessment model for SimaPro carbon emissions analysis

Figure 7.3 IPCC 2007 GWP 20a V1.02 CO2 emissions model comparison after 20 years for e-waste modified asphalt pavement mixtures for a travel and non-travel case (MTU scenario)

Figure 7.4 MEPDG asphalt pavement rutting prediction rutting structure layers for ewaste modified asphalt mixtures 


\section{List of Tables}

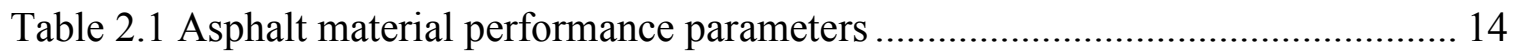

Table 3.1 Bending beam rheometer m-value results for untreated e-waste binders at $18^{\circ} \mathrm{C}$ from three replicates................................................................................. 19

Table 4.1 E-waste asphalt binder mixing and compaction temperatures......................... 30

Table 4.2 Superpave rutting susceptibility for treated e-waste modified asphalt binders.

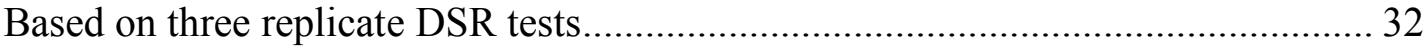

Table 4.3 Bending beam rheometer performance results for modified e-waste asphalt

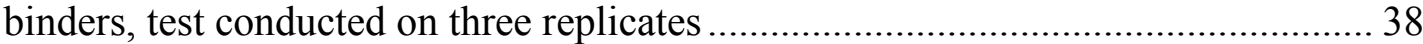

Table 4.4 True performance grade comparisons of treated and untreated e-waste asphalt binders. Based upon Superpave binder results. ..................................................... 39

Table 5.1 Sieve analysis of ABS and HIPS source particles. Based on $500 \mathrm{~g}$ e-waste

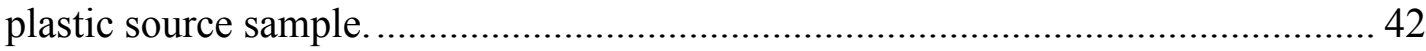

Table 5.2 DSC results glass transition temperatures, based on 1 replicate....................... 46

Table 5.3 Key FTIR spectra wavelengths for e-waste binder analysis ......................... 49

Table 6.1 E-waste modified asphalt binder testing list.............................................. 58

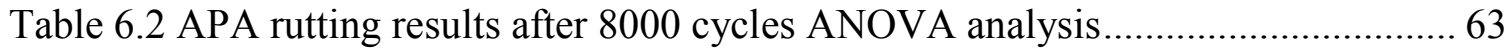

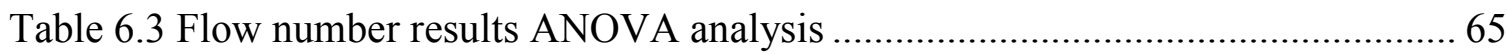

Table 6.4 T-test: Paired two sample for means for control and e-waste mixtures for

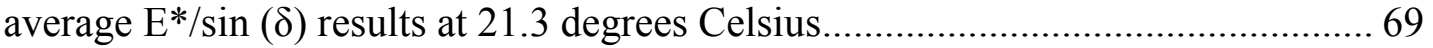

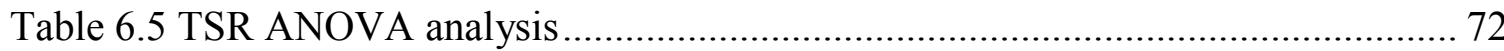

Table 7.1 E-Waste/HMA pavement type dosage classification................................... 78

Table 7.2 Asphalt mixture CO2 emissions rankings calculated from the SimaPro 20 year IPCC 2007 GWP 20a V1.02 CO2 emissions model-rankings from MTU scenario . 80

Table 7.3 Asphalt mixture rutting rankings based on MEPDG analysis ........................ 82

Table 8.1 Summary of untreated electronic waste modified asphalt materials testing versus the control HMA 86 
Table 8.2 Summary of treated electronic waste modified asphalt materials testing versus

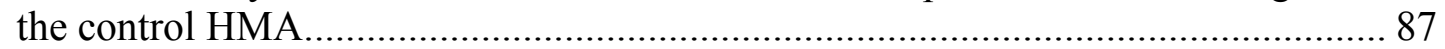




\section{Abbreviations}

ASCE- American Society of Civil Engineers

FTIR-fourier transform infrared microscopy

DSC- differential scanning calorimeter

SEM- scanning electron microscope

$\mathrm{CO}_{2}$-carbon dioxide

HMA-hot mix asphalt

e-waste- electronic waste

ABS-acrylonitrile butadiene styrene

HIPS-high impact polystyrene

PP-polypropylene

PS-polystyrene

ABS-PC- acrylonitrile butadiene styrene/polystyrene

HIPS-PPO- polyenylene oxide

SBS-styrene butadiene styrene

LDPE-low density polyethylene

HDPE-high density polyethylene

$\mathbf{G}^{*}$-asphalt binder complex modulus

ASTM- American Society for Testing and Materials

AASHTO-American Association of State and Highway Transportation Officials

PAV-pressure aging vessel

BBR-bending beam rheometer

RTFO-rolling thin film oven

RPM-revolutions per minute

Paøsec- Pascal-seconds

DSR-dynamic shear rheometer

MPa- megapascals 
T-ABS- chemically treated acrylonitrile butadiene styrene

T-HIPS- chemically treated high impact polystyrene

$\boldsymbol{\delta}$-delta

PG-performance grade

$\mathbf{T}_{\mathbf{g}}$-glass transition temperature

$\mathbf{T}_{\mathbf{f}}$-glass transition extrapolated onset temperature

$\mathbf{T}_{\mathbf{e}^{-}}$glass transition extrapolated end temperature Te,

$\mathbf{T}_{\mathbf{m}^{-}}$glass transition extrapolated midpoint temperature Tm,

TB-tank (unaged) asphalt binder

Control TB- tank (unaged) control asphalt binder/mixture

APA- asphalt pavement analyzer

VMA-voids in mineral aggregate

DM-dynamic modulus

$\mathbf{E} *$-dynamic modulus

$\mathbf{F}_{\mathbf{n}}$-flow number

TSR-tensile

ANOVA-analysis of variation

LCA-life cycle assessment

MEPDG-mechanistic empirical design guide 


\section{Preface}

This dissertation is organized as a collection of original writing, journal papers, and prepared articles for journal submission. One published article and three prepared articles for journal submission are included in this dissertation. Basic information regarding the articles which have been published or submitted is as follows:

Chapter 1 discusses a literature review for the implementation of electronic waste plastics within asphalt binders and mixtures. This article was submitted to the Journal of Cleaner Production; the title of this paper is - Management and Utilization of Electronic Waste Plastics for Use within Pavement Structures: State of the Art and Options for Successful Implementation. This submitted article was authored by Baron Colbert and Zhanping You. Baron Colbert conducted the literature review for this article and wrote the manuscript for submission. Baron Colbert's advisor Zhanping You provided editorial and technical advice and approved the manuscript for submission.

Chapter 3 describes the results for untreated electronic waste plastics for the modification of asphalt binders. This article was published in Journal of Materials in Civil Engineering by American Society of Civil Engineers (ASCE). The title of this paper is - Properties of Modified Asphalt Binders Blended with Electronic Waste Powders. This article was authored by Baron Colbert and Zhanping You. Baron Colbert conducted the laboratory testing, analyzed the data for this article, and wrote the manuscript for this article. Zhanping You provided editorial and technical advice and approved the final manuscript for publication to ASCE.

Chapter 4 describes the results for chemically treated electronic waste plastics for the modification of asphalt binders. The mechanical performance of asphalt binders modified with free radical treated electronic waste plastics was prepared by Baron Colbert, Zhanping You, and Patricia Heiden and submitted to the Journal of Fuel. Baron Colbert conducted the laboratory testing, analyzed the data for this article, and wrote the manuscript for this article. Zhanping You provided technical advice, editorial direction, xii 
and approved the final manuscript for submission. Patricia Heiden provided technical advice for the free radical initiation process, wrote the paragraph discussing free radical initiation discussed in Chapter 4.4, and developed the concept chart for the free radical initiation process of asphalt binder in Figure 4.2.

Chapter 6 describes the performance of treated and untreated electronic waste plastic asphalt mixtures. The title of this paper is - The Mechanical Performance of Asphalt Mixtures Modified with Recycled Electronic Waste Plastics. Baron Colbert authored this published article along with Zhanping You and Julian Mills Beale. This article is in preparation for submission to Journal of Construction and Building Materials. The dissertation author (Baron Colbert) conducted the laboratory testing, analyzed the data for this article, and wrote the manuscript for this article. Zhanping You provided technical advice, editorial direction, and approved the final manuscript for submission. Julian Mills-Beale provided editorial assistance for this article. 


\section{Abstract}

Bulk electric waste plastics were recycled and reduced in size into plastic chips before pulverization or cryogenic grinding into powders. Two major types of electronic waste plastics were used in this investigation: acrylonitrile butadiene styrene (ABS) and high impact polystyrene (HIPS). This research investigation utilized two approaches for incorporating electronic waste plastics into asphalt pavement materials. The first approach was blending and integrating recycled and processed electronic waste powders directly into asphalt mixtures and binders; and the second approach was to chemically treat recycled and processed electronic waste powders with hydro-peroxide before blending into asphalt mixtures and binders. The chemical treatment of electronic waste (e-waste) powders was intended to strengthen molecular bonding between e-waste plastics and asphalt binders for improved low and high temperature performance. Superpave asphalt binder and mixture testing techniques were conducted to determine the rheological and mechanical performance of the e-waste modified asphalt binders and mixtures. This investigation included a limited emissions-performance assessment to compare electronic waste modified asphalt pavement mixture emissions using SimaPro and performance using MEPDG software. Carbon dioxide emissions for e-waste modified pavement mixtures were compared with conventional asphalt pavement mixtures using SimaPro. MEPDG analysis was used to determine rutting potential between the various e-waste modified pavement mixtures and the control asphalt mixture. The results from this investigation showed the following: treating the electronic waste plastics delayed the onset of tertiary flow for electronic waste mixtures, electronic waste mixtures showed some improvement in dynamic modulus results at low temperatures versus the control mixture, and tensile strength ratio values for treated e-waste asphalt mixtures were improved versus the control mixture. 


\section{Electronic waste material background and research gaps ${ }^{1}$}

\subsection{Introduction}

E-waste refers to electronic equipment and products consisting of discarded personal computers, monitors, hard drives, copiers, facsimile machines, cellular phones, and televisions. The composition of e-waste consists of valuable recyclables but also include potentially hazardous material $[1,2]$. The typical life time and decomposition rate for ewaste materials is at least three years on average for personal computers, and cellular phones, to an indefinite amount of time [3]. Other e-waste materials such as glass can last from a minimum of 450 years to an indefinite period of time [4]. The decomposition rate of a material depends on the e-waste material type and the material's conditions of decomposition. Electronic waste plastics consists of approximately $23.3 \%$ of the mass of disposed computers Worldwide, China imports $70 \%$ of all disposed electronic waste materials; various percentages of exported e-waste materials also arrive in countries such as: India, Pakistan, Vietnam, Philippines, Malaysia, Nigeria, and Ghana [3]. As recently as 2006, there is an estimated 1.5 billion lbs. of e-waste generated within the United States, only $10 \%$ of that amount was actually recycled [1]. Future e-waste production estimates show that 3 billion tons of consumer electronics will eventually end up as ewaste in the United States [5]. Current projections show that 2-5\% of the US municipal solid waste stream is composed of e-waste [6], and there is a distinct difference between e-waste composition between household and municipal waste. The driving forces behind

\footnotetext{
${ }^{1}$ Text prepared for submission to the Journal of Cleaner Production - Colbert, B. and Z. You (2012 " Management and Utilization of Electronic Waste Plastics for Use within Pavement Structures: State of the Art and Options for Successful Implementation." Journal of Cleaner Production
} 
the concern for the disposal of e-waste is twofold. First, is the rapid growth of computer technology, and second, is the subsequent amount of obsolete computer technology; current projections show that nearly 1 billion computers are obsolete [7]. The impact ewaste could pose to the environment has led toward the introduction of legislation designed to limit the quantity of e-waste placed within state and local landfill sites [5]. Specifically, these national and international laws are intended to significantly limit and reduce e-waste dumping into increasingly limited landfill space [2]. New research efforts must develop new applications and address environmental hazards which e-wastes may pose to society; due to the increasing worldwide production e-waste, and the subsequent legislation limiting the location and quantity of e-waste.

\subsection{Bulk e-waste plastic properties considerations}

When designing long lasting roadways, pavement engineers must consider the various types and properties of available e-waste plastics. Typical e-waste plastics available include acrylonitrile butadiene styrene (ABS), high impact polystyrene (HIPS), polypropylene (PP), polystyrene (PS), styrene acrylonitrile (SAN), polyethylene (PE), polyurethane (PU), polyamide (PA), acrylonitrile butadiene styrene-polycarbonate (ABS/PC), and polyenylene oxide (HIPS/PPO) [4]. After considering the material properties of available e-waste plastic sources pavement engineers can then design asphalt pavements and binders accordingly. Figure 1.1 below shows typical computer waste plastics used within the computer industry. 
(a)

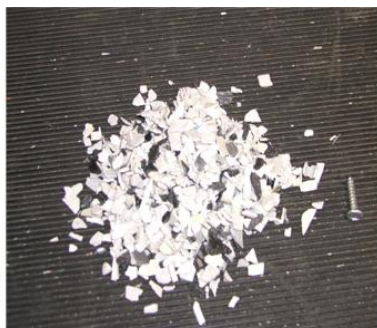

(b)

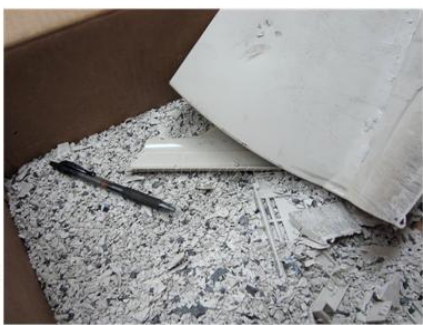

(c)

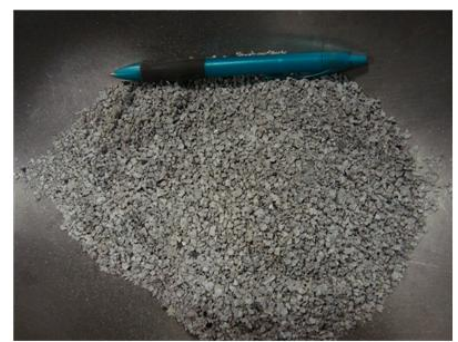

Figure 1.1 Electronic waste computer plastics used for the computer industry, (a) ABS, (b) ABS/PC, (c) HIPS

$\mathrm{ABS}$ is a heterogeneous multiple phase polymer with a rubber component and a combination of styrene acrylonitrile [1]. ABS has good impact strength, chemical resistance, and toughness, and rigidity [8]. E-wastes polymers account for nearly $20 \%$ of e-waste with 15 types of engineered plastics used [4]. Within the e-waste recycling stream, $33 \%$ of the waste stream consists of plastics and $16 \%$ of the waste stream is composed of computer equipment [9]. The percentages of e-waste plastic resins consist of the following: PS 31\%, ABS 16\% and PP 13\% [9]. When considering household ewaste, plastics consist of $35 \%$ of the household waste stream with $3 \%$ of the total household waste stream coming from personal computers [6]. The value of a typical personal computer plastic waste stream is determined by the amount of impurities within the plastic and the personal computer components. For instance, personal computer circuit boards must have no more than 3\% impurities and are valued at $\$ 0.95 / \mathrm{lb}$., recycled personal computer plastics must have no more than $4 \%$ impurities and are valued at $\$ 0.02 / 1 b$., hard mix plastics must have no more than $6 \%$ impurities and are valued at $\$ 0.11 / 1 b$. [10]. Plastics from external product casings are $20 \%$ of the material mass and a valuable end of life recyclable product [11]. Researchers who have investigated the implementation of various e-waste plastics include: Ahanahan et al. who characterized 
scrap computer plastics using an infrared spectrophotometer, differential scanning calorimeter, and thermogravimetric techniques [12]; Balart et al. characterized ABS and PC waste plastic properties, their investigation showed a decrease in mechanical properties performance versus virgin plastics but retained properties favorable to various engineering plastics in the market [13]. Liu et al. also conducted an investigation for determining whether e-waste plastic particle size affected bulk properties of the composite material; a second objective of their investigation was to determine if there were any agents available which would improve compatibility between the plastic powder and composite matrix [14]. Liang and Gupta [15-17] characterized the properties of typical e-waste plastics for use in recycling applications. Finally, Mural et al. [18] characterized polypropylene and waste HIPS blends for use in various packaging applications.

\subsection{E-waste plastic research gaps}

One research gap which needs to be addressed is to determine if virgin rubber could improve the mechanical performance of plastic-rubber blends containing e-waste [12]. The plastics industry typically blends plastics with various virgin or recycled rubbers in order to improve their product. Other research gaps include: the characterization of ewaste plastics and quantifying the environmental and economic end of life cost benefits of electronic waste plastics. This investigation should account for various economic uncertainties using various recycled products such as e-waste plastic coverings [11]. Future research efforts must identify efficient methods of recycling e-waste plastics, considering that the recovered e-waste plastics have a reduced processing expense versus virgin plastics due to high volume of e-waste [19]. Other research issues to address for ewaste plastic recycling is to improve recycling efficiency between for the various types of e-waste plastics such as: Acrylonitrile Butadiene Styrene-Polycarbonate (ABS-PC) which isn't recycled as efficiently as ABS or high impact polystyrene (HIPS) plastics. The lack of efficiency for recycling ABS-PC has decreased the value and appeal for ABS-PC 
among plastics recyclers [1]. The compatibility between the e-waste plastics and other raw materials such as asphalt concrete, portland cement concrete, and metals, is another research topic which must be addressed to help spur the development of future applications for recycled e-waste plastics $[9,20]$.

\subsection{E-waste compatibility issues with aspahlt materials}

The issue of compatibility from integrating e-waste plastics with other nonmetallic materials is crucial for successful implementation of e-waste plastics. The issue of ewaste plastic compatibility is important for obtaining improved and optimized performance for composite materials containing plastic e-waste. Yokoyama and Iji concluded that the compatibility between the e-waste fiberglass powder mixture and epoxy was a factor for improving mechanical performance [21]. Morrison et al. [20] concluded that plastic and rubber compatibility within plastic-rubber modified asphalt binders under low temperature conditions was a factor towards affecting interfacial strength between the dispersed and continuous matrix phases of the asphalt mixture. Indications of incompatibility between asphalt binders and plastic e-waste include modified asphalt binders which may form layers of plastic at the surface of the asphalt binder. Once the plastic forms a thick layer on the asphalt binder surface, the dispersion of plastic is difficult and leads to premature pavement distress. The incompatable plastic modifed aspahlt binder would also produce a viscous asphalt binder, damaging pumping equipment [20]. Cross linking is another indication of incompatibility between e-waste plastics. Anandhan and his coworkers determined that dynamic cross linking between rubber and ABS seemed to play a part in preventing oil from deteriorating the rubber ABS plastic blend [12]. Mechanical performance was correlated to compatibility and improved phase interaction through an investigation conducted by Balart et al. using percentages of plastics [13].

The molecular weight of recycled e-waste plastics have an effect upon the compatibility and performance of materials blended within recycled e-waste plastics. Morrison et al. 
[20] concluded that high temperature performance of rubber-plastic modified asphalt binders were affected by the degree of dispersion. Dissolved or fine particles with heavier molecules have an effect on asphalt binder creep properties [20]. Morrison et al. also concluded that well dispersed modified asphalt binders provided better protection versus permanent deformation in asphalt mixtures. High weight molecular polymers resulted in higher viscosities at high temperatures; and pavement mixtures containing these polymers are ideal for heavy traffic areas [20]. In contrast, asphalt mixture blends with lower molecular weight polymers blend easier into the asphalt mixture, but don't contribute to asphalt binder properties like heavy molecular weight additives [22]. Das and Patil used free radical initiators to generate the start of a chain scission process, In order to control the molecular weight of polypropylene (PP). Free radical initiators are peroxides which are catalysts to the degradation process under controlled rates for plastic pelletization, and can be used in applications where resin makers can control plastic degradation for plastics such as polypropylene [10]. Free radicals recombine to induce branching as reaction times increase; branching helps to improve tensile strength, intermolecular interaction, and is likey to increase the molecular weight of resin over a period of time [10]. Das and Patil concluded that the reduction in molecular weight of PP was a success using free radical initiators and solvents [10]. Lee and his coworkers also worked with styrene butadiene styrene (SBS), a common modifier used in polymer modified asphalt, to improve aging resistance using free radical initiators [23]. In this investigation, the double bonds in the poly butadiene segment of SBS is susceptible to aging; therefore free radicals formed from antioxidants at high temperatures break the double bonds within the molecular structure leading to a cross linking or scission reaction. This reaction produces carbon-peroxide or carbon carbonyl bonds [23]. Colbert and You also conducted an investigation using free-radical initiators to promote compatibility between various ABS and HIPS e-waste plastics and asphalt binders.

Other tests used to indicate compatibility with various recycled e-waste plastics include using measuring sieves and light microscopy to determine compatibility between asphalt 
binder and various waste plastics [24]. FTIR is used to determine compatibility of ewaste plastics by giving information about the material composition, microstructure, and indicating differences between the molecular phases $[8,25]$. An investigation using FTIR to determine compatibility with recycled plastic e-waste materials was conducted by Arnold et al. [25]. Using FTIR mapping, each plastic sample was scanned to indicate the degree of dispersion of poly-ABS molecules. This FTIR analysis indicated that ABS blending success was partially dependent upon the initial nature of the ABS before recycling [25]. Poor mechanical performance was correlated to plastic compatibility from the serrated molecular phase structure (coarse two phase structure).

\subsection{Electronic waste plastic applications for asphalt concrete research}

The utilization of waste materials in hot mix asphalt mixtures is a promising way to efficiently use e-waste plastics, but pavement engineers must consider many factors in order to successfully implement these e-waste within hot mix asphalt (HMA). Pavement engineers shouldn't significantly compromise ultimate HMA performance, increase production cost, or create future disposal problems if e-waste plastics are to be used within HMA [23]. Despite the many factors for considering if e-waste plastics are appropriate for a given pavement project, the use of waste additives within asphalt concrete mixtures have been shown to bring contractors savings in roadway repair and reconstruction operations. HMA has successfully been used to line reservoirs within the United States, chemically restricted waste materials, and seal off the waste materials from the environment [23]. Researchers who have investigated the use of waste plastics within asphalt binder and mixtures include Schroeder who discussed the use of low density polyethylene from waste plastic and sandwich bags; LDPE was converted to pellets and mixed into the asphalt binder at a range $4-7 \%$ by weight of asphalt binder [26]. Hinishoglu and Ağar conducted an investigation for high density polyethylene (HDPE) to determine if it was possible to successfully integrate HDPE as a polymer modified asphalt concrete mixture. Their results indicated that 4\% HDPE modified asphalt mixture had a higher Marshall stability versus virgin mixtures showing increased mixture 
stiffness and ability to distribute pavement loading [27]. The long term aging effect of polypropylene modified HMA was investigated by Othman [28]. This investigation blended polypropylene powder into aged asphalt concrete to simulated field conditions between 5 and 10 years after pavement placement [28]. The results from this investigation shows that polypropylene was incompatible with asphalt mixtures due to a high melt temperature and polypropylene crystallization within the asphalt pavement mixture; it was also concluded that the polypropylene modified mixture improved many mechanical properties at aged and unaged conditions, contributed to surface roughness, and offset the hardening effect of the aged asphalt concrete mixtures [28].

Aglan [22] conducted a study on asphalt pavement and polymer additives. This study investigated polymer products such as: Kraton, Elvax, and Novophalt and used stress fatigue experiments to determine the performance of various polymer modified asphalt pavement mixtures [22]. All tested polymer modified asphalt pavement mixtures increased mixture stiffness and strength with Kraton having a higher flexibility and strength versus the Elvax and Novophalt products [22]. Jeong et al. [29] conducted a laboratory investigation of waste polyethylene (WPE) film for asphalt pavement mixtures. Using Marshall stability, indirect tensile strength, and wheel tracking tests it was concluded that 12\% WPE provided the best performance versus the control and polymer HMA mixtures, although it was stated that future work would be needed to determine the effects of low temperature and moisture upon WPE modified mixtures [29]. Other studies reporting on the performance of waste plastics within asphalt pavement materials include Morrison et al. [20] who conducted a research investigation regarding the performance of waste plastics and recycled rubber tires; it was concluded that the plastic/rubber modified asphalt mixture resulted in an improvement in high temperature performance in terms of loss moduli, loss tangent, and complex modulus $\left(G^{*}\right)$ [20]. Punith and Veeraragavan [30-32] have conducted research using low density polyethylene (LDPE) plastic bags for use within asphalt materials; their results showed improved fatigue and rutting properties for LDPE modified asphalt pavement mixtures. 
Li et al. [23] investigated the improvement of aging resistance for SBS polymer modified asphalt using complex antioxidants, their results indicated that SBS improved the aging resistance for SBS modified binders.

Colbert and You[33] have investigated the properties of electronic waste modified asphalt binders using acrylonitrile butadine styrene and high impact polystyrene plastics. Their results have shown: e-waste plastic modified asphalt binders meet virgin binder high temperature performance criteria, e-waste plastic modified asphalt binders may be stiffer at low temperatures versus virgin asphalt binders, and low percentages of e-waste plastics provide adequate low temperature performance compared to unmodified virgin asphalt binders.

\subsection{Current e-waste plastic research}

Research considering the topic of e-waste plastics applications includes the following [8, 12, 21, 29, 34], Methyl methacrylate butadiene styrene was added to improve the improve the impact resistance of ABS [12]. Jeong et al. used the Marshall design method to determine the performance of waste polyethylene film in asphalt mixtures [29]. An investigation by Yokoyama and Isi [21] investigated the use of printed wire boards from electronic materials for filler for resin construction materials. This investigation pulverized printed wire boards into an effective size of $150 \mu \mathrm{m}$, and tested versus talc, calcium carbonate and silica powders. Despite the difficulty in pulverizing and remelting the printed wire boards, it was shown that the printed wire board powder improved mechanical strength and thermal expansion properties versus the talc, calcium carbonate, and silica epoxy resin blends. Finally, it was concluded that printed wire board powder could be used effectively as a construction filler by separating the powder into copper and nonmetallic fiberglass [21]. 


\subsection{Summary}

The current state of applications for e-waste plastics was reviewed. Current research gaps which researchers must address in order to successfully integrate e-waste plastics in a sustainable manner within asphalt pavement materials was discussed. Issues which hinder the use of e-waste plastics within asphalt pavement materials are e-waste plastic compatibility with asphalt binders and mixtures, the removal or mitigation of hazardous waste materials within e-waste plastic products, and the issue of flame retardants within e-waste. The state of art for recycling e-waste plastics designated for asphalt pavement applications were discussed along with the mechanical properties of these e-waste plastics. Finally, an overview of various e-waste plastic research efforts was given. 


\section{Dissertation hypothesis and objectives}

The purpose of this dissertation is to introduce the concept of recycled electronic waste plastics integration within asphalt pavement materials. This dissertation will discuss how recycled electronic waste plastics are processed and their behavior within asphalt binders and asphalt mixtures. The effect which recycled electronic waste plastics have on high and low temperature behavior within asphalt binders will then be correlated to pavement distresses of rutting, and thermal cracking within asphalt mixtures. Methods to improve low temperature performance will also be discussed. The method which was chosen was to improve low temperature performance of e-waste binders and mixtures is the use of free radical initiators. A hydro-peroxide was then used to chemically treat the recycled electronic waste plastics during the free radical initiation process. The chemically treated e-waste plastics are then placed within asphalt binders and mixtures to determine if an improvement in high and low temperature performance was evident. The untreated and treated electronic waste modified asphalt pavement materials were fabricated within the laboratory and performance was tested within the laboratory. E-waste binders were analyzed using Fourier transform infrared microscopy (FTIR), differential scanning calorimeter (DSC), and a scanning electron microscope (SEM). These tools were used to verify e-waste plastic and asphalt binder compatibility, electronic waste plastic particle size, and to verify if a chemical change did indeed occur. Finally, a limited carbon dioxide $\left(\mathrm{CO}_{2}\right)$ emissions-pavement rutting performance assessment was conducted to compare e-waste modified mixture emissions and performance with the control hot mix asphalt mixture (HMA). Finally, conclusions from these investigations will be made discussing the key findings of this investigation from this dissertation. 


\subsection{Hypothesis}

Given the widespread use of the Superpave design system for asphalt pavements, engineers have used modifiers to improve the range of temperatures and loading conditions which quality pavements can withstand. Various recycled materials have been used to modify and improve pavement properties for new and reconstructed pavement. What is not well understood is whether electronic waste thermoplastics can improve high and low temperature properties under various loading conditions versus conventional hot mix asphalt materials. Until we understand the mechanical behavior of asphalt pavement materials modified with recycled electronic waste plastics, integrating these plastics within pavement structures for reconstruction and rehabilitation purposes will not be viable for the reduction of electronic waste plastics in landfills or the reduction of international shipment of these plastics. It appears that the use of electronic waste plastics will increase asphalt mixture and binder strength, provide improved high temperature rutting performance and stability, the use of free radical initiator will improve bonding through changing the molecular structure of the asphalt binder electronic waste plastic blend improving low temperature performance, and the use of electronic waste plastics will provide comparable low temperature performance and carbon dioxide emissions to conventional hot mix asphalt binder and mixtures.

\subsection{Objectives}

The main objective of this dissertation study is to show that the implementation of electronic waste plastics improve mechanical performance of asphalt pavement materials under low and high temperature conditions. This objective will be accomplished by completing four tasks: 1) asphalt pavement modification using electronic waste plastics.

2) Asphalt pavement modification through chemical treatment of electronic waste plastics through free radical polymerization. 3) Verification of compatibility using DSC and FTIR, e-waste particle size using sieve analysis and SEM, and thermo-properties of electronic waste modified asphalt binders using DSC. 4) Conducting a pavement performance-emissions assessment of electronic waste plastic modified asphalt pavement 
mixtures using SimaPro to determine $\mathrm{CO}_{2}$ emissions and MEPDG to determine rutting performance from asphalt binder and mixture results.

The mechanical behavior and performance of recycled electronic waste plastic modified asphalt pavement materials were determined in part by various laboratory tests. These laboratory tests helped to determine asphalt binder rheological, low temperature, and high temperature performance to verify if e-waste modified asphalt pavement materials do improve strength, stability, and rutting performance. Asphalt mixture simple performance testing, high temperature stability, rutting, and moisture susceptibility properties were also determined through laboratory testing of asphalt mixture specimens.

Table 2.1 below divides the asphalt pavement mixture into its components, electronic waste plastic, e-waste modified asphalt binders, and e-waste asphalt pavement mixtures. This chart displays the key material characteristics and parameters which correspond to improved asphalt pavement materials mechanical performance under high and low temperature condition and corresponding pavement distresses of rutting and stability corresponding to high temperature behavior and thermal cracking corresponding to low temperature behavior. 
Table 2.1 Asphalt material performance parameters

\begin{tabular}{|c|c|c|}
\hline $\begin{array}{l}\text { Asphalt mixture } \\
\text { component }\end{array}$ & $\begin{array}{l}\text { Material } \\
\text { characteristic }\end{array}$ & Key Parameter(s) \\
\hline \multirow{3}{*}{$\begin{array}{l}\text { Electronic waste } \\
\text { plastic }\end{array}$} & compatibility & glass transition temperature ( $\mathrm{Tg}$ ) \\
\hline & & FTIR absorbance \\
\hline & particle size & $\begin{array}{l}\text { scanning electron microscope } \\
\text { analysis }\end{array}$ \\
\hline \multirow{3}{*}{$\begin{array}{l}\text { Modified e-waste } \\
\text { asphalt binder }\end{array}$} & workability & viscosity \\
\hline & $\begin{array}{l}\text { high temperature } \\
\text { behavior }\end{array}$ & complex modulus $\left(\mathrm{G}^{*}\right)$ \\
\hline & $\begin{array}{l}\text { low temperature } \\
\text { behavior }\end{array}$ & creep stiffness/m-value \\
\hline \multirow{4}{*}{$\begin{array}{l}\text { Modified e-waste } \\
\text { mixtures }\end{array}$} & $\begin{array}{l}\text { high temperature } \\
\text { behavior }\end{array}$ & dynamic modulus/APA rut depth/ \\
\hline & & flow number \\
\hline & $\begin{array}{l}\text { low temperature } \\
\text { behavior }\end{array}$ & dynamic modulus \\
\hline & $\begin{array}{l}\text { moisture } \\
\text { susceptibility }\end{array}$ & tensile strength ratio \\
\hline
\end{tabular}




\section{Chapter 3: Evaluation and performance of e-waste binders $^{2}$}

\subsection{Asphalt binder performance characterization}

Superpave binder testing techniques were used to determine the performance of electronic waste modified asphalt binders under various temperature and frequencies. Methods used to determine asphalt binder performance include: ASTM D 4402: Standard Test Method for Viscosity Determination of Asphalt at Elevated Temperatures Using a Rotational Viscometer, AASHTO T 240-09 Effect of Heat and Air on a Moving Film of Asphalt Binder (Rolling Thin-Film Oven Test), ASTM D 6521: Standard Practice for Accelerated Aging of Asphalt Binder Using a Pressurized Aging Vessel (PAV), and AASHTO T 313-12 Determining the Flexural Creep Stiffness of Asphalt Binder Using the Bending Beam Rheometer (BBR).

The rotational viscosity test procedures were used to determine the viscosity of asphalt binder at $135^{\circ} \mathrm{C}$ as an indicator of asphalt binder workability. Viscosity was determined according to test procedure ASTM D4402 $[35,36]$. The \#27 spindle was used to determine asphalt binder viscosities for this project using $10.5 \mathrm{~g}$ of asphalt binder. The mixing and compaction temperature of the e-waste modified asphalt binders were determined using viscosity curves determined by the following viscosity parameters at 100 RPM. Asphalt binder mixing and blending temperatures were defined using the viscosity limits of $0.17 \pm 0.02 \mathrm{~Pa} \bullet \mathrm{s}$ for the mixing range and $0.28 \pm 0.03 \mathrm{~Pa} \bullet \mathrm{s}$ for compaction temperature range.

\footnotetext{
${ }^{2}$ Partial text reprinted with permission from ASCE: - Colbert, B. and Z. You (2012). "Properties of Modified Asphalt Binders Blended with Electronic Waste Powders." Journal of Materials in Civil Engineering 24(10): 1261-1267., Copyright (C) 2012, ASCE. See Copyright clearance in Appendix A.
} 
The Rolling Thin Film Oven (RTFO) and Pressure Aging Vessel (PAV) test procedures were used to age the control and modified e-waste asphalt binder specimens [37]. RTFO asphalt binders were produced according to AASHTO T240 [38]. The RTFO asphalt binders were placed in the PAV oven at $100{ }^{\circ} \mathrm{C}$ for 20 hours. The long term aging of the asphalt binder specimens with the PAV oven followed the ASTM D6521 specification standard. Finally, the PAV aged binders were tested using the Bending Beam Rheometer (BBR) for asphalt binder low temperature testing.

The BBR was used for this investigation to determine the temperatures at which the various asphalt binders can resist low temperature cracking. The AASHTO T 313-09 standard specification was followed for BBR testing in this investigation [39]. Asphalt binder beams of dimensions $6.35 \pm 0.05$ - $\mathrm{mm}$ thick by $12.70 \pm 0.05-\mathrm{mm}$ wide by $127 \pm 2.0$ $\mathrm{mm}$ long were subjected to a constant $980 \pm 50 \mathrm{mN}$ load for $240 \mathrm{~s}$. Creep stiffness and mvalue are parameters of interest for the BBR test. The creep stiffness is defined as the ratio of the constant $980 \mathrm{mN}$ load applied to the variation in strain or displacement in the prepared asphalt beam while the $\mathrm{m}$-value is the slope of the stress against strain curve relationship in a log scale. It's expected that $300 \mathrm{MPa}$ is the maximum value for asphalt binder creep stiffness for BBR testing. M-value is expected to be at least 0.3 for BBR testing.

\subsection{Untreated e-waste binder results}

The two major results from the investigation of electronic waste plastic modified asphalt binders consists of: asphalt binder viscosity at $135^{\circ} \mathrm{C}$ and low temperature binder performance from bending beam rheometer (BBR) testing at various temperatures.

Figure 3.1 below displays the viscosity for the various electronic waste plastic modified asphalt binders. 


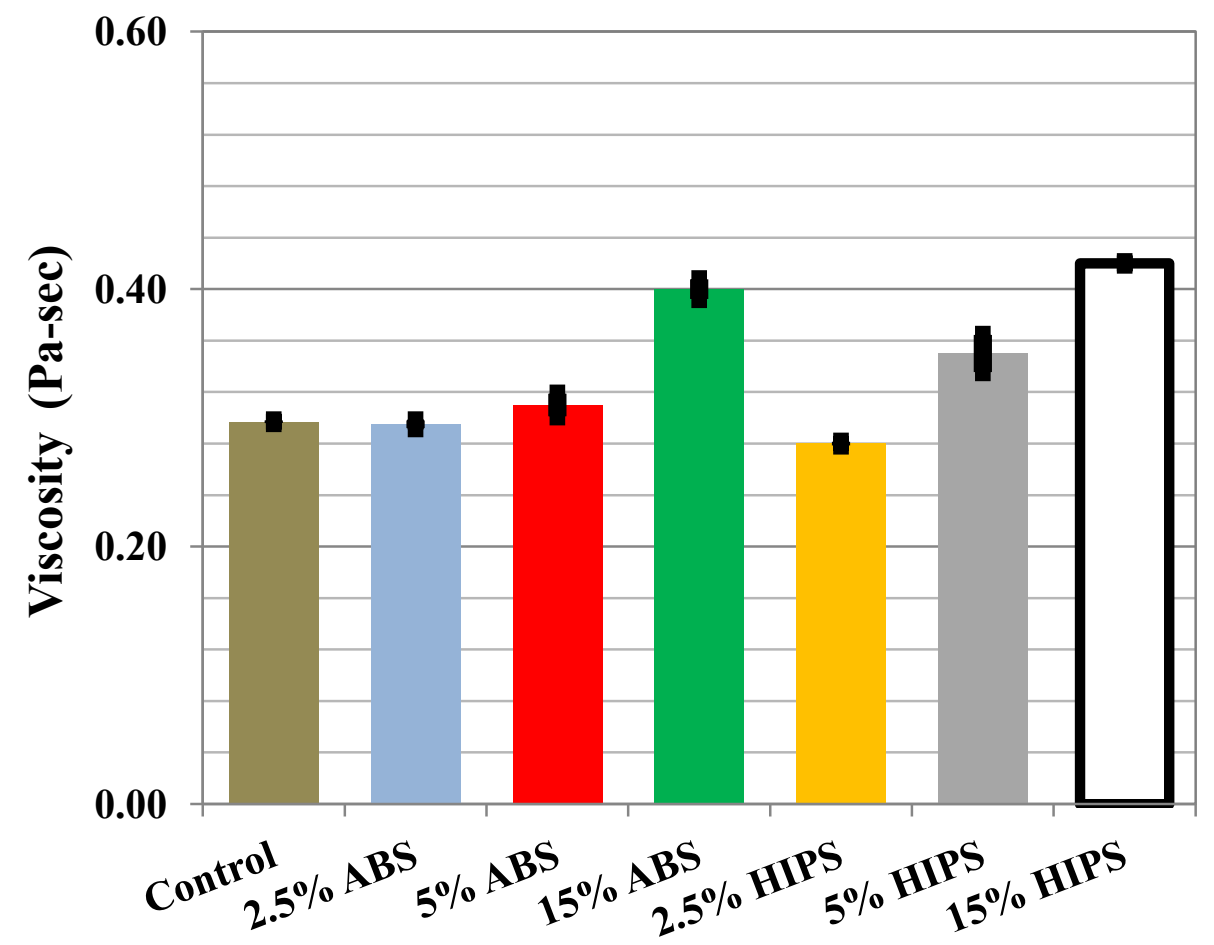

Figure 3.1 Viscosity results for untreated e-waste asphalt binders at $135^{\circ} \mathrm{C}$, taken from three replicates

Figure 3.1 above shows the following results, lower percentages of ABS or HIPS $(2.5 \%)$ resulted in viscosities similar to or lower than the control binder, increasing percentages of ABS or HIPS resulted in increased viscosities, and higher percentages of HIPS are more viscous than comparable percentages of ABS. Along with the asphalt binder viscosity of the entire size distribution of the source recycled ABS and HIPS particles shown in Figure 3.1 above, viscosities were determined for individual particle sizes for 2.5\% ABS and 2.5\% HIPS asphalt binders. Viscosities were determined for the

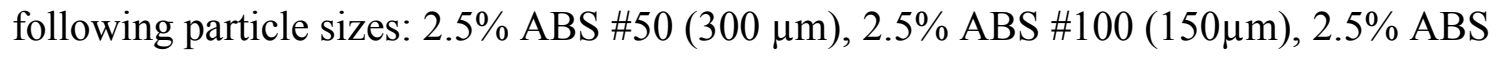

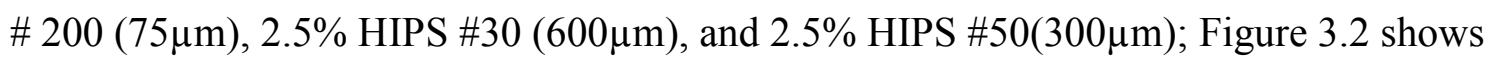
these results below. 


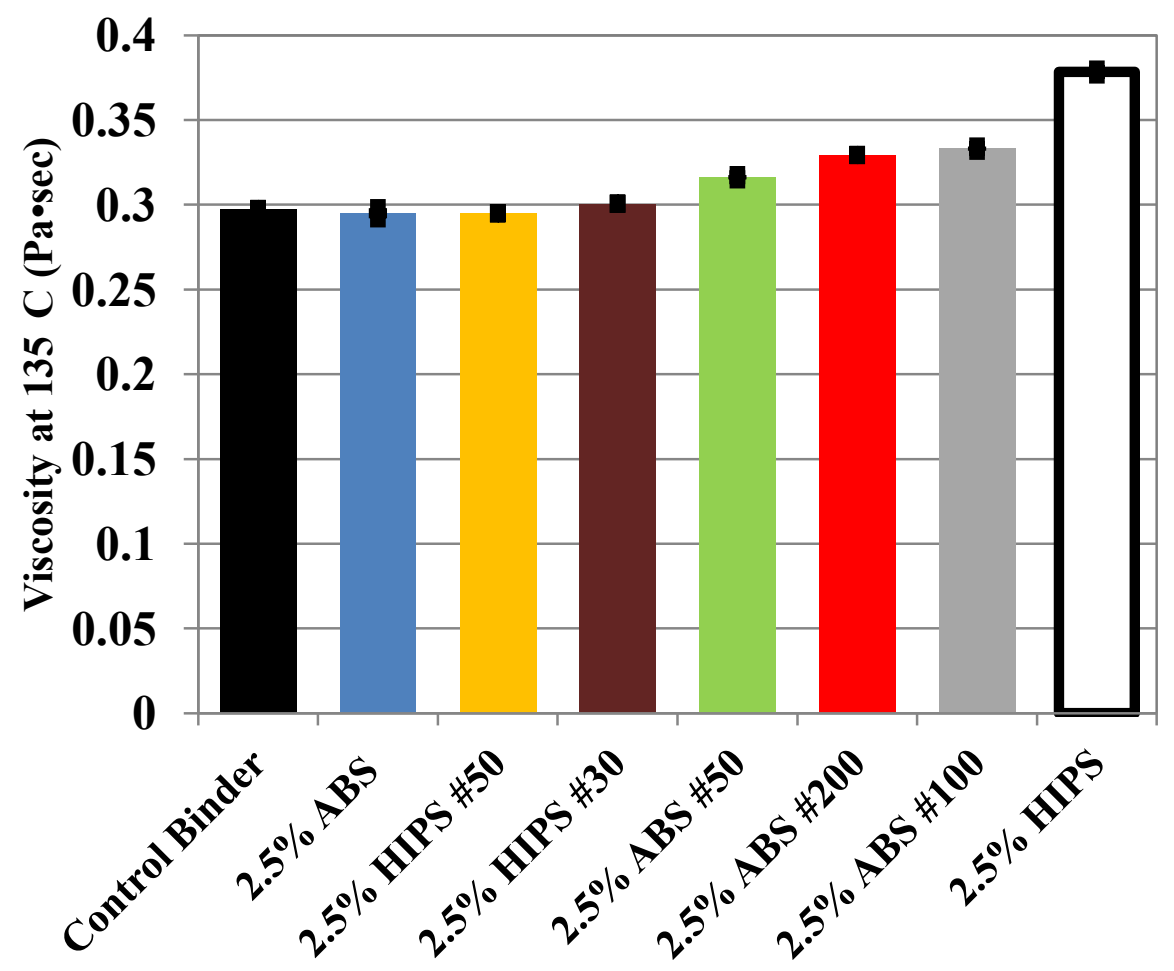

Figure 3.2 E-waste modified binder viscosity for various sized e-waste plastic particles-viscosity test conducted using three replicates

The results from Figure 3.2 show that the source ABS particles $(2.5 \% \mathrm{ABS})$ do not increase viscosity as much as smaller sized ABS particles (2.5\% ABS \#100 and \#200). The results also show that HIPS modified binder decreased in viscosity as the particle size decreased. This decrease in viscosity could be contributed to the ease of melting into the liquid control binder whereas the ABS particles were more difficult to melt and the increase in surface area for the smaller size ABS particles contributing to the increase in viscosity. The source ABS particles and the \#50 and \#30 HIPS particles had comparable viscosities to the control binder. The second major result was gathered from investigating the performance of untreated electronic waste binders was the BBR results at $-18^{\circ} \mathrm{C}$; Table 3.1 shows these results below. 
Table 3.1 Bending beam rheometer m-value results for untreated e-waste binders at $-18^{\circ} \mathrm{C}$ from three replicates

\begin{tabular}{cccc}
\hline $\begin{array}{c}\text { Asphalt } \\
\text { binder } \\
\text { specimen }\end{array}$ & $\begin{array}{c}\text { Temperature } \\
{ }^{\circ} \mathbf{C}\end{array}$ & $\begin{array}{c}\text { M-value \% } \\
\text { M-value } \\
\text { change from } \\
\text { control }\end{array}$ \\
\hline Control Binder & -18 & 0.32 & \\
HIPS 2.5\% & -18 & 0.333 & 3.96 \\
ABS 5\% & -18 & 0.31 & -3.13 \\
ABS 2.5\% & -18 & 0.302 & -5.52 \\
HIPS 5\% & -18 & 0.300 & -6.25 \\
\hline
\end{tabular}

Table 3.1 shows that the control binder outperformed all untreated electronic waste asphalt binders except for the $2.5 \%$ HIPS binder. There was a small percentage difference in BBR m-value between the electronic waste modified asphalt binders and the control binder. At $-18^{\circ} \mathrm{C}$ it was shown that all of the tested binders met the low temperature performance standards for a $-28^{\circ} \mathrm{C}$ asphalt binder. Figure 3.3 below shows the BBR mvalue results for the control binder and the modified e-waste asphalt binders over temperatures ranges of $-12,-15,-18,-21$ and $-24{ }^{\circ} \mathrm{C}$. 


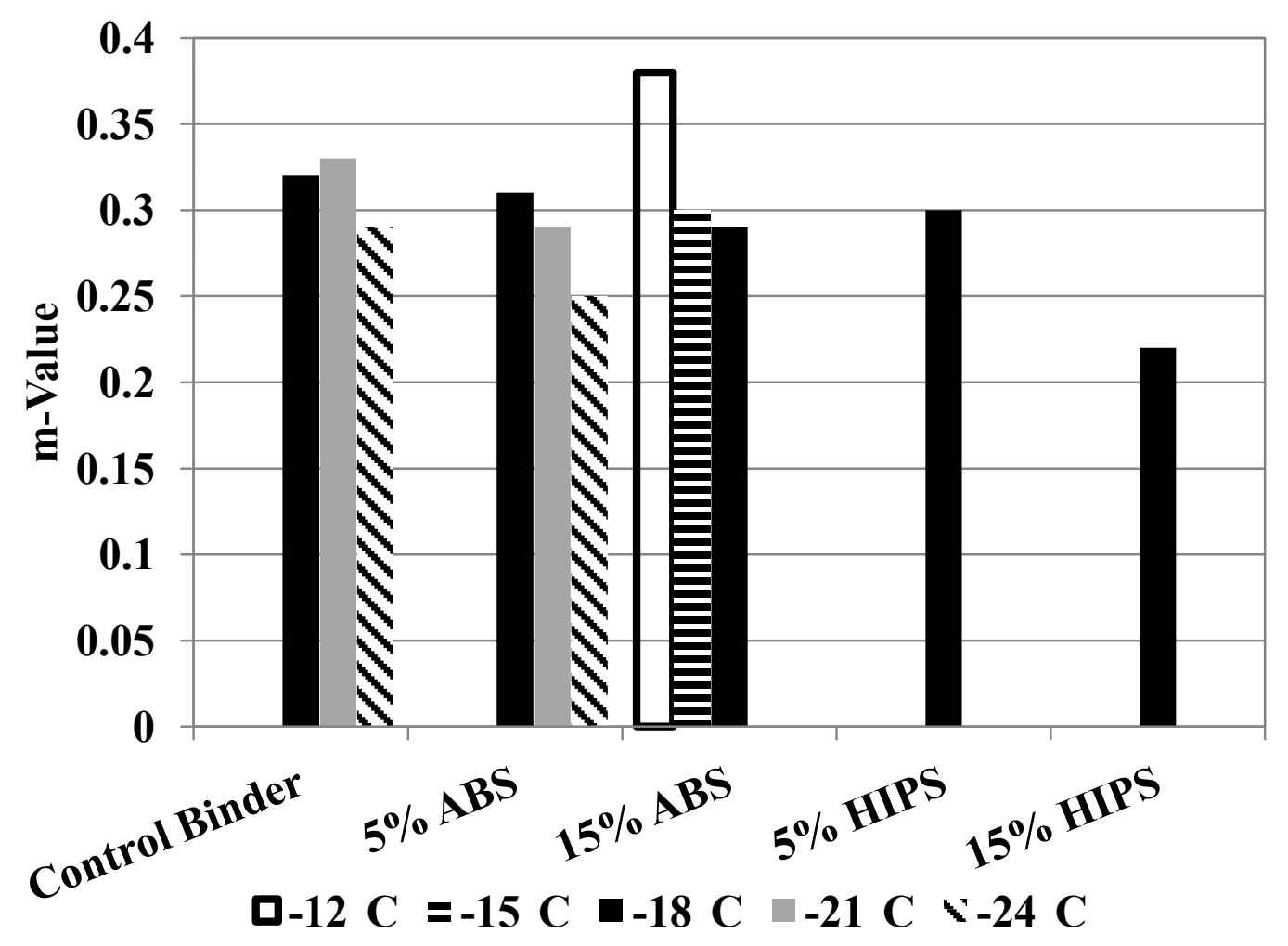

Figure 3.3 BBR M-value comparisons between the control binder and e-waste modified asphalt binders based on three replicates

Figure 3.3 shows that all of the asphalt binders, except the $15 \%$ ABS and the $15 \%$ HIPS modified asphalt binders, met Superpave specifications from the BBR test temperature of $-18^{\circ} \mathrm{C}$ resulting in a low temperature grade of $-28^{\circ} \mathrm{C}$. The results indicated that the control binder met the Superpave minimum m-value requirements of 0.3 for a low temperature grade of $-31^{\circ} \mathrm{C}$. The $5 \%$ HIPS modified asphalt met the BBR test specifications at a testing temperature of $-18^{\circ} \mathrm{C}$. The trend of the results show that the modified e-waste binders are able to meet the low temperature grade BBR m-value requirements at $-28^{\circ} \mathrm{C}$ at the given $\mathrm{BBR}$ test temperature but the low temperature performance of the modified e-waste binders suffer as the BBR testing temperature continues to decrease. 


\subsection{Untreated e-waste binder summary}

Given the performance from untreated electronic waste modified asphalt binders it was shown that untreated electronic waste modified asphalt binders are more viscous than conventional asphalt binders requiring higher mixing and blending temperatures. BBR low temperature performance testing showed that untreated electronic waste plastic modified asphalt binders met Superpave low temperature requirements up to $-28^{\circ} \mathrm{C}$. The BBR results showed that the control binder outperformed all untreated electronic waste plastic modified binder except for the $2.5 \%$ HIPS binder. Since an improvement in low temperature performance wasn't conclusive, a decision was made to chemically treat the ABS and HIPS electronic waste plastics through free radical polymerization. The ABS and HIPS plastics were treated chemically in order to bond the e-waste plastic molecules to the asphalt binder and improve low temperature properties along with maintaining high temperature performance for electronic waste plastic modified asphalt binders. 


\section{Chapter 4: The mechanical performance of asphalt binders modified with free radical treated electronic waste plastics $^{3}$}

\subsection{Introduction}

A free radical initiator, cumene hydro peroxide was used to improve low temperature performance of e-waste modified asphalt binders to improve the low temperature performance of modified ABS and HIPS electronic waste asphalt binders. The purpose of using cumene hydro peroxide was to induce bonding between the plastic polymer (ABS and HIPS) and the asphalt binder molecules. Cumene hydro peroxide was used to treat the electronic waste plastic powders for the improvement of asphalt binder and e-waste plastic interaction. This investigation is intended to verify if there is an improvement in asphalt binder performance versus conventional asphalt binders. Research efforts which this investigation drew upon include the following: Guo et al. [40], Naskar et al. [41], Yokoyama and Iji [21], along with Hinishoğlu and Ağar [27]. Guo et al. [40] investigated the performance of modified waste circuit board asphalt binders and determined that asphalt binder high temperature performance was improved. Naskar et al. [41], investigated the thermal stability of modified waste plastic asphalt binders using various percentages of plastic and determined that 5\% plastic within asphalt binders provided the optimal thermal stability for the modified asphalt binders.

\subsection{Treated e-waste asphalt binder research objectives}

The primary objective of this investigation was to determine the improvement in mechanical performance for free radical treated e-waste plastic modified asphalt binders,

\footnotetext{
${ }^{3}$ Text prepared for submission to the Journal of Fuel - Colbert, B., Z. You, P. Heiden, (2012). "The mechanical performance of asphalt binders modified with free radical treated electronic waste plastics." Journal of Fuel
} 
referred hereafter as treated e-waste modified asphalt binders, versus conventional asphalt binders. The secondary objective of this research effort was to determine if small percentages of treated e-waste plastic will produce improved e-waste modified asphalt binder performance at all temperature ranges. Superpave asphalt binder characterization testing methods were used to achieve the objectives of this investigation. The successful carrying out of the author's experimental plan led to the following results: $5 \% \mathrm{ABS}$ plastic electronic waste by weight of asphalt binder in conjunction with the use of a cumene hydro peroxide met Superpave high and low temperature specifications. Superpave viscosity specifications for treated e-waste modified asphalt binders were obtained. And treated e-waste modified asphalt binders showed viscoelastic behavior similar to the control binder under unaged and post production, rolling thin film oven (RTFO), aged asphalt binders.

\subsection{Materials preparation and testing procedures}

The typical bulk plastics obtained from waste recycled computers were: Acrylonitrile Butadiene Styrene (ABS) and high impact polystyrene (HIPS). The waste plastics were reduced in size in a two-step process with 100 percent of the material passing the \#50 $(300 \mu \mathrm{m})$ sieve. The primary processing technique utilized an industrial shredder to reduce the size of the bulk plastics. The secondary size reduction technique utilized liquid nitrogen to freeze the shredded electronics waste plastics particles and an industrial grinder reduced the plastics into powdered computer plastics. Figure 4.1 shows the equipment and the size of the e-waste plastic particles. 

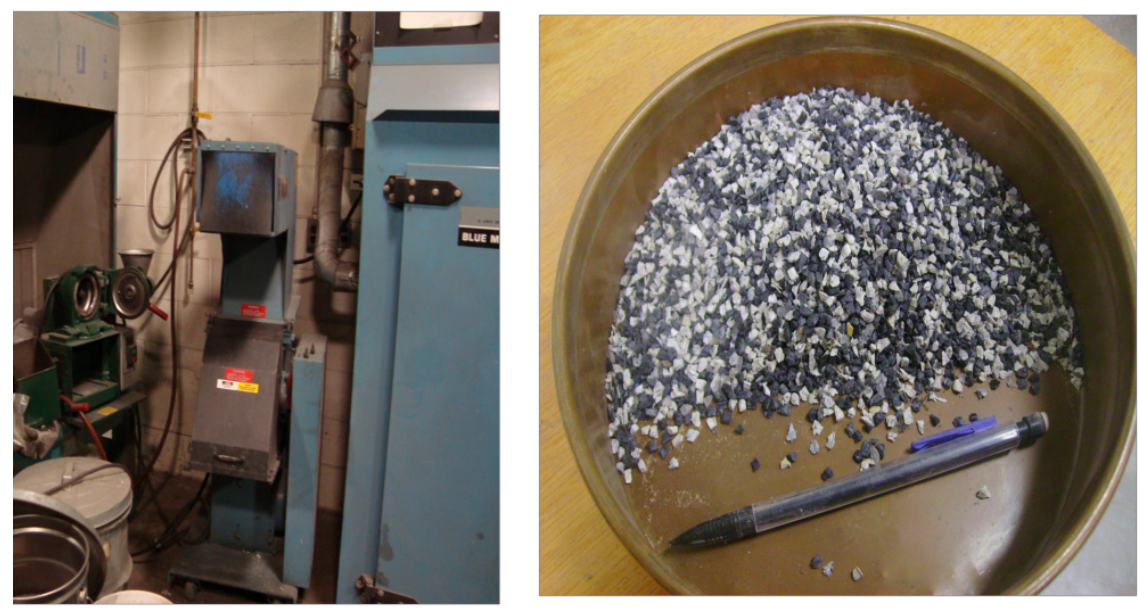

Figure 4.1 Electronic waste materials size reduction equipment, industrial shredder and pulverizer on the left and the source ABS e-waste plastic samples on the right.

\subsection{Peroxide modification of asphalt binder}

Cumene hydro peroxide, was used as the free radical initiator for this investigation, having a half-life temperature of $158^{\circ} \mathrm{C}$ at 10 hours and $188^{\circ} \mathrm{C}$ at 1 hour [42]. The peroxide first dissociates and abstracts a susceptible hydrogen atom from a polymer backbone, as shown in Figure 4.2. Once this reactive polymeric radical forms, many different radical reactions can occur [43, 44], including thermo-oxidative degradation of the polymer chains, altering the rheological properties of the polymers, and grafting reactions can enhance the stability of polymer blends [45]. The peroxide-promoted modification of e-waste plastics would take place in three steps: 1) Contact between melted ABS and HIPS chains and thermally generated peroxide radicals occurs at an appropriate melting temperature. 2) The radicals abstract hydrogen atoms, causing a range of different reactions, including chain scissions depending on the conditions. 3) Finally, molecular weight can rebuild, improving strength properties [45]. 


\section{Thermal breakdown of peroxide into radicals}
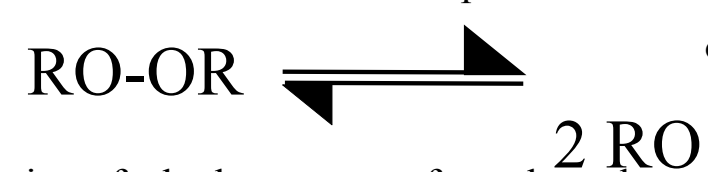

Radical abstraction of a hydrogen atom from the polymer backbone, producing a polymeric radical.

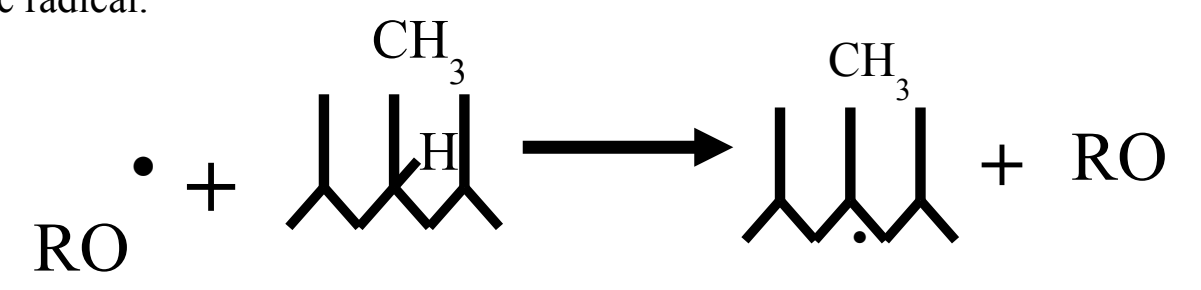

Reactive polymeric radical

Figure 4.2 Free radical initiation treatment process of e-waste plastics.

After the bulk e-waste plastics were reduced to powder, the powders were coated and mixed with cumene hydro peroxide $(0.02 \%$ by weight of e-waste plastic powder). For all modified asphalt binders tested in this investigation the e-waste plastic powders composed of $5 \%$ by weight of the asphalt binder. The e-waste plastics powders were then blended and melted into the control binder. A high shear blender mixed the asphalt binder, e-waste powders, and cumene hydro peroxide together for 45 minutes at 5000 RPM and at 3000 RPM for 15 minutes to ensure complete melting and blending of the ewaste plastics within the asphalt binder. The control and modified e-waste asphalt binders used for this investigation included: 5\% ABS modified asphalt binder; treated 5\% ABS modified asphalt binder, 5\% HIPS modified asphalt binder, treated 5\% HIPS modified asphalt binder, and a control tank asphalt binder. The base asphalt binder used as the control asphalt binder for this investigation was a virgin asphalt binder with a performance grade of 58-28 from a construction site used in Gladstone, Michigan. Finally, viscosity measurements which were taken in Pa-sec included temperatures of $120,135,150,165,180,195$, and $210^{\circ} \mathrm{C}$. The complex modulus and phase angle along 
with creep stiffness in MPa and m-value were also measured. Figure 4.3 displays the experimental plan for this investigation.

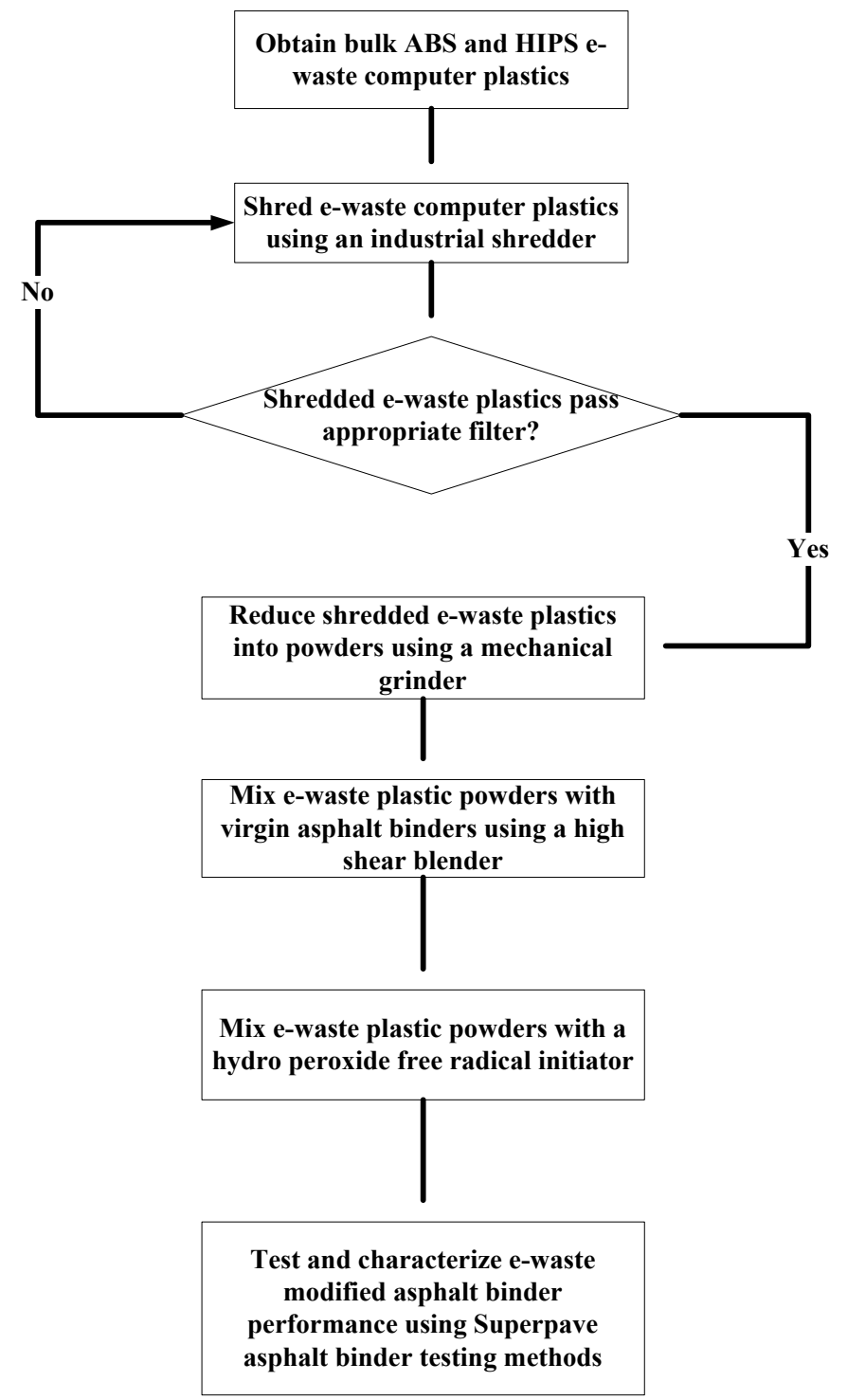

Figure 4.3 Electronic waste materials processing flowchart.

\subsubsection{Asphalt binder viscosity characterization}

Viscosity for asphalt binders were determined according to test procedure ASTM D4402 $[35,36]$ at $135^{\circ} \mathrm{C}$ as an indicator of asphalt binder workability. The \#27 spindle was used to characterize asphalt binder viscosities for this investigation using $10.5 \mathrm{~g}$ of asphalt 
binder. The mixing and compaction temperature of the e-waste modified asphalt binders were determined using viscosity curves determined by the following viscosity parameters. Asphalt binder mixing and blending temperatures were defined using the viscosity limits of $0.17 \pm 0.02 \mathrm{~Pa} \bullet \mathrm{s}$ for the mixing range and $0.28 \pm 0.03 \mathrm{~Pa} \bullet \mathrm{s}$ for compaction temperature range. Measurements for viscosity were determined at 100 RPM.

\subsubsection{Dynamic shear rheometer testing}

The dynamic shear Rheometer (DSR) was used to characterize the viscoelastic behavior of the treated e-waste modified asphalt binders. Procedures for the DSR are given in AASHTO 315: Determining the Rheological Properties of Asphalt Binder Using a Dynamic Shear Rheometer (DSR), where the asphalt sample is positioned between a fixed plate and an oscillating plate [46]. Three test replicates were conducted for this procedure. Physical property measurements using the DSR for asphalt binder are made using tank, rolling thin film oven aged (RTFO binder), and pressure aging vessel (PAV) aged binders. An $8 \mathrm{~mm}$ DSR plate was used to determine complex modulus and delta for PAV aged asphalt binders. A $25 \mathrm{~mm}$ DSR plate was used to determine complex modulus and delta for the tank and RTFO aged asphalt binders. Complex modulus $\left(\mathrm{G}^{*}\right)$ and phase angle $(\delta)$ are the performance measurements expected to determine viscoelastic behavior for the e-waste modified asphalt binders.

\subsubsection{Asphalt binder artificial aging test procedures}

Rolling Thin Film Oven (RTFO) and Pressure Aging Vessel (PAV) ovens were used to age the control and modified e-waste asphalt binders [37]. RTFO asphalt binders were produced according to AASHTO T240 [38]. The RTFO asphalt binders were placed in the PAV oven at $100{ }^{\circ} \mathrm{C}$ for 20 hours. The long term aging of the asphalt binder specimens followed the ASTM D6521 specification standard. Finally, the PAV aged binders were tested using the Bending Beam Rheometer (BBR) for asphalt binder low temperature testing. 


\subsubsection{Bending beam rheometer testing}

The BBR was used for this investigation to determine the temperatures at which the various asphalt binders can resist low temperature cracking. The AASHTO T 313-09 standard specification was followed for BBR testing in this investigation [39]. Asphalt binder beams dimensions for BBR testing are: $6.35 \pm 0.05-\mathrm{mm}$ thick by $12.70 \pm 0.05-\mathrm{mm}$ wide by $127 \pm 2.0-\mathrm{mm}$ long. These beams then were placed under a constant load of $980 \pm 50 \mathrm{mN}$ for $240 \mathrm{~s}$. Creep stiffness and m-value are parameters of interest for BBR testing. The creep stiffness is defined as the ratio of the constant $980 \mathrm{mN}$ load applied to the change in strain or displacement in the prepared asphalt beam. The m-value is the rate of change in the stress against strain. This m-value slope is plotted in log scale. The maximum value for asphalt binder creep stiffness for BBR testing to meet Superpave specifications is $300 \mathrm{MPa}$ [39]. M-value must be at least 0.3 for BBR testing to meet specification at a given temperature grade[39].

\subsection{Results}

\subsubsection{Viscosity results}

The addition of free radical initiators to e-waste modified asphalt binders resulted in lower viscosities, and lower blending and compaction temperatures versus untreated ewaste modified asphalt binders as shown in Figure 4.4. 


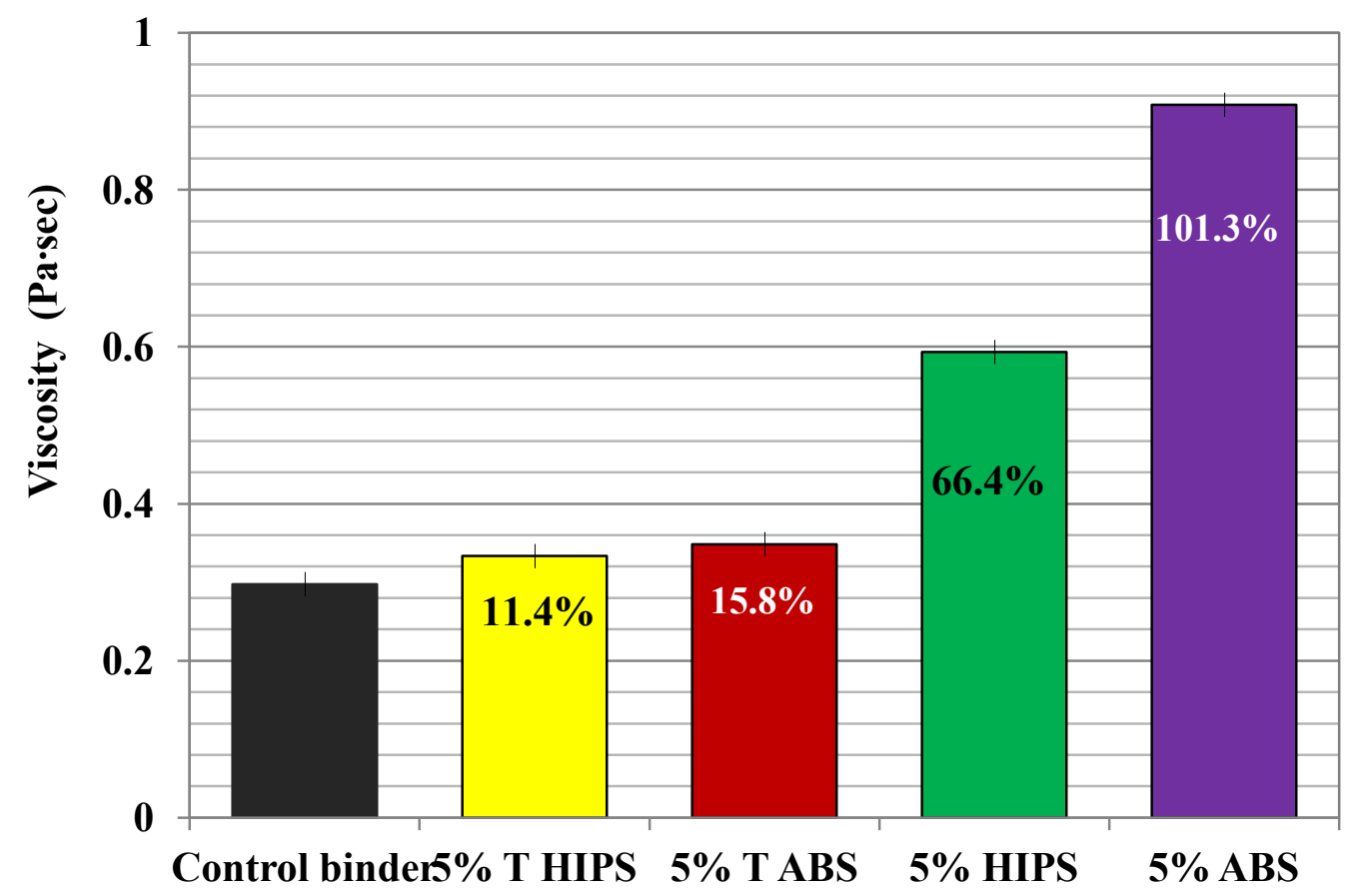

Figure 4.4 Viscosity of e-waste modified asphalt binder measured at $135^{\circ} \mathrm{C}(5 \%$ ABS and 5\% HIPS are the untreated ABS/HIPS modified binders, and the treated 5\% ABS/HIPS are the treated ABS/HIPS modified binders, percent differences between control binder in black HIPS, white ABS). Based on three replicates

The results from Figure 4.4 confirm that the addition of free radical initiators significantly reduced the viscosity of the treated e-waste modified asphalt binders with both ABS and HIPS. The viscosities are comparable to the control virgin binder, while the formulations with the e-waste that were not treated with initiator were significantly higher. There is an $89.1 \%$ reduction in 5\% ABS viscosity compared to the treated 5\% ABS viscosity and a 52\% reduction in viscosity between the 5\% HIPS and treated 5\% HIPS modified asphalt binders. Therefore, the use of free radical initiators can potentially increase both workability and asphalt pumping compared to untreated e-waste modified asphalt binders. Table 4.1 summarizes the effect of viscosity on blending and mixing temperatures for the electronic waste modified asphalt binders. 
Table 4.1 E-waste asphalt binder mixing and compaction temperatures

\begin{tabular}{lll}
$\begin{array}{l}\text { Asphalt binder } \\
\text { specimen }\end{array}$ & $\begin{array}{l}\text { Mixing temperature } \\
\text { range }{ }^{\circ} \mathrm{C}\end{array}$ & $\begin{array}{l}\text { Compaction temperature } \\
\text { range }{ }^{\circ} \mathrm{C}\end{array}$ \\
\hline Control binder & $147-154$ & $134-139$ \\
$5 \%$ ABS & $169-175$ & $157-161$ \\
Treated 5\% ABS binder & $147-154$ & $136-142$ \\
HIPS 5\% & $168-175$ & $156-162$ \\
Treated 5\% HIPS binder & $136-139$ & $136-139$ \\
\hline
\end{tabular}

Temperature versus viscosity curves were produced in order to determine the mixing and compaction range of the treated e-waste modified asphalt binders. It should be noted that the conventional viscosity-temperature curve is used herein to provide a reference point. While the data doesn't show if true mixing or compaction occurred, the curve for the HIPS modified asphalt binder is similar to the control as shown in Figure 4.5.

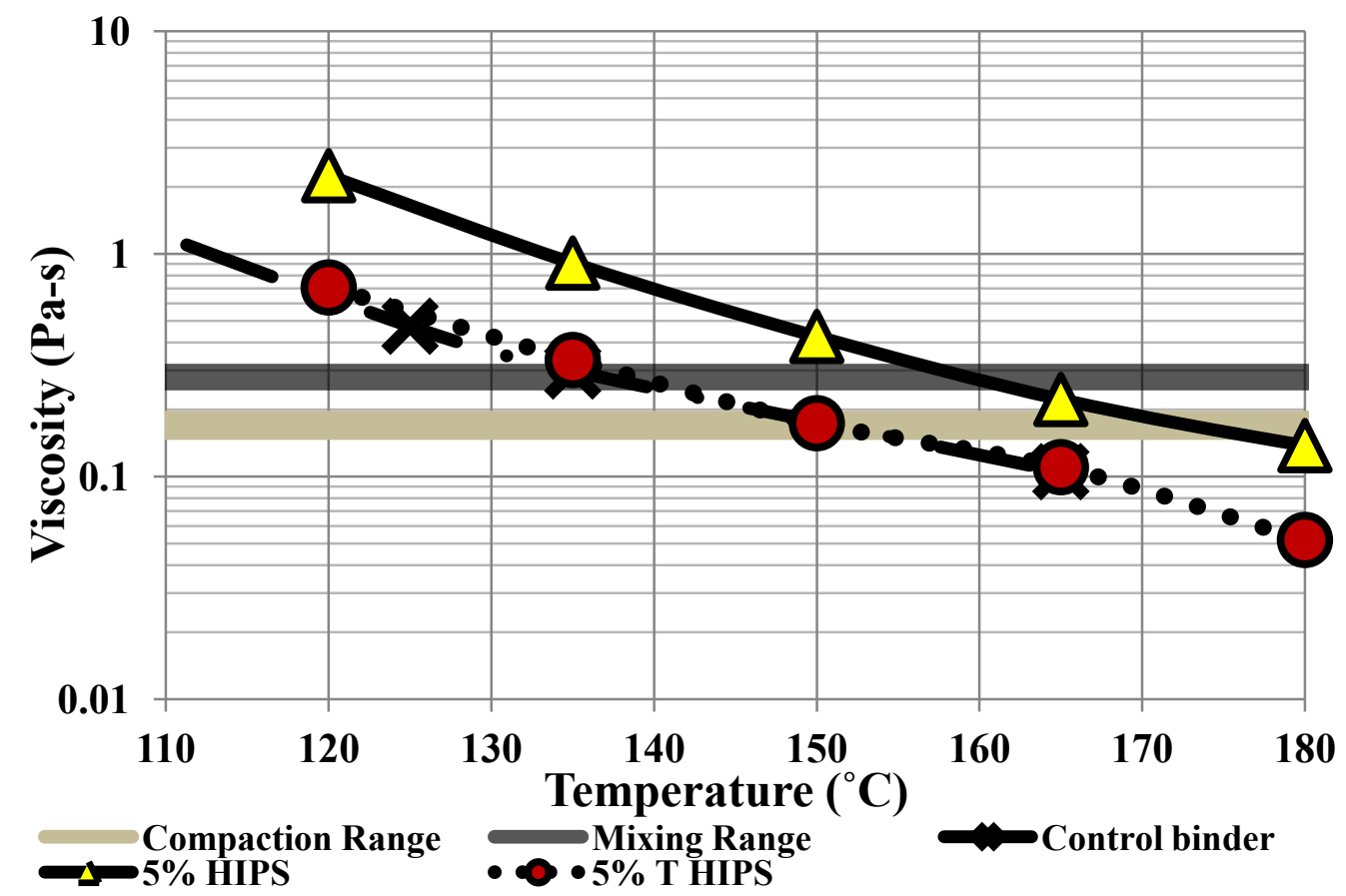

Figure 4.5 HIPS modified asphalt binder rotational viscosity temperature curve based on three replicates

The results from Figure 4.5 show the following: The mixing and compaction temperature range for the treated 5\% HIPS modified asphalt binder is reduced compared to the 
untreated 5\% HIPS modified e-waste asphalt binder, having a nearly $24^{\circ} \mathrm{C}$ decrease in compaction temperature and a $23^{\circ} \mathrm{C}$ temperature reduction in mixing temperature. The mixing and compaction temperature range for the control virgin binder is similar to the treated 5\% HIPS modified asphalt binder. The treated 5\% HIPS modified asphalt binder compaction temperature is shown to be greater than the control binder based on viscosity results. Untreated ABS modified asphalt binder compaction and mixing temperatures are also greater than the control binder, as displayed in Figure 4.6.

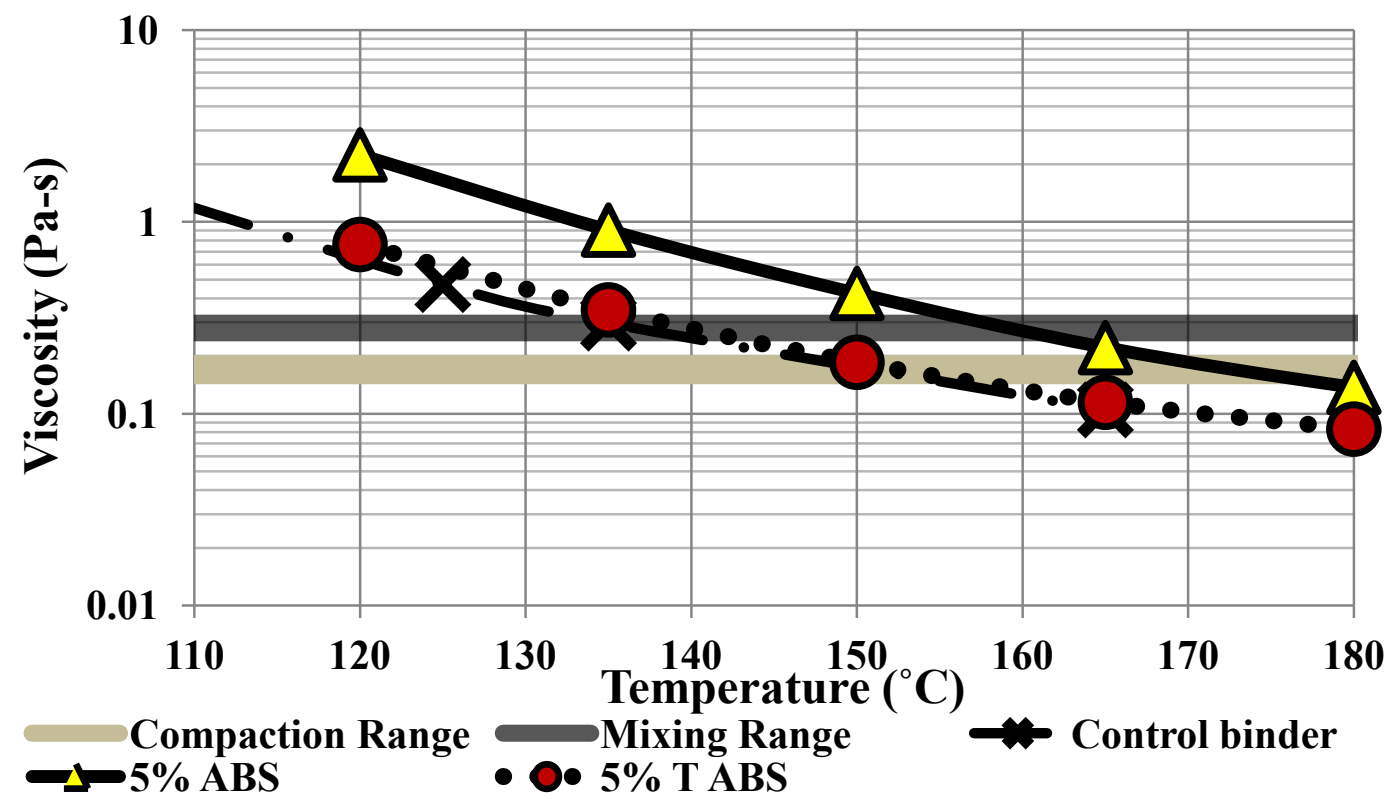

Figure 4.6 ABS modified rotational viscosity temperature curve. Based on three replicates

Specifically, the mixing and compaction temperatures for treated 5\% ABS modified asphalt binder are lower than the untreated 5\% ABS modified e-waste asphalt binder. There is a $21^{\circ} \mathrm{C}$ difference in compaction temperature and a $23^{\circ} \mathrm{C}$ difference for mixing temperature. 


\subsubsection{Complex moduli of e-waste modified asphalt binders}

The complex moduli were determined to obtain results for the rutting parameter $\mathrm{G}^{*} / \mathrm{sin} \delta$ at various temperatures for the treated ABS and HIPS modified asphalt binders for tank binder and RTFO aged binder conditions. The results are summarized in Table 4.2.

Table 4.2 Superpave rutting susceptibility for treated e-waste modified asphalt binders. Based on three replicate DSR tests

\begin{tabular}{|c|c|c|c|c|c|}
\hline $\begin{array}{l}\text { Asphalt } \\
\text { binder } \\
\text { specimen }\end{array}$ & $\begin{array}{c}\text { Temperature } \\
{ }^{\circ} \mathrm{C}\end{array}$ & $\begin{array}{c}\text { Tank } \\
\text { binder } \\
\mathrm{G}^{*} / \sin \delta \\
(\mathrm{KPa})\end{array}$ & $\begin{array}{l}\text { Passes tank binder } \\
\text { specifications } \\
\text { (1 KPa Minimum) }\end{array}$ & $\begin{array}{c}\text { RTFO } \\
\text { binder } \\
\mathrm{G}^{*} / \sin \delta \\
(\mathrm{KPa})\end{array}$ & $\begin{array}{c}\text { Passes RTFO } \\
\text { binder } \\
\text { specifications } \\
(2.2 \mathrm{KPa} \\
\text { minimum) }\end{array}$ \\
\hline \multirow{2}{*}{$\begin{array}{l}\text { Control } \\
\text { binder }\end{array}$} & 58 & 1.11 & Yes & 4.39 & Yes \\
\hline & 64 & 0.51 & No & 1.84 & No \\
\hline \multirow{5}{*}{$\begin{array}{l}\text { Untreated } \\
5 \% \text { HIPS } \\
\text { binder }\end{array}$} & 58 & 177.19 & Yes & 69.76 & Yes \\
\hline & 64 & 74.29 & Yes & 6.36 & Yes \\
\hline & 70 & 48.98 & Yes & 1.92 & No \\
\hline & 76 & 2.84 & Yes & N/A & No \\
\hline & 82 & 1.64 & Yes & N/A & No \\
\hline \multirow{5}{*}{$\begin{array}{c}\text { Treated 5\% } \\
\text { HIPS } \\
\text { binder }\end{array}$} & 58 & 47.24 & Yes & 47.95 & Yes \\
\hline & 64 & 81.85 & Yes & 23.21 & Yes \\
\hline & 70 & 132.95 & Yes & 11.13 & Yes \\
\hline & 76 & 104.12 & Yes & 5.36 & Yes \\
\hline & 82 & 397.38 & Yes & 2.57 & Yes \\
\hline \multirow{5}{*}{$\begin{array}{l}\text { Untreated } \\
5 \% \text { ABS } \\
\text { binder }\end{array}$} & 58 & 19.87 & Yes & 8.5 & Yes \\
\hline & 64 & 8.93 & Yes & 3.9 & Yes \\
\hline & 70 & 4.15 & Yes & 1.8 & No \\
\hline & 76 & 2.06 & Yes & N/A & No \\
\hline & 82 & 1.03 & Yes & N/A & No \\
\hline \multirow{5}{*}{$\begin{array}{l}\text { Treated 5\% } \\
\text { ABS binder }\end{array}$} & 58 & 3321.68 & Yes & 9291.45 & Yes \\
\hline & 64 & 3137.87 & Yes & 1096.79 & Yes \\
\hline & 70 & 93.95 & Yes & 0.05 & No \\
\hline & 76 & 2.41 & Yes & N/A & No \\
\hline & 82 & 25.27 & Yes & $\mathrm{N} / \mathrm{A}$ & No \\
\hline
\end{tabular}


Table 4.2 shows that in all conditions for tank binder and RTFO aged binders the treated e-waste modified asphalt binders met Superpave rutting parameter specifications for asphalt binders at $58^{\circ} \mathrm{C}$. It's shown that the treated 5\% ABS has a lower rutting parameter than the treated 5\% HIPS binder for RTFO aged binders. The results also show that the Superpave high temperature performance grade for rutting susceptibility is met for not only the control grade of $58^{\circ} \mathrm{C}$ but also at least a one temperature grade bump in performance at $64^{\circ} \mathrm{C}$ for the e-waste tank and RTFO aged binder conditions. Treating the $5 \%$ HIPS with the hydro-peroxide resulted in a five grade bump in performance at PG or $82^{\circ} \mathrm{C}$.

Figure 4.7 shows a comparison of the complex moduli (or dynamic shear moduli) master curve of the unaged e-waste modified asphalt binders and the un-aged control tank binder. Figure 4.8 shows a comparison of the complex moduli (or dynamic shear moduli) master curve of PAV aged e-waste modified asphalt binders and PAV aged control binder. The complex modulus master curve temperatures used in Figures 4.7 and 4.8 include: $40,46,52,58,64$, and $70^{\circ} \mathrm{C}$ with a reference temperature of $40^{\circ} \mathrm{C}$. The data from these curves has shown the following: Over the entire reduced frequency range all un-aged e-waste modified asphalt binders tested had lower stiffness than the control binder. Both ABS and HIPS treated e-waste modified asphalt binders had a lower stiffness than their corresponding untreated asphalt binders. Figure 4.7 shows that the ABS and HIPS tank binders had similar complex modulus values over the reduced frequency range of $1^{-4}$ to $25 \mathrm{~Hz}$. The Treated ABS and HIPS modified asphalt binders had similar complex modulus values also. The treated e-waste modified asphalt binders had lower complex modulus values versus the untreated e-waste modified asphalt binders. 


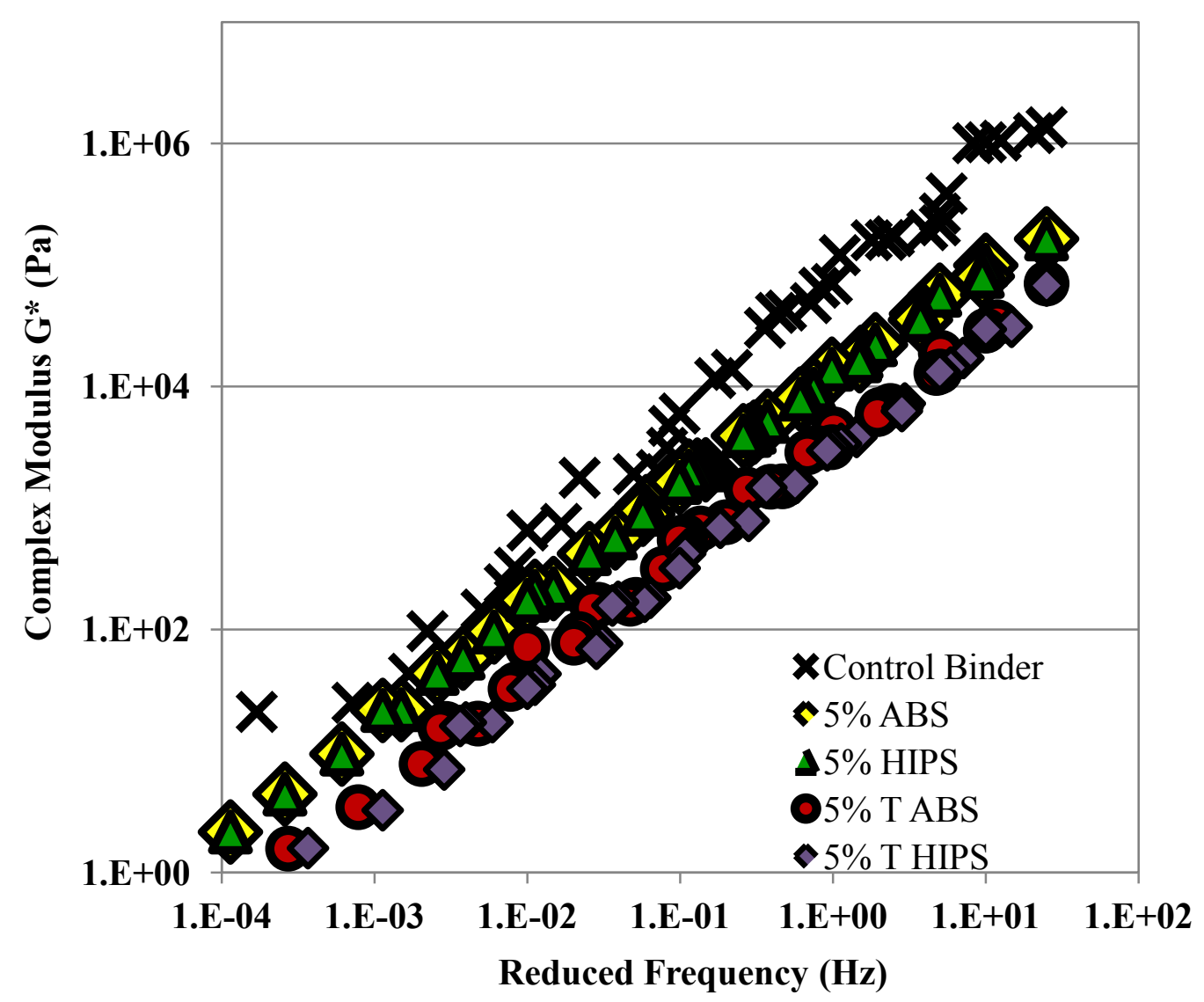

Figure 4.7 Five percent e-waste modified asphalt binder mastercurve results for unaged tank binders, mastercurve temperatures include reference temperature $40^{\circ} \mathrm{C}$. Based on three replicate DSR tests

Figure 4.8 shows the mastercurve of the PAV aged e-waste modified asphalt binders in comparison to the PAV aged control binder. 


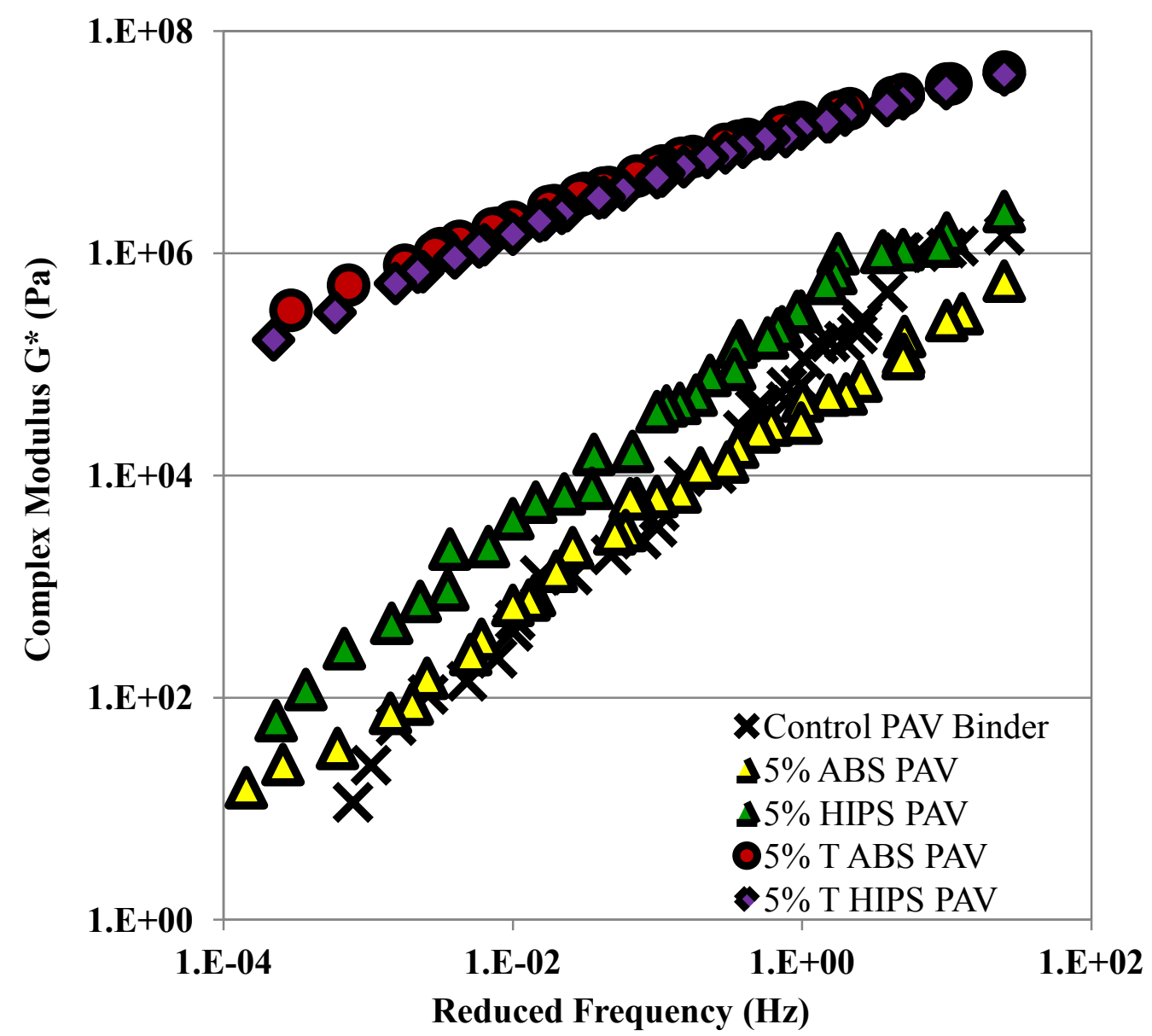

Figure 4.8 E-waste modified asphalt binder mastercurve results for PAV aged asphalt binders, the complex modulus master curve reference temperature is $40^{\circ} \mathrm{C}$. Based on three replicate DSR tests.

Figure 4.8 shows that the PAV aged 5\% treated ABS and HIPS binders were approximately two orders of magnitude in stiffness. The treated and untreated HIPS binders were stiffer than the PAV aged control and untreated ABS binders. At lower frequencies the PAV aged control binder was softer versus the ABS and HIPS e-waste modified asphalt binders.

\subsubsection{Low temperature asphalt binder performance results}

The bending beam rheometer (BBR) was utilized to determine thermal cracking potential of the control and treated e-wasted modified asphalt binders. Creep stiffness and m- 
values were determined for treated e-waste modified asphalt binders at BBR test temperatures of -18 and $-21^{\circ} \mathrm{C}$ corresponding to field temperatures of -28 and $-31^{\circ} \mathrm{C}$, respectively. According to AASHTO specification T 313 [39], the maximum creep stiffness allowed to meet the low temperature asphalt binder grade is $300 \mathrm{MPa}$ and the minimum m-value allowed to meet the low temperature asphalt binder grade is 0.3 .

Figures 4.9 and 4.10 show the BBR creep stiffness and m-values for the treated e-waste modified asphalt binder samples at BBR test temperature of $-18^{\circ} \mathrm{C}$ which corresponds to a pavement surface temperature of $-28^{\circ} \mathrm{C}$.

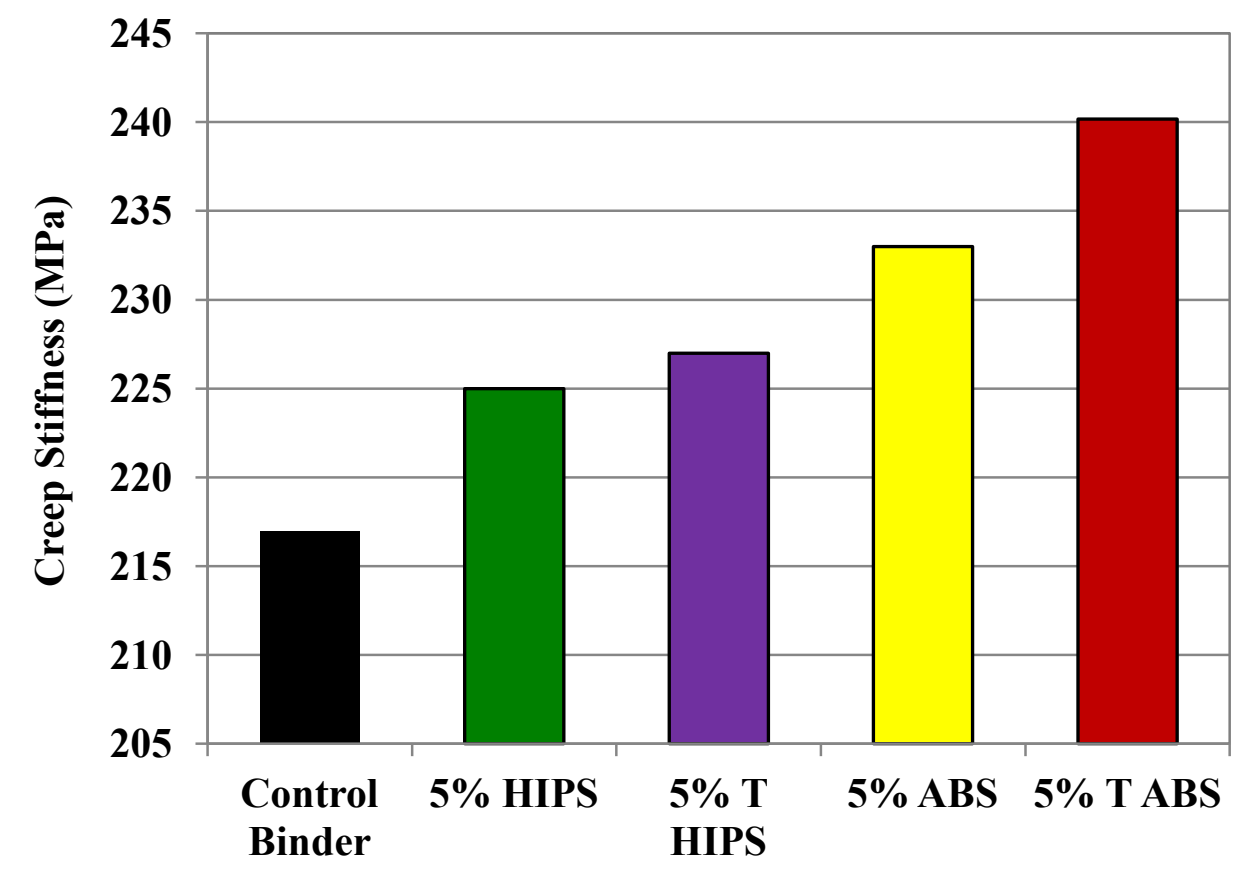

Figure 4.9 Bending beam rheometer creep stiffness results for e-waste modified asphalt binders at $\mathrm{BBR}$ test temperature of $-18^{\circ} \mathrm{C}$. Based on three replicate DSR tests 


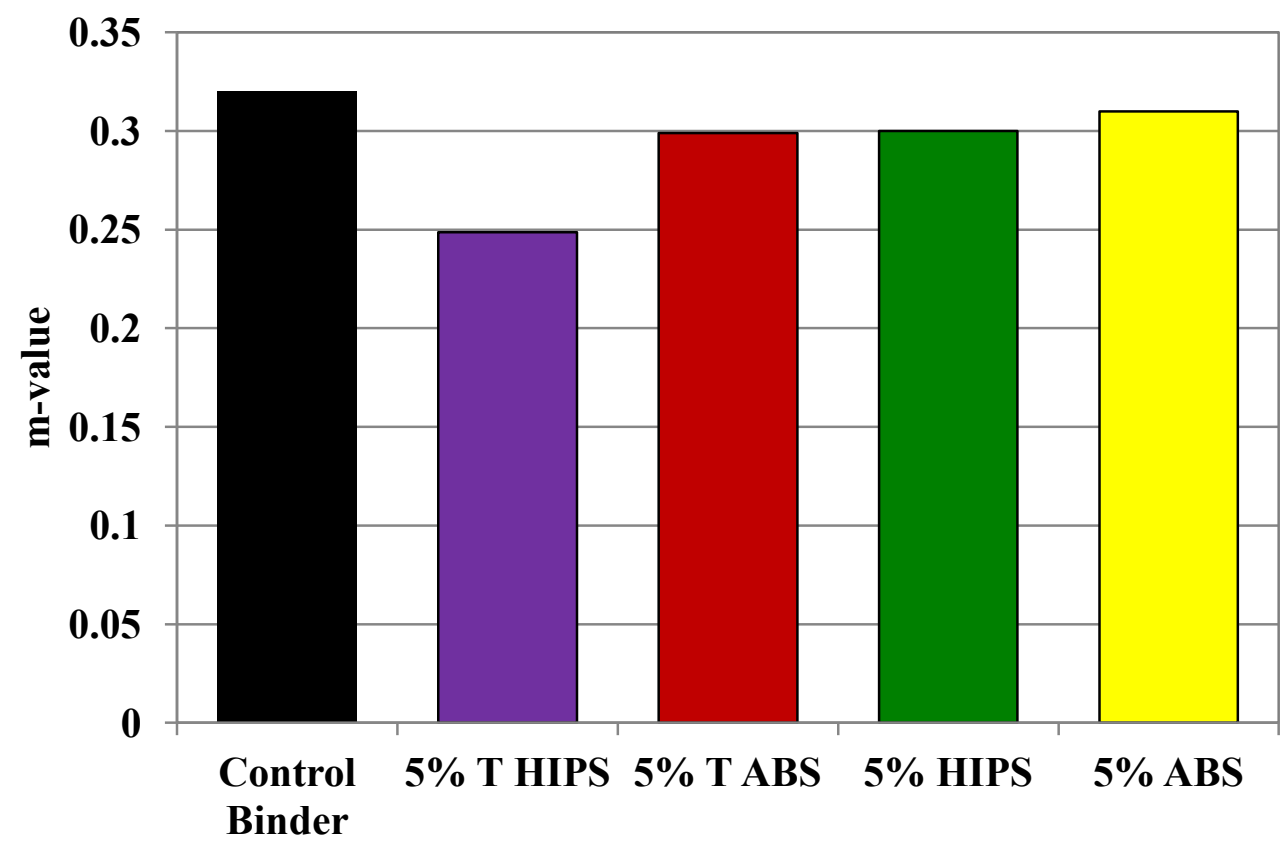

Figure 4.10. Bending beam rheometer low temperature m-value results for e-waste modified asphalt binders (specification for $-28^{\circ} \mathrm{C}$ ) $\mathrm{BBR}$ test temperature of $-18^{\circ} \mathrm{C}$. Based on three replicate DSR tests

Figure 4.9 showed that all asphalt binder samples met creep stiffness specifications for $28^{\circ} \mathrm{C}$. The control asphalt binder was assumed to have a low temperature performance grade of $-28^{\circ} \mathrm{C}$ but from the results in Figure 4.10, BBR testing shows that the control binders exceed low temperature cracking specifications beyond a field temperature of $-28^{\circ} \mathrm{C}$. The results showed that the low temperature testing specifications of $-28^{\circ} \mathrm{C}$ from BBR testing were met in all cases, except for the PAV aged 5\% untreated HIPS binder. The 5\% untreated HIPS binder failed the m-value performance specifications for a field temperature of $-28^{\circ} \mathrm{C}$. Only the control binder exceeded low temperature performance specifications of $-28^{\circ} \mathrm{C}$. Table 4.3 summarizes the results for the BBR performance for asphalt binder field temperatures of -28 and $-31{ }^{\circ} \mathrm{C}$. 
Table 4.3 Bending beam rheometer performance results for modified e-waste asphalt binders, test conducted on three replicates

\begin{tabular}{llllll}
\hline $\begin{array}{l}\text { Asphalt } \\
\text { binder } \\
\text { specimen }\end{array}$ & $\begin{array}{l}\text { BBR test } \\
\text { temperature }{ }^{\circ} \mathrm{C}\end{array}$ & M-value & $\begin{array}{l}\text { Creep } \\
\text { stiffness } \\
(\mathrm{MPa})\end{array}$ & $\begin{array}{l}\text { Met } \\
\text { specs? }\end{array}$ & $\begin{array}{l}\text { Improved } \\
\text { asphalt binder } \\
\text { properties? }\end{array}$ \\
\hline $\begin{array}{l}\text { Control } \\
\text { binder }\end{array}$ & -18 & 0.32 & 217 & Yes & N/A \\
& -21 & 0.33 & 281 & Yes & Yes \\
5\% ABS & -18 & 0.31 & 233 & Yes & Yes \\
Treated 5\% & -21 & 0.29 & 298 & No & No \\
ABS & -18 & 0.30 & 240 & Yes & Yes \\
HIPS 5\% & -21 & 0.26 & 330 & No & No \\
Treated & -18 & 0.3 & 225 & Yes & No \\
HIPS 5\% & -18 & 0.25 & 227 & No & No \\
\hline
\end{tabular}

Considering the results from Table 4.3, the control binder met low temperature specifications for a field temperature of $-31^{\circ} \mathrm{C}$ corresponding to BBR test temperature of $-21{ }^{\circ} \mathrm{C}$. The control binder showed that its asphalt binder properties were improved at $-21^{\circ} \mathrm{C}$ due to ability of the control binder to withstand changes in binder stiffness at lower temperatures. This binder also showed improved elasticity at lower temperatures where the e-waste modified binders didn't add sufficient elasticity to the asphalt binder at $21^{\circ} \mathrm{C}$. The asphalt binders modified with $5 \%$ treated $\mathrm{ABS}$ met the $-28^{\circ} \mathrm{C}$ field temperature binder specification for BBR testing at $-18^{\circ} \mathrm{C}$, although this binder had slightly lower m-values and higher creep stiffness at BBR testing temperatures of $-18^{\circ} \mathrm{C}$ and $-21{ }^{\circ} \mathrm{C}$ respectively compared to the control and asphalt binders modified with $5 \%$ treated ABS. The asphalt binders modified with 5\% treated HIPS had similar stiffness at BBR test temperature of $-18^{\circ} \mathrm{C}$ but only the untreated $5 \%$ HIPS binder met Superpave specifications. 


\subsubsection{Treated e-waste performance grade results}

The treatment of ABS and HIPS plastics with free radical initiators for the modification of asphalt binder improved high temperature properties but did not necessarily improve low temperature performance. Table 4.4 shows a continuous or "true grade" of the asphalt binder specimens, and shows that the continuous grade of the treated and untreated binders were comparable in terms of high temperature performance and differentiate when considering low temperature performance.

Table 4.4 True performance grade comparisons of treated and untreated e-waste asphalt binders. Based upon Superpave binder results.

\begin{tabular}{lc}
\hline Asphalt binder specimen & True performance grade \\
\hline Control binder & PG 58-31 \\
$5 \%$ ABS & PG 64-28 \\
Treated 5\% ABS & PG 64-28 \\
HIPS 5\% & PG 64-28 \\
Treated HIPS 5\% & PG 82-25 \\
\hline
\end{tabular}

\subsection{Summary}

The addition of e-waste plastics did not meet the control binder low temperature grade. The ABS treated and untreated binders' performance performed better than the $5 \%$ treated HIPS binder in terms of low temperature performance. There was a large increase in the high temperature grade for the HIPS and between the treated and non-treated binders but not in the ABS modified binders. These results may indicate that the hydro peroxide initiator reaction reacted well with the rubber component within the HIPS 
plastics which would be expected to extend the high temperature range of the HIPS asphalt binders as there was a sufficient bonding reaction within the HIPS molecules between the asphalt binder, HIPS, and rubber component of HIPS. This large jump did not happen in the ABS modified binders due to an insufficient amount of rubber content within ABS source. 


\section{Chapter 5. E-waste binder aging susceptibility and chemical reaction verification.}

\subsection{Introduction and background}

A series of tests were conducted to determine the bulk and thermal properties of ABS and HIPS e-waste plastics within asphalt binders. Verification of the effects of chemical modification of the ABS and HIPS plastics was also accomplished. The objectives of this investigation were as follows:

- Scanning electron microscope testing was conducted to determine the shape and size distribution of ABS and HIPS powders.

- Fourier transform infrared (FTIR) was conducted on ABS and HIPS binder samples to verify chemical changes within the asphalt binder from free-radical polymerization of the e-waste plastics.

- FTIR analysis was also conducted to determine if significant aging occurred within the modified e-waste binders as determined by increased carbon, sulfur, or oxidation of the e-waste modified asphalt binders.

- Determine and verify compatibility between the e-waste particles and asphalt binder using differential scanning calorimetry to determine any changes or multiple glass transition temperatures which may correspond to the asphalt binder and e-waste powders.

\subsection{SEM procedures and analysis}

The procedure for the ABS and HIPS particle size verification consisted of a scanning electron microscope (SEM) analysis of e-waste modified asphalt binders. This analysis included a size distribution analysis and observation of the structure of the plastic ewaste. A size distribution analysis was determined using ImageJ software to 
automatically determine e-waste plastic particle sizes from SEM photographs. A sieve analysis was conducted on the source ABS and HIPS particles and is shown below in Table 5.1.

Table 5.1 Sieve analysis of ABS and HIPS source particles. Based on $500 \mathrm{~g}$ e-waste plastic source sample.

\begin{tabular}{lll}
\hline & \multicolumn{2}{l}{ Percent Passing } \\
Sieve Size & ABS & HIPS \\
\hline $3 / 4$ in $(19.0 \mathrm{~mm})$ & $99.98 \%$ & $100 \%$ \\
$3 / 8$ in $(9.5 \mathrm{~mm})$ & $99.98 \%$ & $100 \%$ \\
No. $4(4.75 \mathrm{~mm})$ & $99.96 \%$ & $100 \%$ \\
No. $8(2.36 \mathrm{~mm})$ & $99.92 \%$ & $100 \%$ \\
No. $16(1.18 \mathrm{~mm})$ & $99.92 \%$ & $100 \%$ \\
No. $30(600 \mu \mathrm{m})$ & $31.90 \%$ & $64.39 \%$ \\
No. $50(300 \mu \mathrm{m})$ & $6.04 \%$ & $21.39 \%$ \\
No. $100(150 \mu \mathrm{m})$ & $1.40 \%$ & $0 \%$ \\
No. $200(75 \mu \mathrm{m})$ & $0.58 \%$ & $0 \%$ \\
Pan & $0.00 \%$ & $0 \%$ \\
\hline
\end{tabular}

Figures 5.1 and 5.2 below show the shape and size distribution of the ABS e-waste particles SEM and ImageJ software analysis.

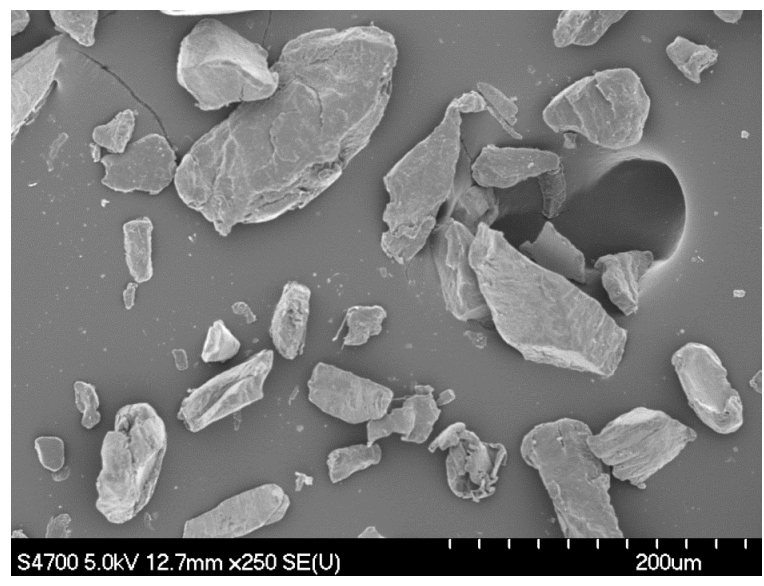

Figure 5.1 Hitachi S-4700 SEM photo of ABS particles at 250X magnification 


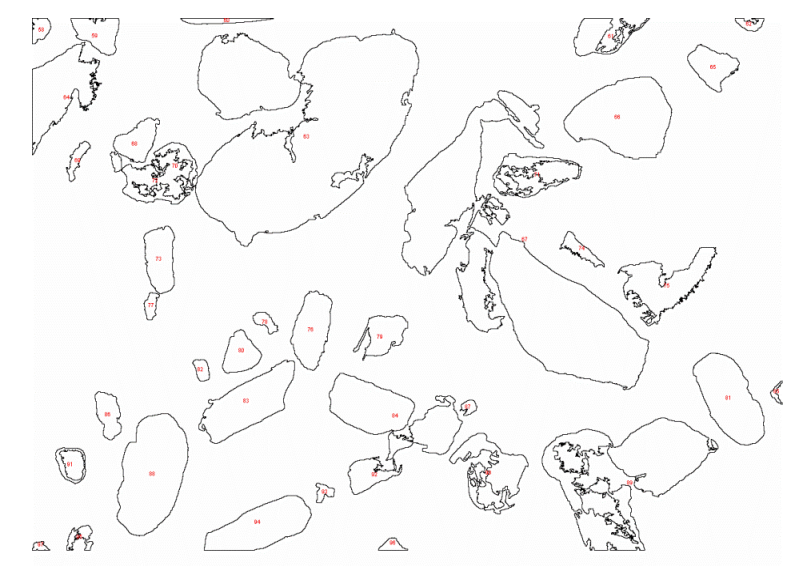

Figure 5.2 ImageJ particle size distribution boundaries of ABS particles from SEM photograph

ImageJ image processing software a size analysis was conducted to determine the particle size distribution of ABS particles passing the No. 200 sieve $(75 \mu \mathrm{m})$. Figure 5.3 displays a size distribution based on the number of ABS particles detected by ImageJ from based on the effective radius of the detected particles.

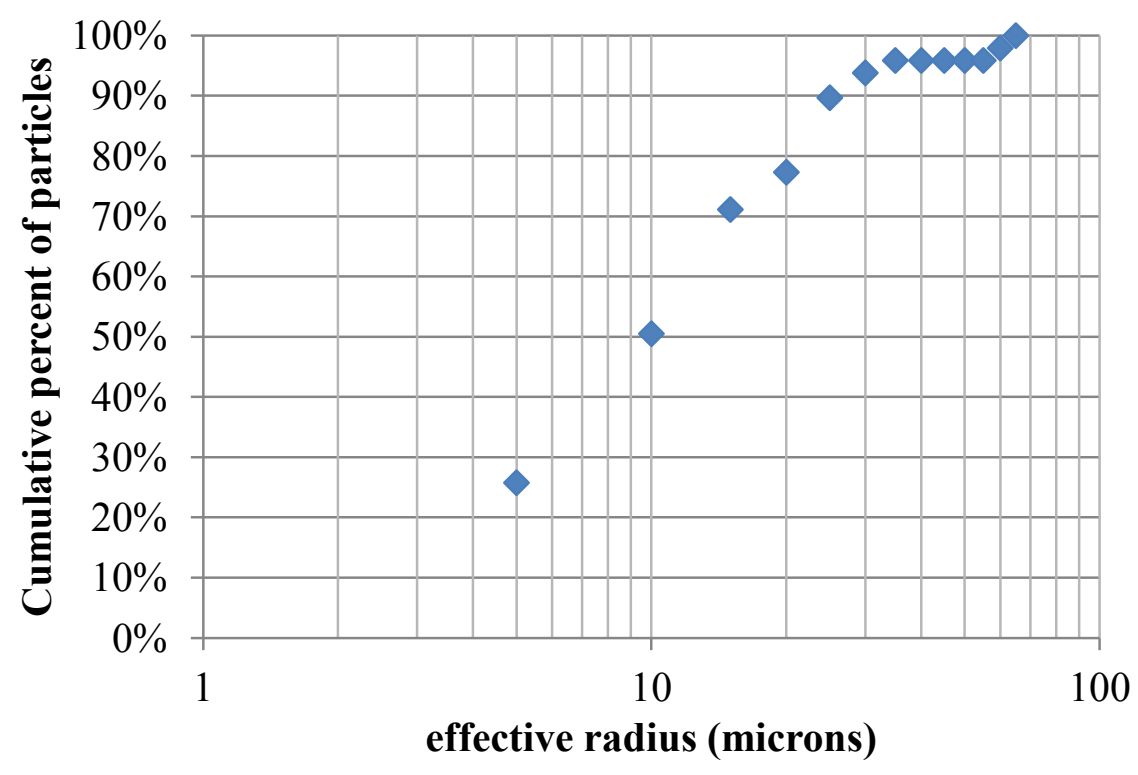

Figure 5.3 ABS powder size distribution of particles less than $75 \mu \mathrm{m}$ based on SEM photograph 
HIPS powder size distribution of particles passing the No. 200 sieve $(75 \mu \mathrm{m})$ was also conducted. Figure 5.4 displays an SEM photo of HIPS particles under $75 \mu \mathrm{m}$ and Figure 5.5 displays the selected HIPS particles for size distribution analysis.

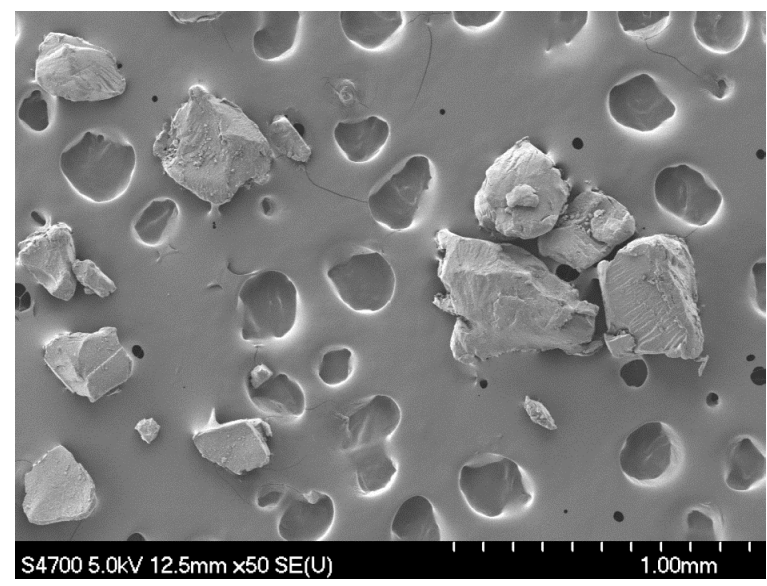

Figure 5.4 Hitachi S-4700 SEM photo of HIPS particles at 50X magnification
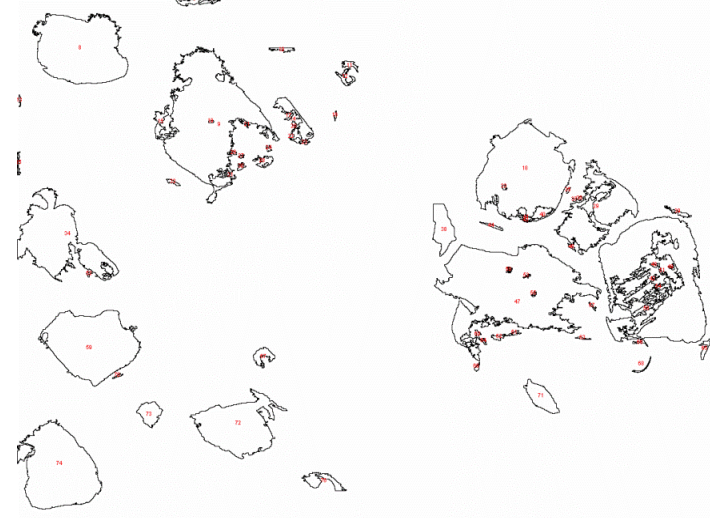

Figure 5.5 ImageJ particle size distribution boundaries of HIPS particles from SEM photograph

After reviewing the SEM photographs for the ABS and HIPS particles, a size distribution was calculated. The relative size distribution for the HIPS powder particles from ImageJ particle analysis are displayed below in Figure 5.6. 


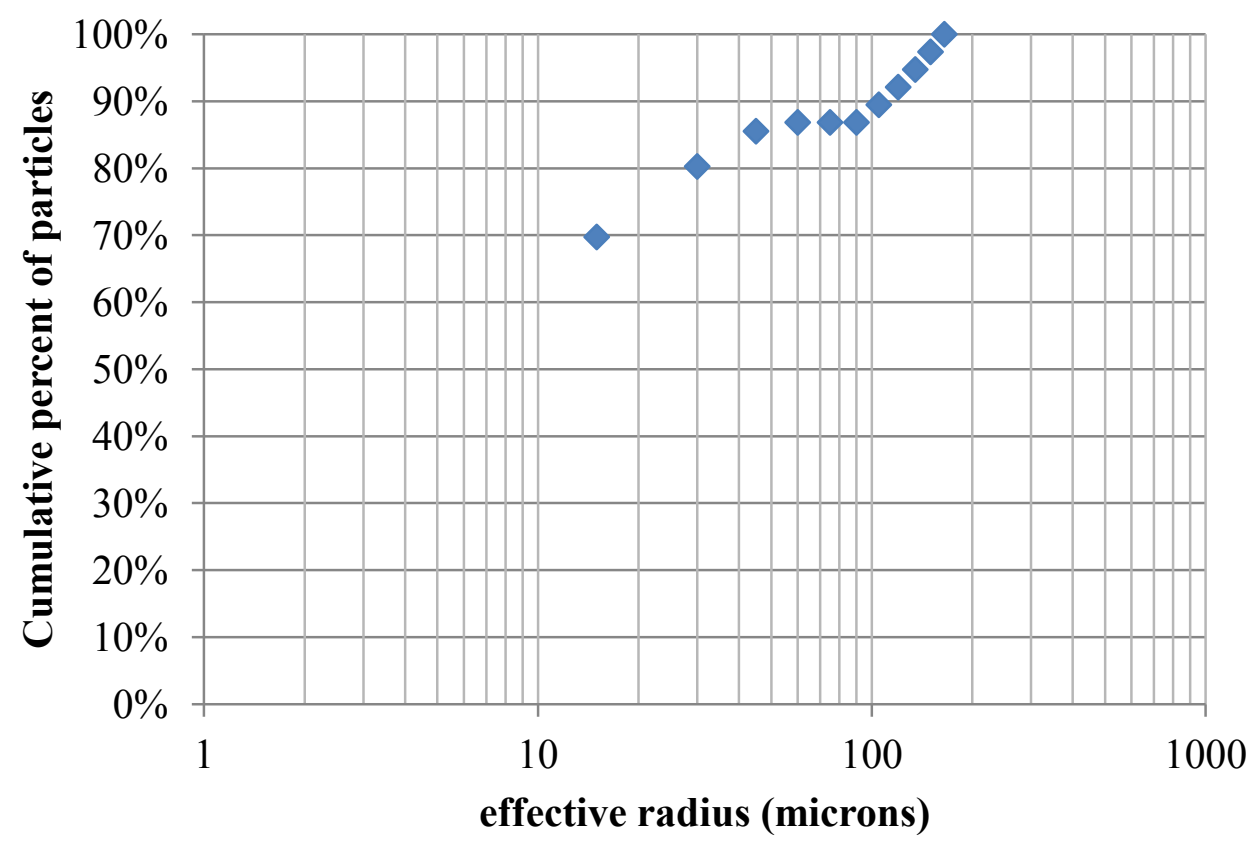

Figure 5.6 HIPS powder size distribution of particles based on SEM photograph

The sieve size distribution shows that the majority of the source ABS particles are retained on the No. $30(600 \mu \mathrm{m})$ sieve. The SEM analysis shows that majority of the powder particles passing the No. $200(75 \mu \mathrm{m})$ are between $4-25 \mu \mathrm{m}$. The majority of HIPS particles are retained on the No. $50(300 \mu \mathrm{m})$ sieve. The SEM analysis shows that majority of the powder particles passing the No. $200(75 \mu \mathrm{m})$ are between $15-75 \mu \mathrm{m}$.

\subsection{Differential scanning calorimeter procedures}

Differential scanning calorimetry (DSC) is a technique used to determine the presence of multiple glass transition temperatures $\left(\mathrm{T}_{\mathrm{g}}\right)$. Glass transition temperature is used as an indicator for heterogeneous systems. Incompatible systems with various polymers show two or more $\mathrm{T}_{\mathrm{g}}$ 's corresponding to the individual $\mathrm{T}_{\mathrm{g}}$ of the system components.

Completely compatible systems will show one $\mathrm{T}_{\mathrm{g}}$. Incomplete compatibility from DSC testing shows two changing $\mathrm{T}_{\mathrm{g}}$ values within the composition range of the individual components[13]. DSC testing can help to determine the point where there is subtle 
movement of the e-waste plastic and asphalt binder polymer chains, between the solid, liquid, and crystalline states of the asphalt binder and e-waste plastics. Longer regions of transition for the determination of $\mathrm{T}_{\mathrm{g}}$ indicated a material is able to absorb more energy as the material transitions from a solid to crystalline state. This longer transition state would indicate a stronger interaction between the asphalt and e-waste plastic. A typical DSC program for specimen analysis may involve a specimen of approximately 5-7 $\mathrm{mg}$ of plastic, and conducting multiple runs of the DSC. A first run of the DSC program would heat the specimen up to a range of $30-160{ }^{\circ} \mathrm{C}$ at $10^{\circ} \mathrm{C} / \mathrm{min}$ to eliminate the previous memory of the specimen. A cooling cycle would follow, and finally a second heating cycle at $30-160^{\circ} \mathrm{C}$ at $10^{\circ} \mathrm{C} / \mathrm{min}$ would be conducted where a $\mathrm{T}_{\mathrm{g}}$ would be measured on this second run[13]. DSC analysis can indicate poor mechanical performance of plastic mixtures to incompatibility of various plastic composites through the presence of multiple $\mathrm{T}_{\mathrm{g}}$ 's $[13,25]$.

\subsection{DSC results}

DSC results consist of heat flow charts for each of the e-waste modified asphalt binder samples after quenching (DSC cooling cycle) and the extrapolated glass transition temperature for at the onset, midpoint, and end temperature points. Table 5.2 displays the glass transition temperatures for the modified e-waste binders.

Table 5.2 DSC results glass transition temperatures, based on 1 replicate

\begin{tabular}{lllllll}
\hline \multirow{2}{*}{ Binder specimen } & \multicolumn{3}{c}{ Before Quench } & \multicolumn{4}{c}{ After Quench } \\
\cline { 2 - 7 } & $\mathrm{T}_{\mathrm{f}}\left({ }^{\circ} \mathrm{C}\right)$ & $\mathrm{T}_{\mathrm{e}}\left({ }^{\circ} \mathrm{C}\right)$ & $\mathrm{T}_{\mathrm{m}}\left({ }^{\circ} \mathrm{C}\right)$ & $\mathrm{T}_{\mathrm{f}}\left({ }^{\circ} \mathrm{C}\right)$ & $\mathrm{T}_{\mathrm{e}}\left({ }^{\circ} \mathrm{C}\right)$ & $\mathrm{T}_{\mathrm{m}}\left({ }^{\circ} \mathrm{C}\right)$ \\
\hline Control & -36.35 & -11.65 & -24.01 & -36.06 & -13.04 & -24.63 \\
\hline $2.5 \%$ ABS & -37.42 & -10.74 & -24.07 & -37.14 & -12.62 & -24.85 \\
\hline $2.5 \%$ T ABS & -34.16 & -11.52 & -22.74 & -35.50 & -13.57 & -24.57 \\
\hline $2.5 \%$ HIPS & -36.65 & -8.99 & -22.90 & -37.87 & -10.69 & -24.27 \\
\hline $2.5 \%$ T HIPS & -35.76 & -16.89 & -26.34 & -34.11 & -17.12 & -25.78 \\
\hline
\end{tabular}

Figure 5.7 displays the heat flow results after quenching the modified e-waste asphalt binders. The difference between the initial starting points of the DSC data within Figure 5.7 corresponds to the initial energy needed to maintain the heat flow between the asphalt 
binder sample and the DSC reference. The key parameter for the analysis of DSC data is the initial, midpoint, and ending for the transition between the solid (liquid nitrogen quenched) state and the initial "wiggle" of the e-waste plastic-asphalt binder polymers which occurs before complete liquidation of the asphalt binder.

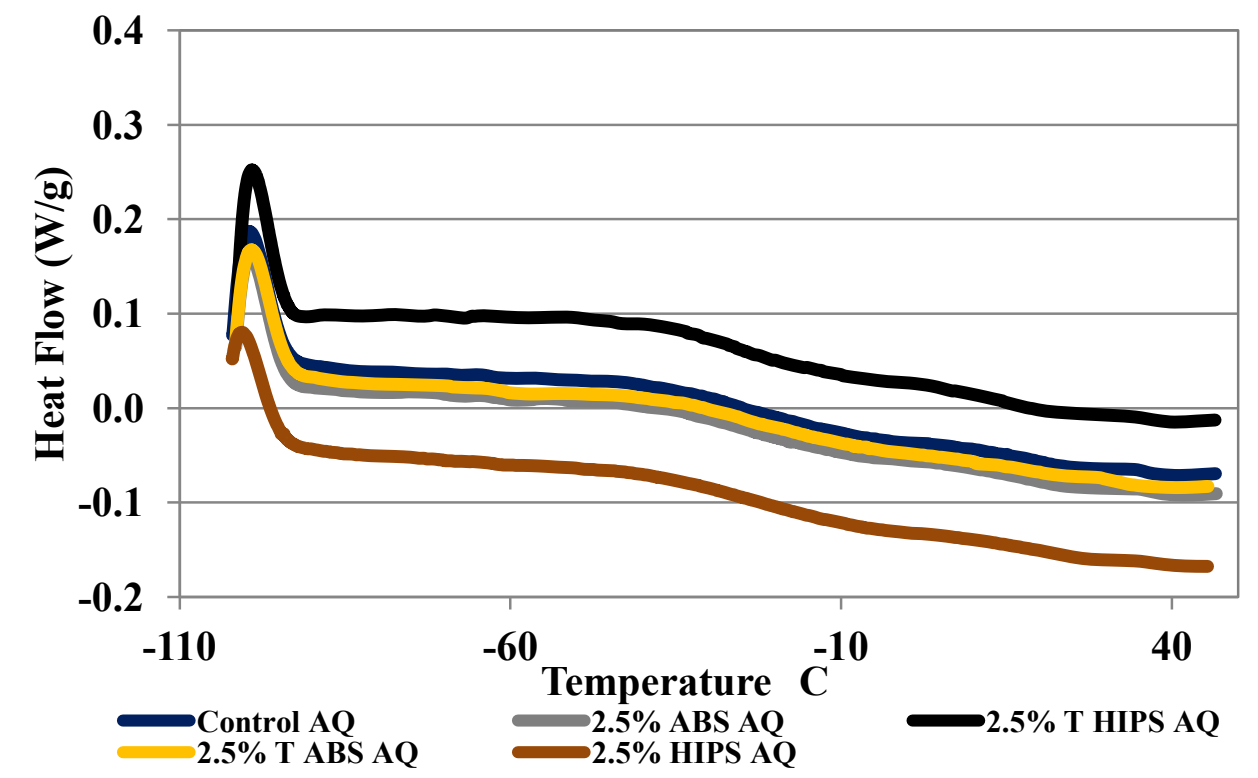

Figure 5.7 DSC modified e-waste samples after quenching; the decreasing heat flow indicates an exothermic reaction, based on 1 replicate

From Figure 5.7 it is shown that there is an exothermic reaction by the modified e-waste asphalt binders. There appears to be a single glass transition temperature for all binder specimens with a long downward break in heat flow after the initial onset of a transition from a solid to the initial movement of asphalt-plastic polymers. This long gradual break in the DSC data may indicate a strong interaction between the asphalt binder and e-waste plastics. Figure 5.8 shows the change in DSC glass transition results due to quenching for the e-waste modified asphalt binders. 


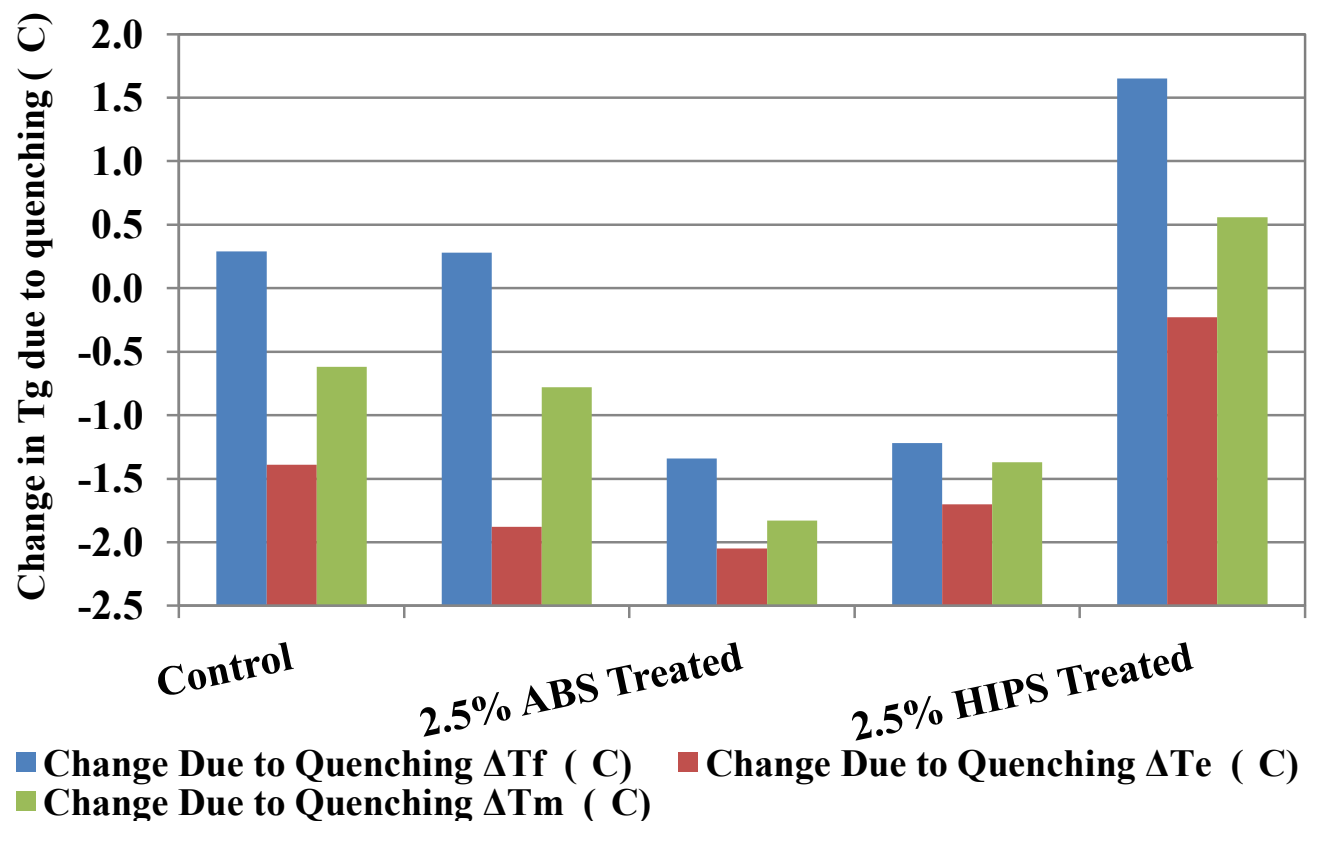

Figure 5.8 DSC glass transition temperature change due to quenching for e-waste modified asphalt binders: A) using the extrapolated onset temperature $\left.T_{f}\left({ }^{\circ} \mathrm{C}\right), \mathrm{B}\right)$ using the extrapolated end temperature $T_{e}, C$ ) using the midpoint temperature $T_{m}$, based on 1 replicate

The results from Figure 5.8 indicate that there is a small change in $T_{g}$ from quenching the asphalt binder samples when considering the various interpretations of the glass transition temperature. The range of temperature changes resulting from the quenching of e-waste modified asphalt binder were $1.6^{\circ} \mathrm{C}$ for $\Delta \mathrm{T}_{\mathrm{f}}$ to as low as $-2^{\circ} \mathrm{C}$ for $\Delta \mathrm{T}_{\mathrm{e}}$. These results imply that with the clearing the previous memory of the e-waste binder samples there is one glass transition temperature indicating suitable comparability between e-waste plastic particles and asphalt binder. 


\subsection{FTIR wavelength spectra analysis}

FTIR analysis can be was used for this investigation in order to determine if a chemical change occurred for treated e-waste plastics within the asphalt binder. This determination is made qualitatively by noting differences between various asphalt binder samples at key wavelengths. Table 5.3 lists the key FTIR spectra used for the e-waste modified asphalt binder analysis.

\section{Table 5.3 Key FTIR spectra wavelengths for e-waste binder analysis}

\begin{tabular}{lll}
\hline $\begin{array}{l}\text { Molecular } \\
\text { structure }\end{array}$ & $\begin{array}{l}\text { FTIR spectra peak (area } \\
\left.\text { in } \mathrm{cm}^{-1}\right)\end{array}$ & Description \\
\hline $\begin{array}{l}\text { Asphalt } \\
\text { binder }\end{array}$ & $600-3500$ & $\begin{array}{l}\text { FTIR spectra for analysis [25, 49] } \\
\text { absorbance peak indicating C-O-C } \\
\text { stretching vibration[47] } \\
\text { oxidation from C=O bonds[25] }\end{array}$ \\
\hline & 1260 & $\begin{array}{l}\text { hydroxyl group indicating } \\
\text { degradation[13] }\end{array}$ \\
& 3250 & $\begin{array}{l}\text { CN bonds from polyacrylonitrile } \\
{[13,25,50]}\end{array}$ \\
ABS & $2236(2248-2224)$ & $\begin{array}{l}\text { tran-2-butene 1,4,dilgroup- } \\
\text { polybutadiene [13, 25, 50] } \\
\text { benzene rings from polystyrene group } \\
{[13,25,50]}\end{array}$ \\
& $967(984-949)$ & C-H bonds from butadiene [25] \\
\hline
\end{tabular}

The FTIR results consists of charts showing superimposed FTIR spectra from the control asphalt binder along with the HIPS and ABS treated and non-treated modified asphalt binders. These charts are plotted as absorbance versus wavelength in Hz. It is assumed that changes between the FTIR spectra from the control binder indicate molecular changes within the material. Therefore, to verify chemical changes due to the addition of hydro peroxide for inducing free radical polymerization, control tank asphalt binder 
specimens are compared with the control tank asphalt binder for ABS and HIPS modified binders. Figures 5.9 through 5.13 compare the ABS and HIPS treated and untreated asphalt binders with the control binder to verify molecular changes within the asphalt binder.

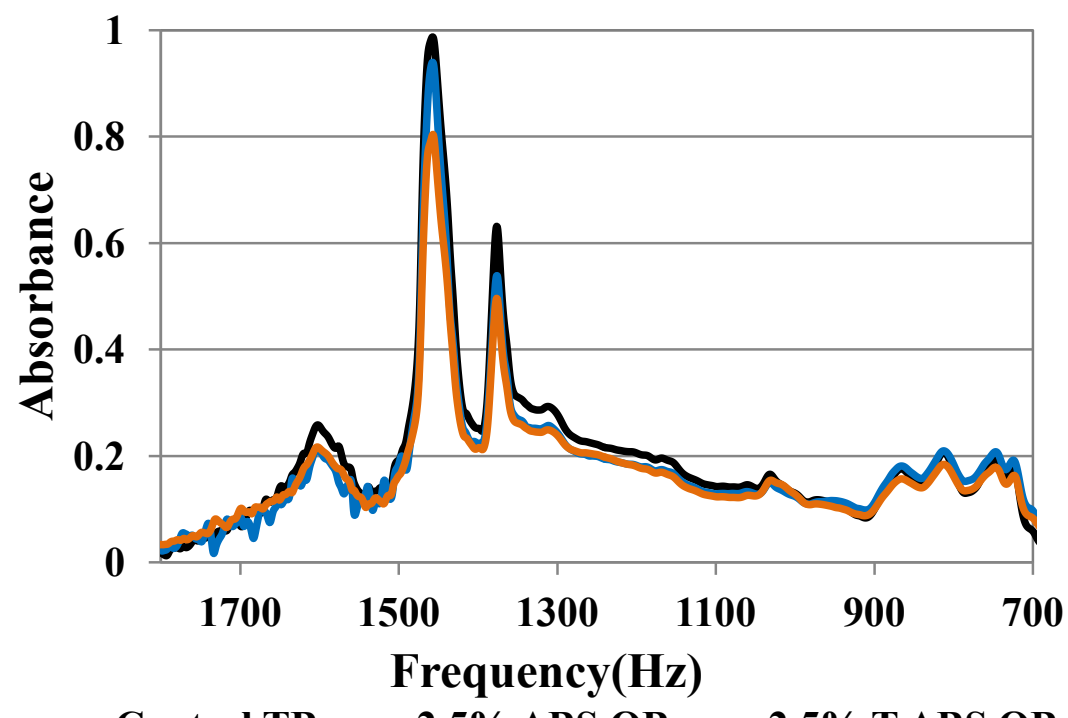

Figure 5.9 FTIR qualitative analysis of $2.5 \%$ ABS e-waste binders, based on 1 replicate

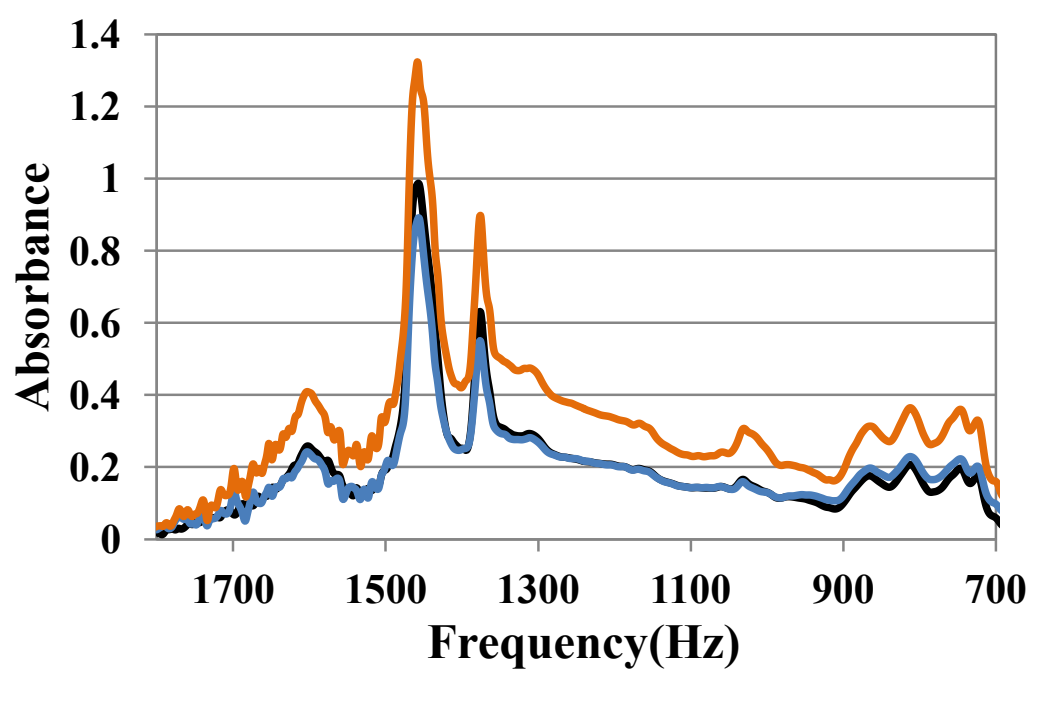

- Control TB $-5 \%$ ABS OB $-5 \%$ T ABS OB

Figure 5.10 FTIR qualitative analysis of 5\% ABS e-waste binders, based on 1 replicate 
Figures 5.9 and 5.10 both indicate that the addition of hydro peroxide induces a chemical change within the T-ABS binder when compared to the control tank binder (TB). This effect is more pronounced as the percentage of ABS increases, as in Figure 5.9 the untreated and treated ABS spectra are similar where in Figure 5.10 at $5 \%$ ABS the ABS and $\mathrm{T}$ ABS binders are distinctly different.

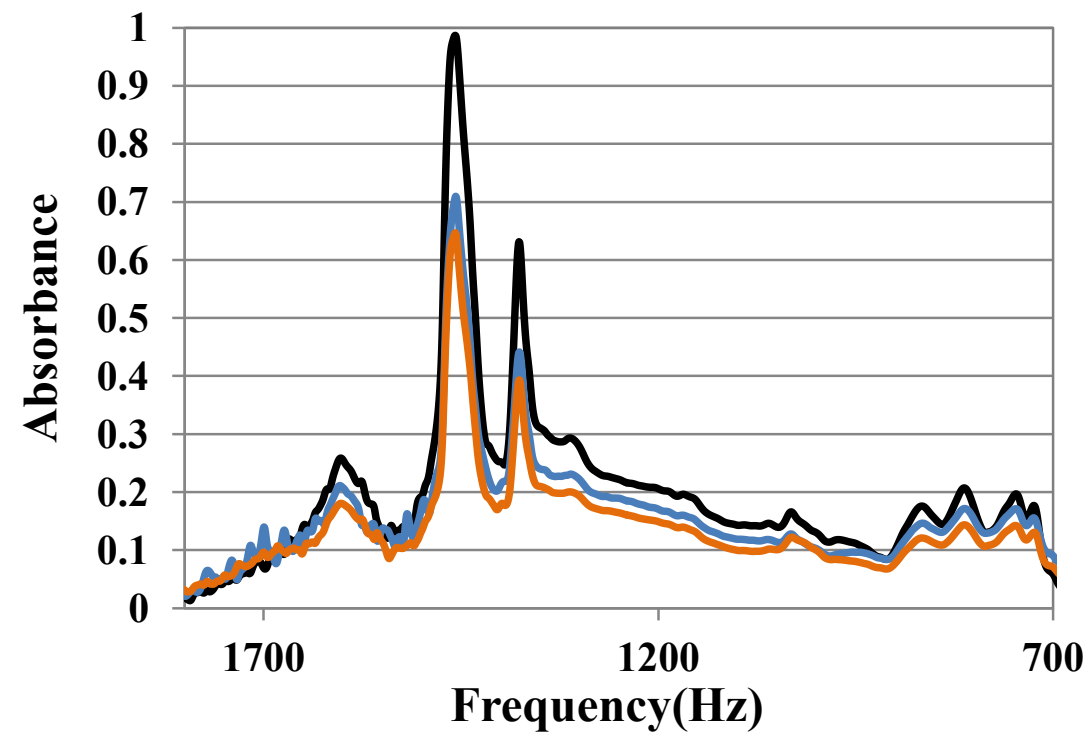

- Control TB $-2.5 \%$ HIPS OB $-2.5 \%$ T HIPS OB

Figure 5.11 FTIR qualitative analysis of 2.5\% HIPS e-waste binders, based on 1 replicate 


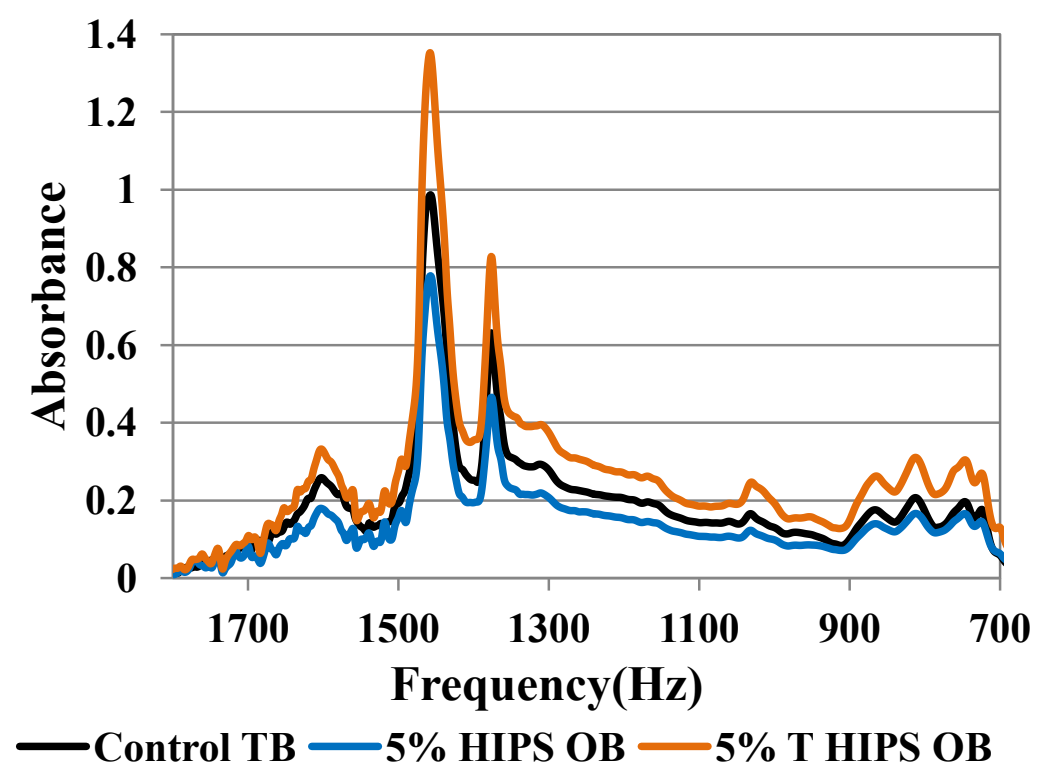

Figure 5.12 FTIR qualitative analysis of 5\% HIPS e-waste binders, based on 1 replicate

Figures 5.11 and 5.12 also indicate that the addition of hydro peroxide induces a chemical change within the T-HIPS binder when compared to the control tank binder (TB). For both the $2.5 \%$ and $5 \%$ HIPS binders the FTIR results indicate a distinct chemical change along from the control binder for the HIPS and T HIPS binders. This effect is may be due to the rubber component within the HIPS plastic molecules interacting with the hydro peroxide and asphalt binder. In general the FTIR results indicate a chemical change in ABS and HIPS chemically treated binders compared to the control binder.

\subsection{Aging susceptibility of electronic waste asphalt binders}

Figure 5.13 below shows the FTIR spectra for the control asphalt binder at tank binder(unaged), rolling thin film(RTFO), and pressure aging vessel (PAV) aged asphalt binder samples. 


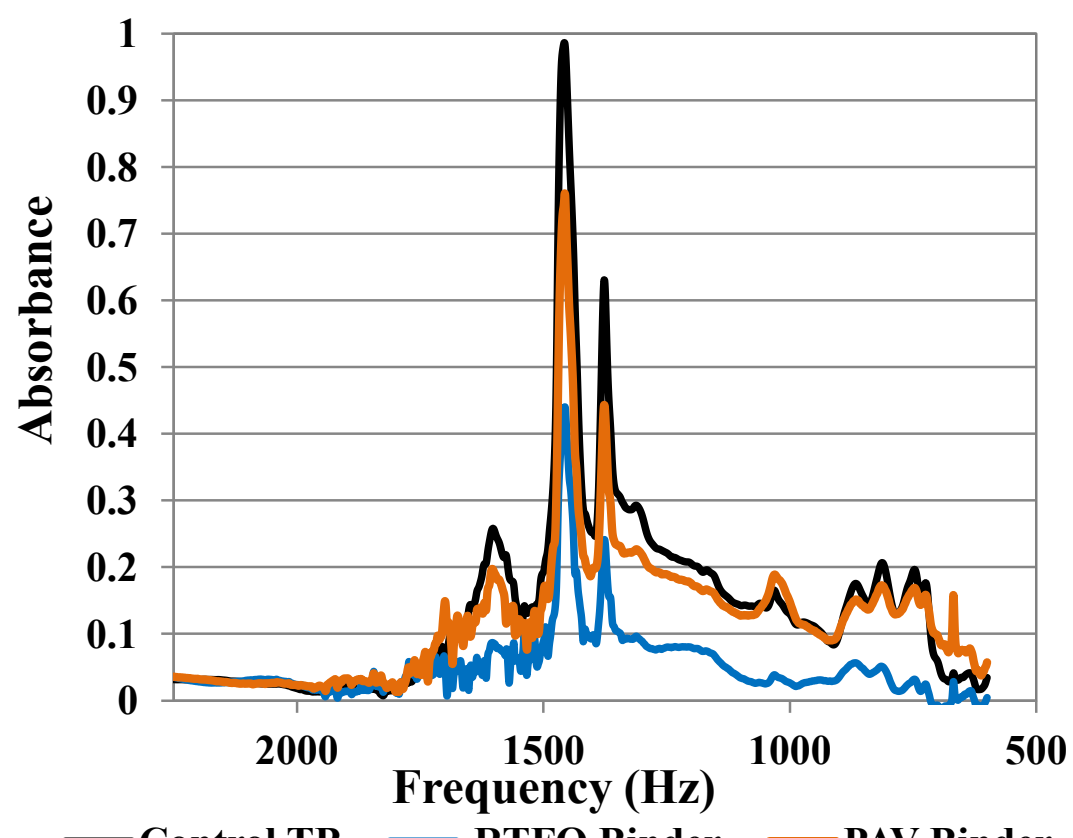

Figure 5.13 FTIR spectra for control PG 58-28 asphalt binders at unaged tank binder (Control TB), rolling thin film aged (RTFO binder), and pressure aging vessel aged (PAV Binder) conditions. , based on 1 replicate

From Figure 5.13 the FTIR results show a difference between the control binder aging states especially at the targeted functional group frequencies as shown in Table 5.3. These differences correspond to the change in oxidation levels within the tested asphalt binder at various aging states.

In order to quantifiy the degree of asphalt binder aging, two indices were used to determine the magnititude of aging which has occurred. A method developed by Lamontagne [48], focused upon carbonyl (a carbon atom double bonded with an oxygen atom) and sulphoxide (a sulfur atom double bonded with an oxygen atom) bonds within organic compounds and quantifies the amount of bonding as an index as shown in equations [1] and [2] below: 
$\mathrm{I}_{\mathrm{c}=\mathrm{o}}=\frac{\text { Area of the carbonyl band around } 1700 \mathrm{~cm}^{-1}}{\text { Area of the spectral bands between } 2000 \text { and } 600 \mathrm{~cm}^{-1}}$

$\mathrm{I}_{\mathrm{s}=\mathrm{O}}=\frac{\text { Area of the sulphoxide band around } 1030 \mathrm{~cm}^{-1}}{\text { Area of the spectral bands between } 2000 \text { and } 600 \mathrm{~cm}^{-1}}$

Carbonyl and sulphoxide indices are indicators of the rate of aging for the various asphalt binder functional group molecules. The results from the carbonyl and sulphoxide index analysis are shown below in Figures 5.14 and 5.15 for untreated and treated ABS and HIPS asphalt binders.

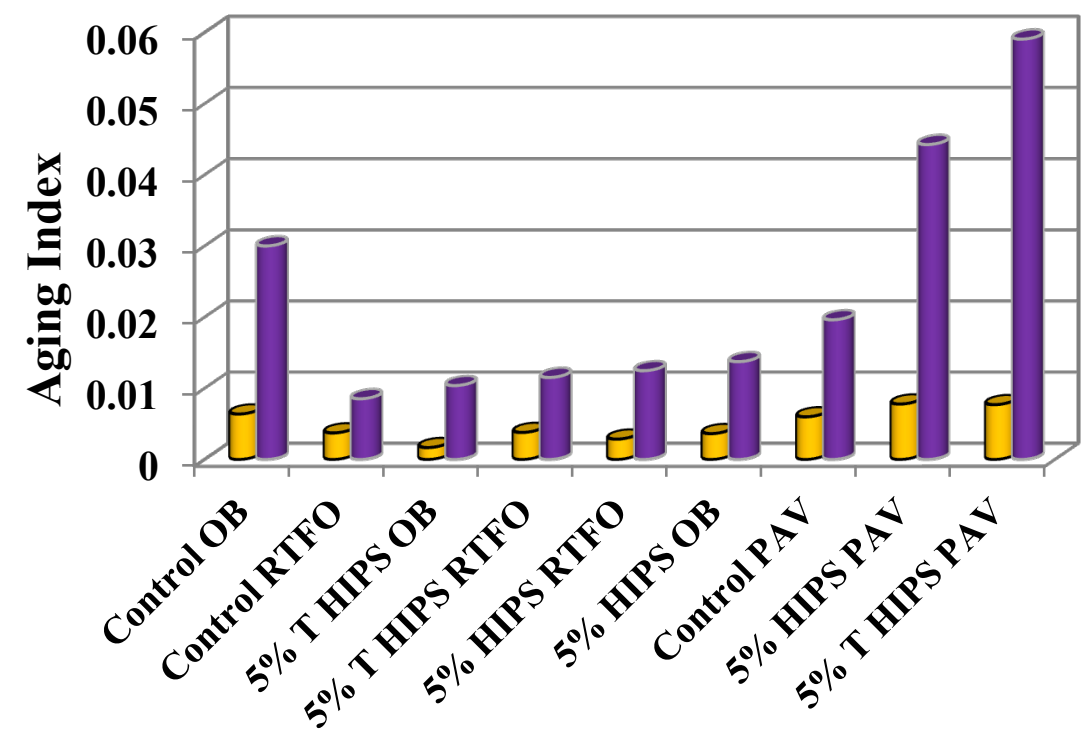

$\square$ CARBONYL INDEX $\square$ SULPHOXIDE INDEX

Figure 5.14 Bar chart of aging index for HIPS modified asphalt binder, based on 1 FTIR test replicate

Figure 5.14 above shows that the carbonyl and sulphoxide aging indices are the greatest for the 5\% HIPS PAV binders. The unaged and RTFO aged ABS and HIPS binders have similar sulphoxide and carbonyl indices compared to the control RTFO binder. The results show that these binders have similar bonding network strengths based on the aging indices. The control PAV and 5\% HIPS PAV binder are shown to have the strongest molecular bonding network based on increased aging indices. 


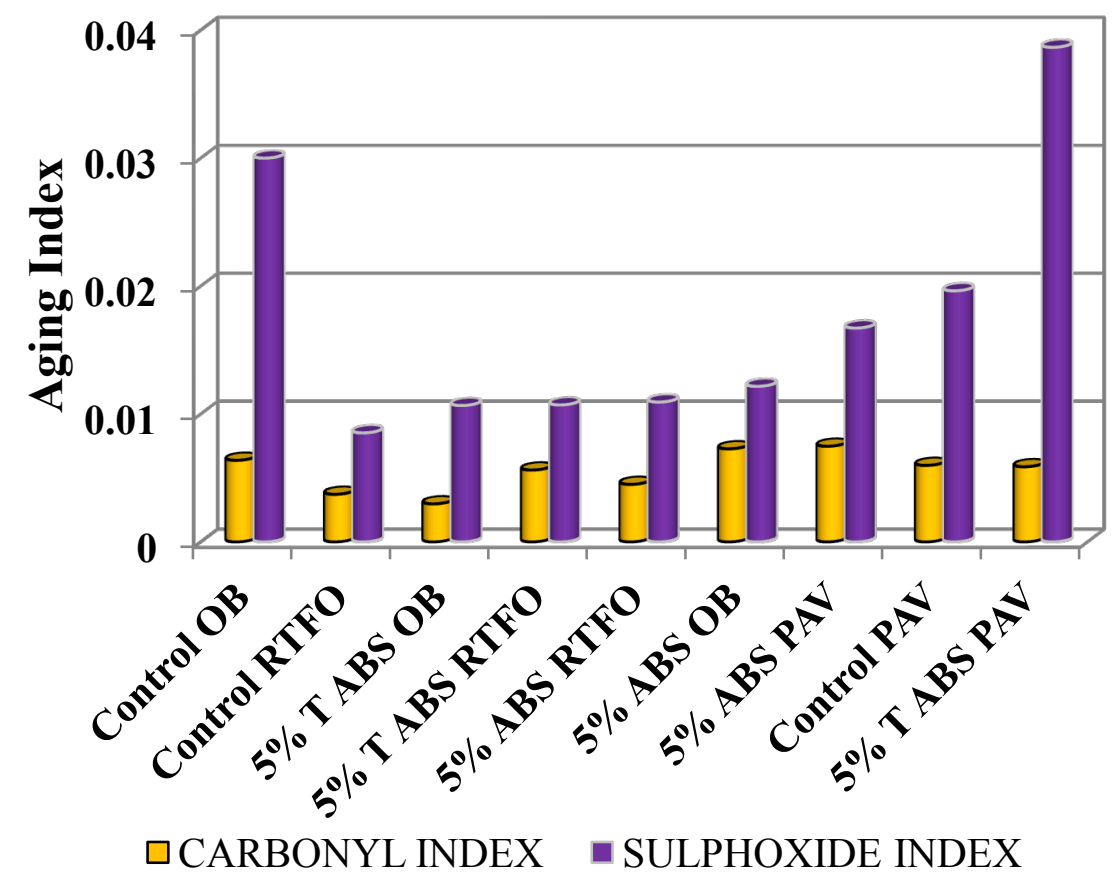

Figure 5.15 Bar chart of aging index for ABS modified asphalt binder, based on 1 FTIR test replicate

Figure 5.15 above shows that the carbonyl and sulphoxide aging indices are the greatest for the control PAV and 5\% ABS PAV binders. The original and RTFO control binders have similar bonding network strengths with the OB and RTFO ABS and HIPS binders, which are based on a comparison with their sulphoxide and carbonyl indices. The ABS modified binder network strength is slightly weaker than the control and 5\% T ABS PAV binder network strength. The results from both the ABS and HIPS aging index charts indicate that the PAV aged binders may have asphalt binder aging concerns, especially for the treated ABS and HIPS binders. These aging concerns for the treated ABS and HIPS binders may affect asphalt mixture low temperature performance. The increase in molecular network strength from the treated ABS and HIPS binders may indicate that rutting susceptibility, mixture stability, and mixture strength may improve with the addition of hydro peroxide as indicated by the FTIR aging index results. 


\subsection{Summary}

Asphalt binder aging susceptibility, size distribution of ABS and HIPS, and verification of chemical modification of e-waste modified binders using free radical initiators were determined. Characterization of the modified e-waste plastic asphalt binders aging and chemical modification was accomplished using Fourier Transform Infra-red Spectroscopy (FTIR). The degree of compatibility between the e-waste and PG 58-28 control asphalt binder was investigated using differential scanning calorimetry. ABS and HIPS particle size distribution was accomplished using sieve analysis and scanning electron microscope techniques. 


\section{Chapter 6: The mechanical performance of asphalt mixtures modified with recycled e-waste plastics ${ }^{4}$}

\subsection{Introduction}

Given the promises in performance for e-waste modified asphalt binders under various temperature conditions it was then decided to compact the various treated and untreated e-waste binders with aggregates to determine how the asphalt binder results correlated with mixture performance. The major performance tests which would be conducted to determine asphalt mixture performance includes are listed in Table 6.1 below.

${ }^{4}$ Text prepared for submission to the Journal of Construction and Building Materials Colbert, B.W., Z. You, Mills-Beale, J., (2012) The Mechanical Performance of Asphalt Mixtures Modified with Recycled Electronic Waste Plastics." Journal of Construction and Building Materials 57 
Table 6.1 E-waste modified asphalt binder testing list

\begin{tabular}{|c|c|c|c|}
\hline \multirow{2}{*}{$\begin{array}{l}\text { Asphalt } \\
\text { binder }\end{array}$} & \multirow{2}{*}{$\begin{array}{l}\text { Sample } \\
\text { code }\end{array}$} & \multirow{2}{*}{$\begin{array}{l}\% \\
\text { modifier }\end{array}$} & Characterization test codes $(*)$ \\
\hline & & & Hot mix asphalt (HMA) \\
\hline PG 58-28 & Control & 0 & APA, DM, FN, and TSR \\
\hline \multirow{2}{*}{ ABS } & $2.5 \% \mathrm{ABS}$ & 2.5 & APA, DM, FN, and TSR and BF \\
\hline & $5.0 \% \mathrm{ABS}$ & 5.0 & $\mathrm{APA}, \mathrm{DM}$, and FN \\
\hline \multirow{2}{*}{ HIPS } & $2.5 \% \mathrm{ABS}$ & 2.5 & APA, DM, FN, and TSR \\
\hline & $5.0 \% \mathrm{ABS}$ & 5.0 & $\mathrm{APA}, \mathrm{DM}$, and FN \\
\hline \multirow{3}{*}{$\begin{array}{l}\text { Treated } \\
\text { ABS }\end{array}$} & $2.5 \% \mathrm{~T}$ & 2.5 & \multirow[t]{2}{*}{ APA, DM, FN, and TSR } \\
\hline & ABS & & \\
\hline & $\begin{array}{l}5.0 \% \mathrm{~T} \\
\mathrm{ABS}\end{array}$ & 5.0 & $\mathrm{APA}, \mathrm{DM}$, and FN \\
\hline \multirow{3}{*}{$\begin{array}{l}\text { Treated } \\
\text { HIPS }\end{array}$} & $2.5 \% \mathrm{~T}$ & 25 & \multirow{3}{*}{ APA, DM, FN, and TSR } \\
\hline & HIPS & $2 . J$ & \\
\hline & $\begin{array}{l}5.0 \% \mathrm{~T} \\
\text { HIPS }\end{array}$ & 5.0 & \\
\hline
\end{tabular}

* APA - Asphalt pavement analyzer; DM - Dynamic modulus;

FN - Flow number; TSR - Tensile strength ratio

The APA, dynamic modulus, and flow number correspond to high temperature performance, while the dynamic modulus and the tensile strength ratio test, and correspond to intermediate temperature conditions. The dynamic modulus test corresponds to low temperature conditions at $-10^{\circ} \mathrm{C}$. Using these tests to determine asphalt mixture performance, the following questions are intended to be addressed:

- Does the improvement in high temperature performance from the e-waste modified binders hold true for e-waste modified asphalt mixtures versus the control mixture?

- Will chemical treatment of the ABS and HIPS plastics improve low temperature performance for e-waste modified mixtures?

- E-waste modified binder data based on FTIR analysis data has shown increased aging indices versus the control binder. Will there be a diminished intermediate 
temperature performance for e-waste modified mixtures based on the aging potential of e-waste modified binders?

Through addressing these questions, it can be determined if the implementation of electronic waste plastics can be a viable material for the use of reconstruction and rehabilitating asphalt pavement.

\subsection{Characterization of e-waste modified HMA mixture}

Aggregates for this investigation were obtained from Hancock, MI. The nominal maximum aggregate size for the asphalt mixture gradation was $1 / 2 "(12.5 \mathrm{~mm})$ sieve. The designed traffic level for this gradation is an E3 mixture which is designed to withstand traffic levels greater than 1 million ESALS and lower than 3 million according to Michigan Department of Transportation specifications [49]. The control asphalt binder obtained for this investigation was a PG 58-28 neat asphalt binder from Gladstone, MI. The control binder was used to blend the various e-waste plastics used in this investigation to produce modified asphalt binders. The optimal asphalt binder content for the asphalt mixtures using this gradation is $5.7 \%$ by weight of mixture. Asphalt mixture performance was tested on the asphalt mixtures containing the control asphalt binder along with mixtures containing 2.5 and 5\% ABS and HIPS treated and untreated modified asphalt binders. The asphalt mixtures were compacted to 86 gyrations with a targeted VMA of $17.4 \%$. These mixtures were also designed to contain $4 \%$ air voids with an optimum binder content of $5.7 \%$. Figure 6.1 below displays the experimental setup 
for this investigation.

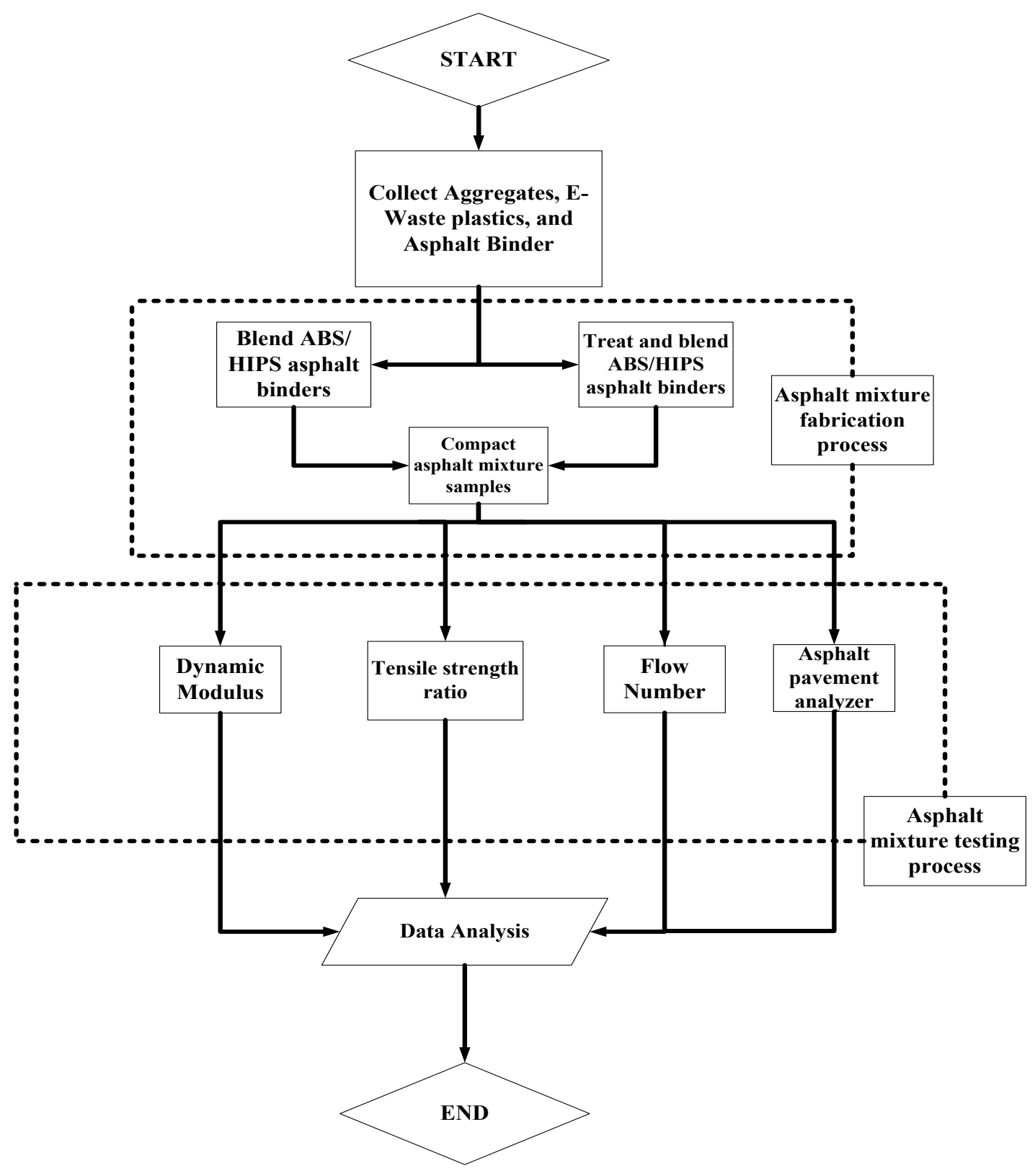

Figure 6.1 Electronic waste materials experimental flowchart 


\subsection{E-waste mixture rutting susceptibility}

Wheel tracking tests were conducted, in order to determine the effect of rutting within the laboratory compacted asphalt mixture samples. The Asphalt Pavement Analyzer (APA) was used in this investigation to determine rutting resistance for the laboratorycompacted HMA samples. The procedures of the AASHTO T 340-10 [50] were followed so that the inelastic permanent deformation (rutting)can be determined. In order to match the high temperature grade of mixtures, the testing temperature was set to $58{ }^{\circ} \mathrm{C}$. Each APA test was run for 8000 cycles with the determined rutting depth of an asphalt sample expressed in millimeters ( $\mathrm{mm})$.

The rutting results consisted of the average rutting depth in $(\mathrm{mm})$ for the various e-waste modified asphalt mixtures, the total average rutting depth for the mixtures after 8000 APA wheel cycles, and an ANOVA analysis of the data comparing average rutting depths after 8000 wheel cycles to the mixture type. The ANOVA analysis was conducted with an alpha of 0.05 and assumed no difference between the mean rutting depths between mixture types. Figure 6.2 below displays the average rutting depth after 8000 wheel cycles. 


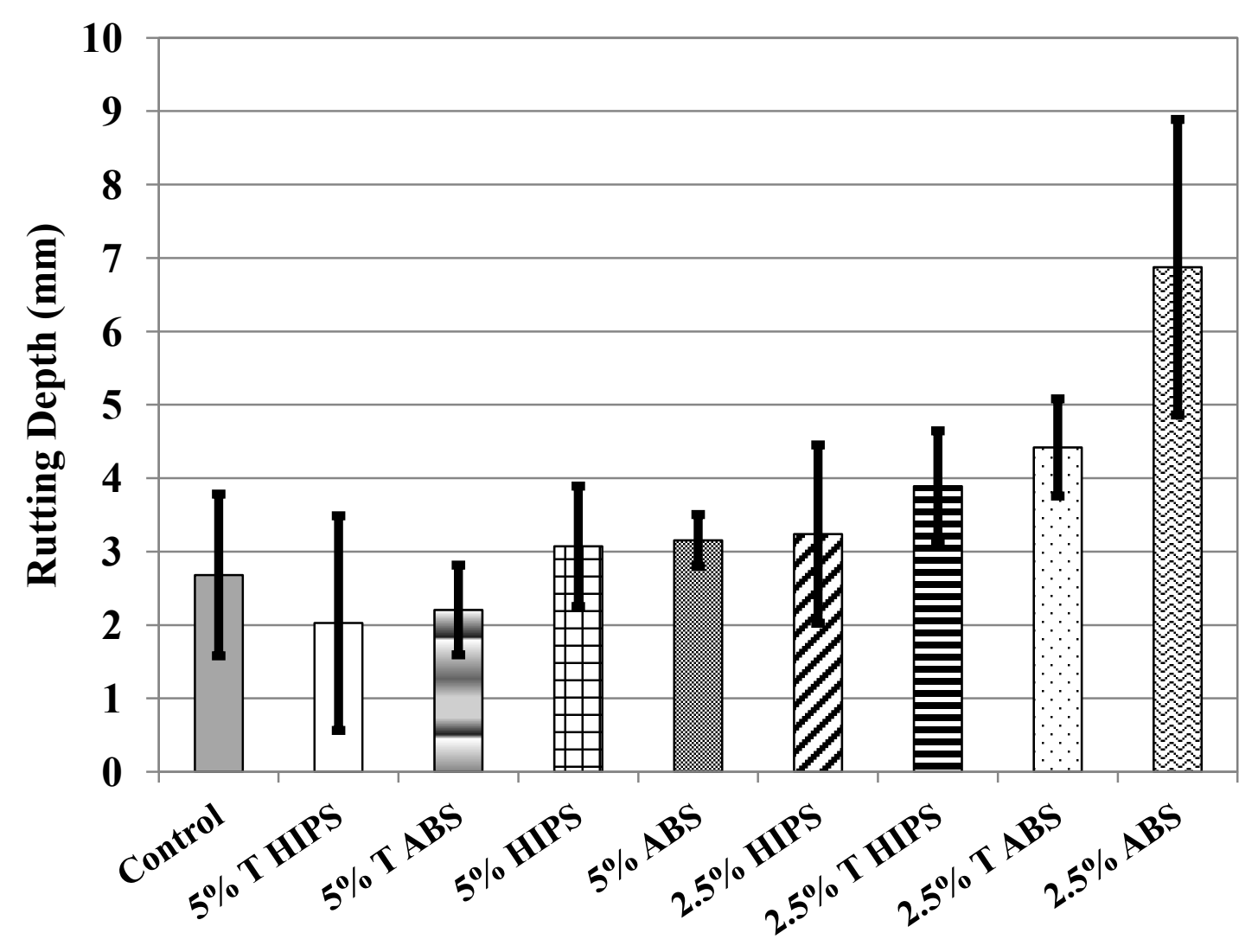

Figure 6.2 APA rutting depth after 8000 APA cycles, based on three replicates

Figure 6.2 shows that only 5\% T ABS and 5\% T HIPS has a lower average APA rut depth after the course of 8000 cycles versus the control mixture. Increased percentages of e-waste were effective in reducing e-waste modified mixture rutting. Chemical treatment of the e-waste plastic mixtures was effective in reducing rutting for increased percentages of e-waste plastics. A decrease in rutting when comparing the HIPS and ABS modified mixtures occurred, where the HIPS modified mixture was less rutting susceptible versus the ABS mixtures. The 5\% treated ABS and HIPS had the lowest and rutting depth performance. Table 6.2 shows the results of the ANOVA analysis for average rutting depth after 8000 wheel cycles. 
Table 6.2 APA rutting results after 8000 cycles ANOVA analysis

\begin{tabular}{llll}
\hline Source of variation & Sum of squares & $\begin{array}{l}\text { Degrees } \text { Of } \\
\text { freedom }\end{array}$ & Mean squared \\
\hline Between groups & 51.82 & 8 & 6.48 \\
Within groups & 22.12 & 18 & 1.23 \\
Total & 73.94 & 26 & \\
$F$-value & 5.272 & & \\
$P$-value & $1.65 \mathrm{E}-03$ & & \\
$F$ critical & 2.510 & There is a significant difference in the APA rutting results \\
\hline \multirow{2}{*}{ Conclusion } & and e-waste modified mixture type & \\
\hline
\end{tabular}

The results of the ANOVA analysis considered the average mixture rutting after 8000 wheel cycles, and the resulting p-value was $1.65 * 10^{-3}$. This $\mathrm{p}$-value is less than an alpha value of 0.05 and indicates that for the given e-waste modified mixtures tested for rutting; there was a statistical significant difference in the rutting performance when considering the HIPS and ABS mixtures along with the control mixture. This implies that e-waste mixture type is a factor for the determination of in average rutting versus the control mixture.

\subsection{E-waste mixture stability}

The flow number test is also known as the dynamic creep test. This test determines the tertiary flow of asphalt mixture samples as a function of the loading cycles. Loading cycles consists of a series of rest and loading periods. A loading period of $0.1 \mathrm{sec}$ is followed by a rest period of $0.9 \mathrm{sec}$. These loading cycles are accompanied by an increase in permanent strain of the asphalt mixture and progression through the primary, secondary and tertiary stages of asphalt mixture permanent strain. The testing temperature selected for this test was the effective rutting temperature. The effective rutting temperature is derived from the average annual air temperature of Michigan [51]. This temperature was determined to be $45^{\circ} \mathrm{C}$ as obtained from the Michigan Department 
of Transportation (MDOT) report [52]. The air void of the asphalt mixture specimens was $7 \pm 1 \%$, and the sample dimensions were 100 -mm in diameter and 150 -mm in height.

The flow number results consisted of the average flow number before the tertiary stage for the various e-waste modified asphalt mixtures, and an ANOVA statistical analysis comparing the average mixture flow number and e-waste modified mixture type. The ANOVA analysis was conducted with an alpha of 0.05 and assumed no difference between the mean flow numbers between mixture types. Figure 6.3 below displays the average flow number of the various e-waste modified mixture types.

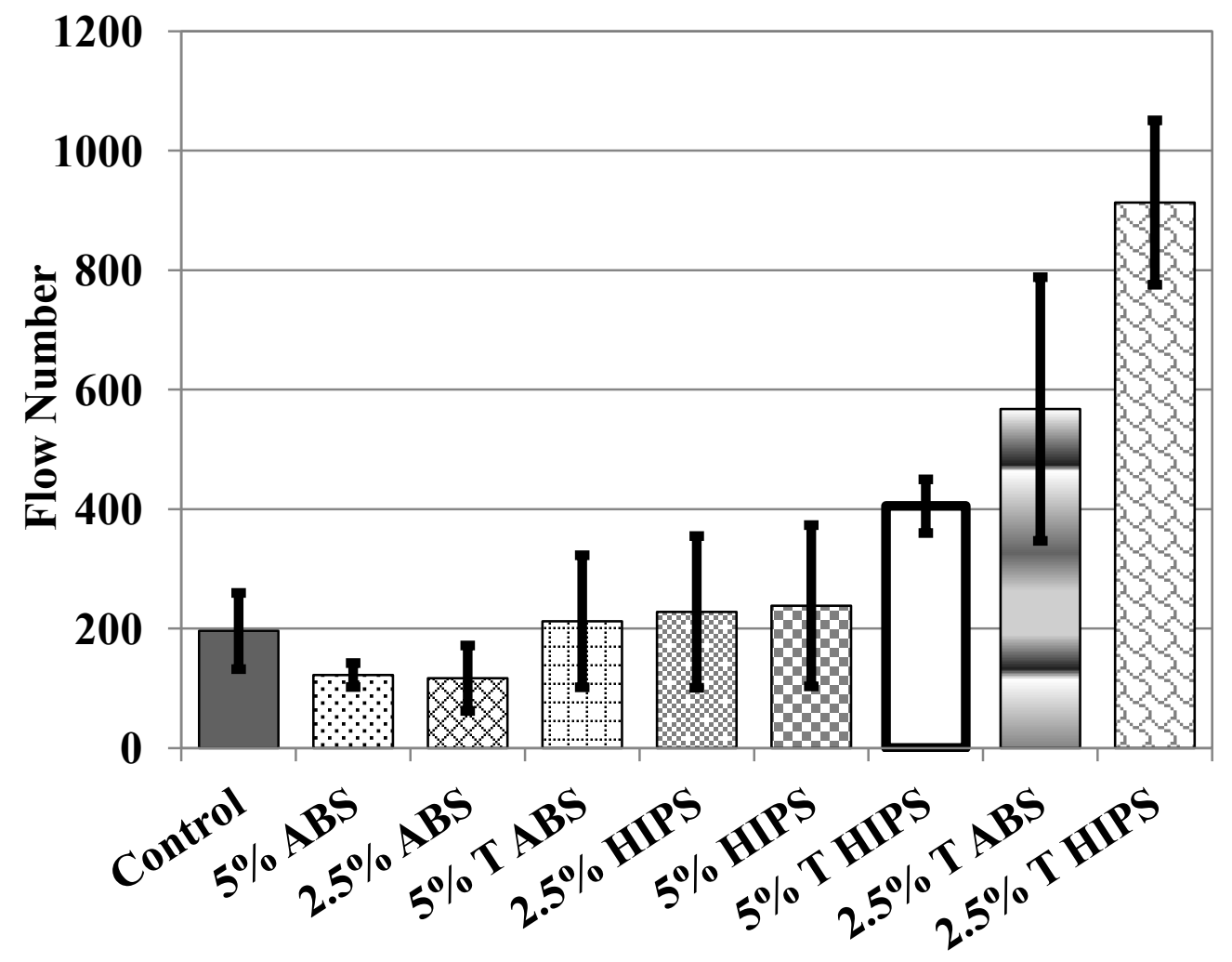

Figure 6.3 E-waste modified asphalt mixture flow number results, based on three replicates

The results from Figure 6.3 show that the average flow numbers for the treated and untreated mixtures were greater than the control sample except for the untreated ABS mixtures. In general, treating the modified e-waste mixtures resulted in an increase in 
flow number for both the ABS and HIPS mixtures. Increasing the amount of e-waste plastic for untreated mixtures resulted in a decrease in flow number for ABS mixtures. The flow numbers between the $2.5 \%$ and $5 \%$ HIPS mixture are similar. Increasing the amount of e-waste plastic for treated mixtures resulted in a decrease in flow number for both the ABS and HIPS mixtures. Table 6.3 below show the ANOVA results from the flow number data.

Table 6.3 Flow number results ANOVA analysis

\begin{tabular}{llll}
\hline Source of variation & Sum of squares & Degrees of freedom & Mean squared \\
\hline Between groups & $1.62 \mathrm{E}+06$ & 8 & 203021.6 \\
Within groups & $2.47 \mathrm{E}+05$ & 18 & 13749.0 \\
Total & $1.87 \mathrm{E}+06$ & 26 & \\
F-value & 14.8 & & \\
$P$-value & $1.86 \mathrm{E}-06$ & & \\
F critical & 2.5 & There is a significant difference in the flow number results \\
\hline \multirow{2}{*}{ Conclusion } & and e-waste modified mixture type & \\
\hline
\end{tabular}

The results of the ANOVA analysis considered the average mixture flow number, and the resulting $\mathrm{p}$-value was $1.86^{*} 10^{-6}$. This $\mathrm{p}$-value is less than an alpha value of 0.05 and indicates that for the given e-waste modified mixtures tested for flow number, there was a statistical significant difference in the improvement in flow number performance when considering 2.5 and 5\% treated HIPS and ABS mixtures along with the control mixture. This implies that the treatment of the e-waste plastics and e-waste mixture type are factors for the improvement in average flow number performance over the control mixture. The flow number results are an indication of the high temperature stability of the mixture. This data shows that chemical treatment of e-waste mixtures improves stability of mixtures versus the control in small percentages. Additionally the addition of untreated HIPS improves high temperature stability. When considering the high temperature binder results the flow number results also indicate a general improvement in performance as well. 


\subsection{Dynamic moduli of e-waste modified asphalt mixtures}

Dynamic modulus $\left(E^{*}\right)$ is a crucial parameter for determining the viscoelastic behavior of asphalt pavement materials. It serves as a simple performance test and a key input for the American Association of State Highway and Transportation Officials (AASHTO) Mechanistic-Empirical Pavement Design Guide (MEPDG). The dynamic modulus test is conducted under sinusoidal loading conditions. Following AASHTO TP 62 specifications, an IPC universal testing machine (UTM-100) was used in this investigation [53]. Using the dynamic modulus ( $\left.\mathrm{E}^{*}\right)$ simple performance test, asphalt mixtures performance at low, intermediate, and high temperature conditions were conducted. Low temperature performance was determined from the $\mathrm{E}^{*}$ test under high frequency $(25 \mathrm{~Hz})$. High and intermediate $\mathrm{E}^{*}$ performance was determined using $\mathrm{E}^{*} / \mathrm{sin}$ (ס) at 0.01 and $1 \mathrm{~Hz}$ respectively. High temperature performance was correlated to low frequencies and low temperature performance was correlated to higher frequencies. Figure 6.4 below displays the average dynamic modulus results for modified e-waste mixtures at $-10{ }^{\circ} \mathrm{C}$. 


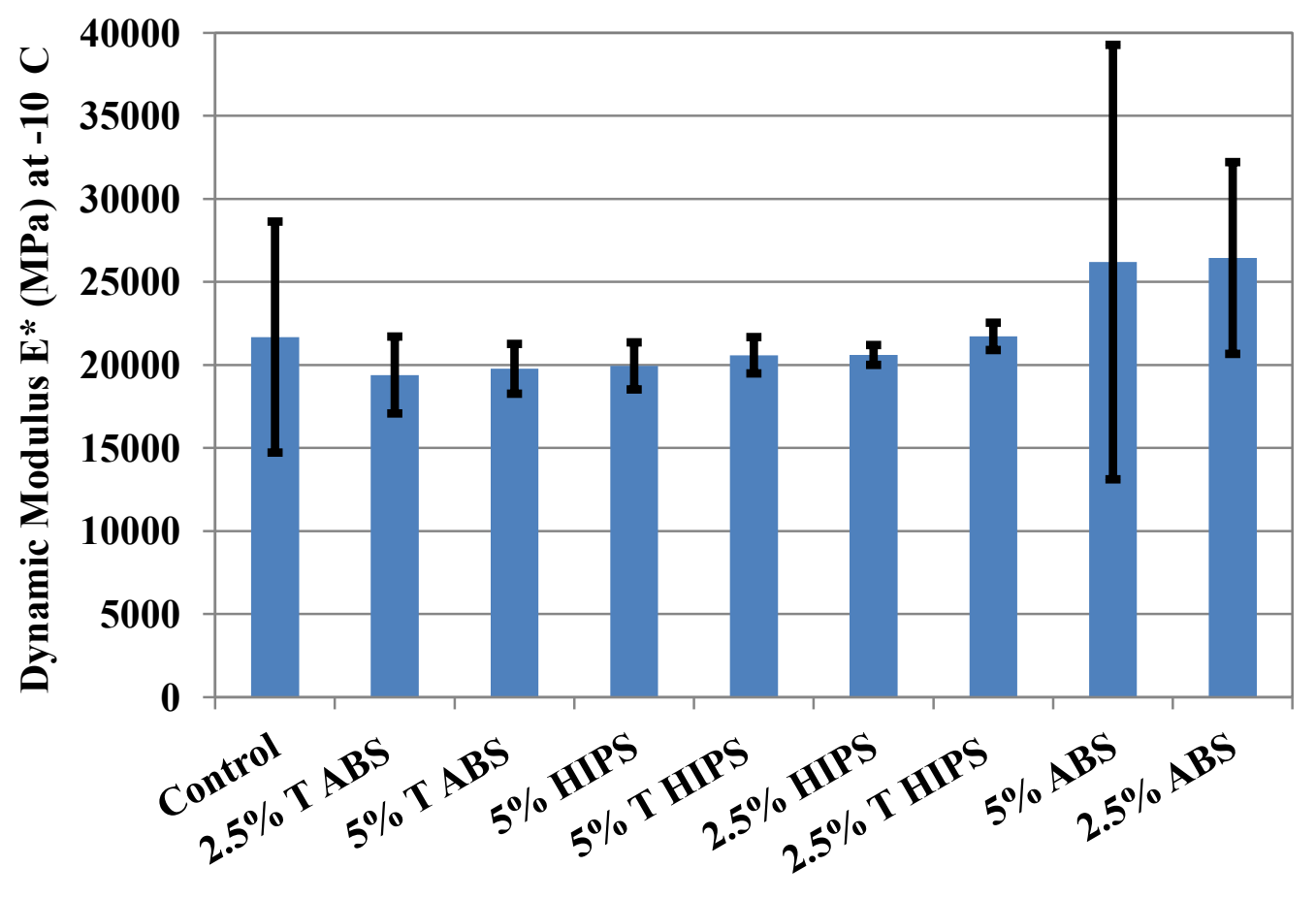

Figure 6.4 Dynamic modulus results for modified e-waste mixtures at $\mathbf{- 1 0}$ degrees Celsius and $25 \mathrm{~Hz}$, based on three replicates

Figure 6.4 shows that the control dynamic modulus values are comparable to the $2.5 \%$ HIPS e-waste modified mixtures. At $-10^{\circ} \mathrm{C}$ Figure 6.4 indicates that the treated e-waste modified mixtures have higher dynamic modulus values versus the $2.5 \%$ ABS and HIPS mixtures. Figure 6.5 below displays the $\mathrm{E}^{*} / \sin ($ delta) results for modified e-waste mixtures at $21.3^{\circ} \mathrm{C}$. 


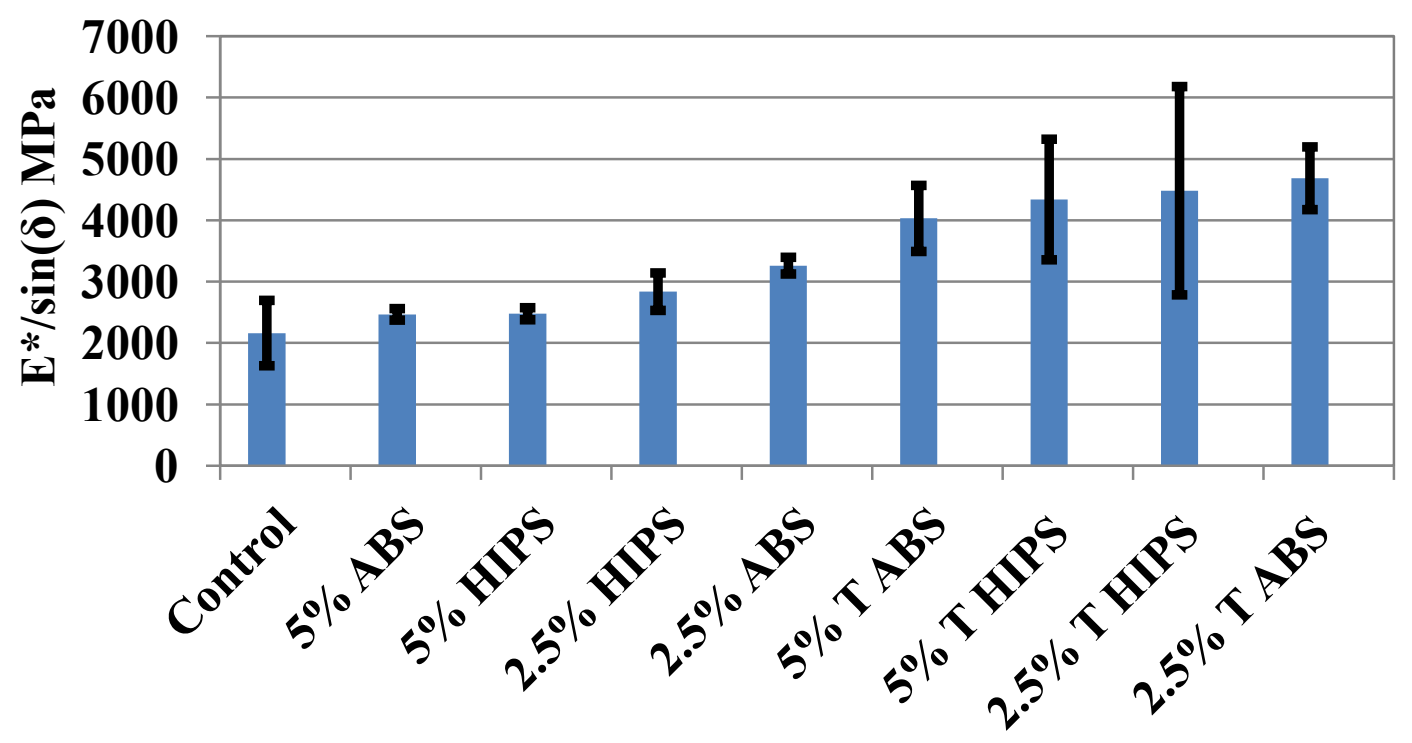

Figure $6.5 \mathrm{E} * /$ sin (delta) results for modified e-waste mixtures at 21.3 degrees Celsius and $1 \mathrm{~Hz}$, based on three replicates

From Figure 6.5 is shown that over all frequencies the control dynamic modulus values are lower than all of the e-waste modified mixtures. At $21.3{ }^{\circ} \mathrm{C}$ the treated e-waste modified mixtures have higher dynamic modulus values versus the $2.5 \%$ ABS and HIPS mixtures. The treated ABS and HIPS mixtures in general have higher $\mathrm{E}^{*}$ values versus the untreated ABS and HIPS mixtures at all tested frequencies. Finally for treated and untreated mixtures lower percentages of ABS and HIPS result in increased $\mathrm{E}^{*} / \sin \delta$. Table 6.4 below displays the paired t-test results for the control and e-waste mixtures at 21.3 degrees Celsius. 
Table 6.4 T-test: Paired two sample for means for control and e-waste mixtures for average $E^{*} / \sin (\delta)$ results at 21.3 degrees Celsius

\begin{tabular}{|c|c|c|c|c|c|c|}
\hline & Control & $\begin{array}{l}2.5 \% T- \\
A B S\end{array}$ & $\begin{array}{l}2.5 \% \\
\text { HIPS }\end{array}$ & $\begin{array}{l}\% T- \\
A B S\end{array}$ & $\begin{array}{l}5 \% T- \\
\text { HIPS }\end{array}$ & $\begin{array}{l}2.5 \% \\
A B S\end{array}$ \\
\hline Mean E* & 1298 & 2279 & 1530 & 2021 & 2200 & 3285 \\
\hline Variance & 95242 & 91233 & 39199 & 114820 & 155659 & 258333 \\
\hline Observations & 3 & 3 & 3 & 3 & 3 & 3 \\
\hline $\begin{array}{c}\text { Pearson } \\
\text { correlation }\end{array}$ & & -0.722 & 0.994 & 0.322 & 0.895 & 0.030 \\
\hline $\begin{array}{c}\text { Hypothesized } \\
\text { mean } \\
\text { difference }\end{array}$ & & 0 & 0 & 0 & 0 & 0 \\
\hline Degrees freedom & & 2 & 2 & 2 & 2 & 2 \\
\hline t Stat & & -3.00 & -3.53 & -3.32 & -8.60 & -5.87 \\
\hline $\begin{array}{c}\mathrm{P}(\mathrm{T}<=\mathrm{t}) \text { one- } \\
\text { tail }\end{array}$ & & 0.048 & 0.036 & 0.040 & 0.007 & 0.014 \\
\hline
\end{tabular}

From the t-test analysis and considering the mean mixture $\mathrm{E}^{*}$ at $21.3^{\circ} \mathrm{C}$ with e-waste modified mixture type, the t-test analysis show that there was a significant difference between the mean increase in $\mathrm{E}^{*} / \sin (\delta)$ from the control for the following mixtures: $2.5 \%$ treated ABS, $2.5 \%$ HIPS, $5 \%$ treated ABS, $5 \%$ treated HIPS, and $2.5 \%$ ABS. The p-value of these mixtures were less than alpha of 0.05 and indicates that for the given ewaste modified mixtures tested there was a statistical significant difference the increase in mean $\mathrm{E}^{*} / \sin (\delta)$ at intermediate frequencies $(1 \mathrm{~Hz})$ and temperature $\left(21.3^{\circ} \mathrm{C}\right)$ and mixture type with a $95 \%$ confidence level. This implies that at intermediate temperature and loading frequencies, that at low percentages of e-waste (2.5\% HIPS, $2.5 \% \mathrm{ABS}$, treated $2.5 \% \mathrm{ABS}$ ) and for higher percentages of treated e-waste (5\% t-ABS, 5\% t HIPS) there is a significant difference in the fatigue parameter versus the control mixture. Figure 6.6 below displays the $\mathrm{E}^{*} / \mathrm{sin}$ (delta) results for modified e-waste mixtures at $39.2{ }^{\circ} \mathrm{C}$. 


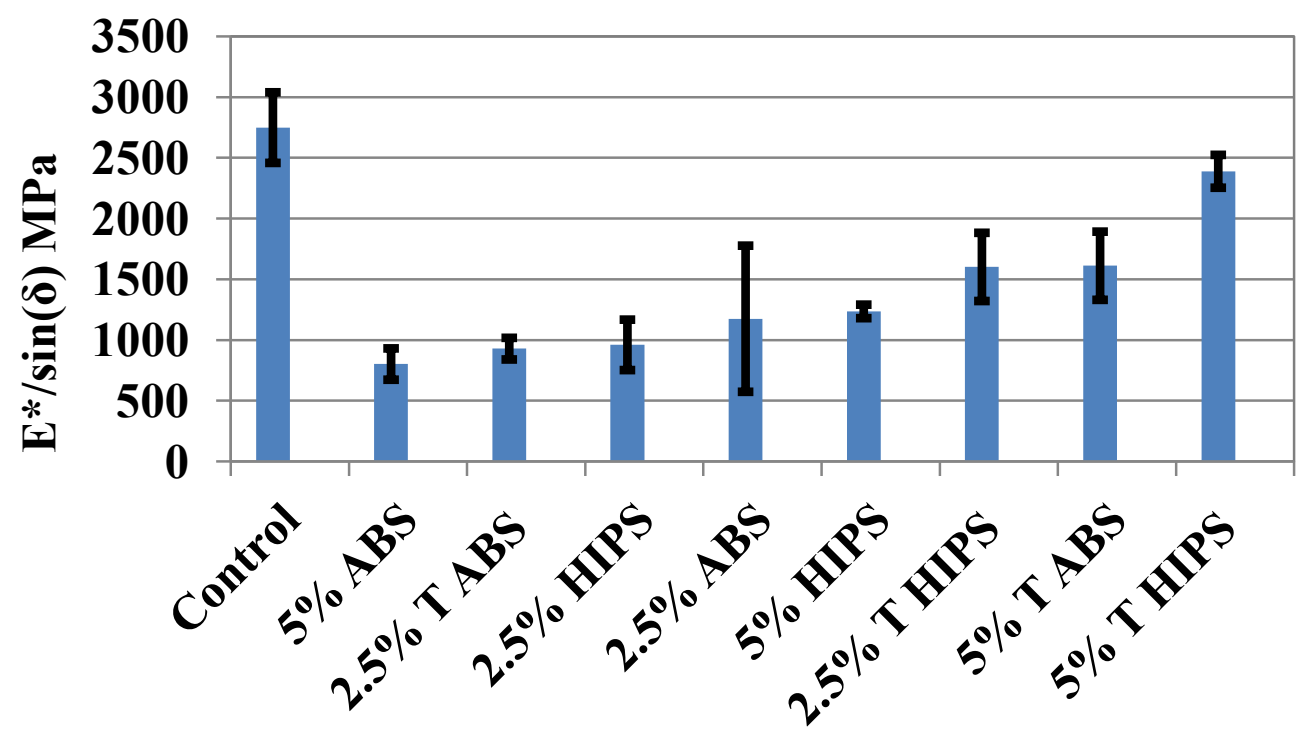

Figure $6.6 \mathrm{E} * / \mathrm{sin}$ (delta) results for modified e-waste mixtures at 39.2 degrees Celsius and $0.01 \mathrm{~Hz}$

Figure 6.6 shows that over for the frequency of $0.01 \mathrm{~Hz}$ the control dynamic modulus values are higher than all of the e-waste modified mixtures at $39.2{ }^{\circ} \mathrm{C}$. High percentages of treated e-waste modified mixtures have higher $\mathrm{E}^{*} / \sin (\delta)$ values were the most rutting resistant of the e-waste modified mixtures. The 5\% untreated HIPS mixture was the most rutting resistant of the untreated mixtures at high temperatures. Generally, the chemical treatment of high percentages of e-waste was effective in improving rutting resistance versus untreated mixtures.

\subsection{E-waste mixture moisture susceptibility}

An asphalt pavement's resistance of moisture damage is an important property for designing long lasting pavements. The Modified Lottman Test was implemented to predict the moisture susceptibility for the designed e-waste modified asphalt pavement mixtures. The testing procedure to determine the pavement moisture susceptibility is AASHTO T283- Standard Method of Test for Resistance of Compacted Hot Mix Asphalt (HMA) to Moisture-Induced Damage [24]. The peak tensile stresses for the conditioned and unconditioned samples were used to determine tensile strength ratio (TSR). 
The moisture susceptibility results consisted of the average tensile stress $(\mathrm{KPa})$ for the various e-waste modified asphalt mixtures, the average tensile strength ratio (TSR) for the tested mixtures, and an ANOVA analysis of the TSR results comparing average mixture TSR to mixture type. The ANOVA analysis was conducted with an alpha of 0.05 and assumed no difference between the mean TSR between mixture types. A plot of the effect of the treated and untreated e-waste modified HMA is provided in Figure 6.7

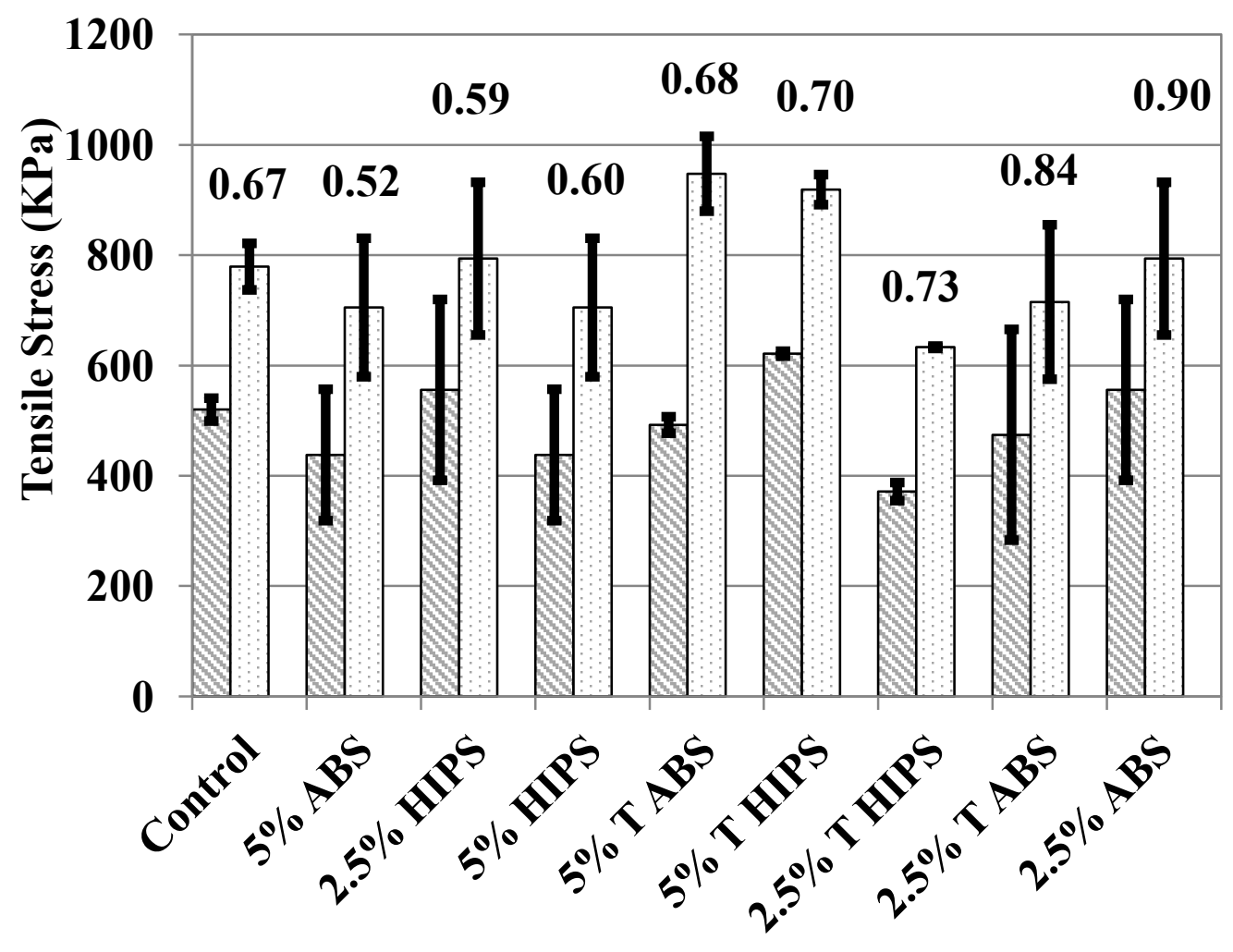

Q Conditioned $\square$ Unconditioned

Figure 6.7 Moisture susceptibility performance of control PG 58-28 and e-waste modified HMA, based on three replicates

The addition of e-waste plastics improved the TSR in all cases except for the $5 \% \mathrm{ABS}$, and the untreated HIPS mixtures. The addition of electronic waste improved unconditioned (dry) tensile strength for, 2.5\% HIPS, 2.5\% ABS, and the 5\% treated ABS and HIPS mixtures. The results show that under intermediate temperature conditions ewaste chemical treatment is effective for high percentages of e-waste. When considering 
TSR and tensile strength improvement for conditioned and unconditioned strength, $5 \% \mathrm{~T}$ ABS, 5\% T HIPS, and 2.5\% ABS all show improvement versus the control mixture. Table 6.5 shows the results of the TSR ANOVA analysis between the e-waste mixture types.

\section{Table 6.5 TSR ANOVA analysis}

\begin{tabular}{lllllll}
\hline Source of variation & $\begin{array}{l}\text { Sum of } \\
\text { squares }\end{array}$ & $\begin{array}{l}\text { degrees } \\
\text { of } \\
\text { freedom }\end{array}$ & $\begin{array}{l}\text { Mean } \\
\text { squared }\end{array}$ & $\begin{array}{l}F- \\
\text { value }\end{array}$ & $\begin{array}{l}\text { P- } \\
\text { value }\end{array}$ & $\begin{array}{l}F \\
\text { critical }\end{array}$ \\
\hline Mixture type & 0.354 & 8 & 0.044 & 3.28 & 0.0172 & 2.51 \\
Test replicates & 0.242 & 18 & 0.013 & & & \\
Total & 0.596 & 26 & & & & \\
Conclusion & E-waste mixture TSR is dependent upon mixture type \\
\hline
\end{tabular}

From the results of the ANOVA analysis considering the average TSR, the resulting pvalue was 0.0172 . This $p$-value is less than the alpha value of 0.05 , indicating that for the given e-waste modified mixtures tested for TSR there is a statistical significant difference. This implies that is given the tested mixtures, mixture type is a significant factor in TSR performance when considering the control mixture.

\subsection{Summary}

The characterization electronic waste plastic modified asphalt mixtures were conducted. The mechanical performances of these mixtures were compared to the control mixture, using various Superpave mixture tests. APA, flow number test, and high temperature dynamic modulus testing characterized high temperature mixture behavior. Intermediate temperature performance was characterized by dynamic modulus, and TSR testing. Low temperature dynamic modulus testing characterized low temperature performance for ewaste modified asphalt mixtures. 


\section{Chapter 7: A performance-emissions assessment for the comparison of e-waste modified asphalt mixtures}

\subsection{Introduction}

Increasing public concern about the environment has increased demand for efficient, sustainable materials to be used for roadway construction. There has been a demand for research to address the sustainability of these materials due to the increase in recycled materials used for rehabilitation and roadway construction projects. Therefore, a limited carbon dioxide emissions MEPDG performance assessment of e-waste modified asphalt mixtures was conducted. This emissions-performance assessment was conducted in order to address the degree of sustainability of electronic waste plastic modified asphalt mixtures; the procedure for conducting this limited assessment is highlighted in Figure 7.1 below. 


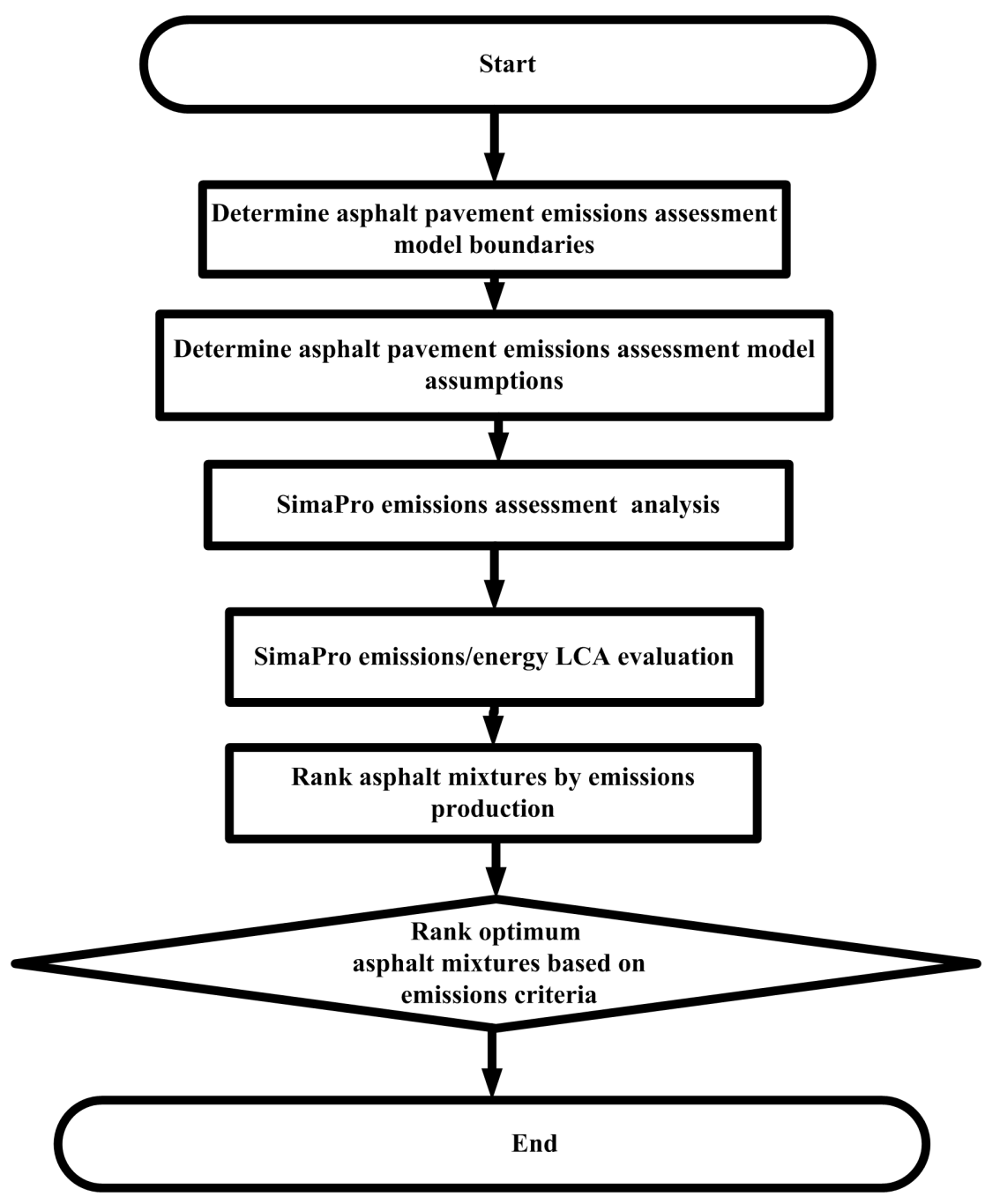

Figure 7.1 Schematic for the selection of sustainable materials by asphalt mixture performance and emissions

The objectives which of this investigation are as follows:, 1) projecting the amount of carbon dioxide from the production of electronic waste plastic asphalt pavement mixtures, 2) comparing the projected $\mathrm{CO} 2$ emissions and mixture performance using a mechanistic-empirical design guide (MEPDG) among the various e-waste mixtures versus conventional HMA mixtures, 3) Ranking e-waste modified mixtures by considering expected emissions and performance for a given mixture. The goal of this investigation is to provide a limited analysis for e-waste modified mixtures by considering $\mathrm{CO}_{2}$ emissions and total rutting of an asphalt pavement layer for future 
studies. The initial concepts for this investigation were derived from research on the sustainability and benefits of Warm Mix Asphalt (WMA) [54-56], in terms of environmental impact through emissions output and energy usage (fuel).

\subsection{Emissions assessment model and assumptions}

This assessment compared $\mathrm{CO}_{2}$ emissions of various untreated e-waste mixtures versus the control HMA mixture. The tool used to conduct this initial assessment was SimaPro 7.3 and the emissions model used was IPCC 2007 GWP 20. This model was used to simulate a 20 year projected carbon dioxide emissions due to the construction of e-waste modified pavements. This model incorporates two scenarios, 1) the travel scenario and 2) the MTU site scenario. The assumptions which were used for this model are as follows:

- The functional unit is assumed to be lane-miles.

- The Pavement Structure is assumed to have a subbase depth of 10"' a base layer of 8", and a surface HMA layer of 6".

- The travel scenario assumes that the ABS and HIPS are transported from their respective recycling facility to the HMA batch plant.

- The travel scenario assumes e-waste plastics, aggregates, and asphalt binder are transported are first transported to the batch plant before transportation to the construction site 7 miles $(11.3 \mathrm{~km})$.

- The travel scenario assumes aggregate quarry and HMA batch plant was in Hancock, MI assumed to be 1 mile $(1.61 \mathrm{~km})$ away.

- The travel scenario assumes the asphalt binder is delivered to batch plant from Gladstone, MI. 157 miles (253 km).

- The HIPS plastics were transported to batch plant from Ashland, WI 149 miles $(240 \mathrm{~km})$ in the travel scenario.

- The ABS plastics were transported from Rockford, MI to batch plant 486 miles $(782 \mathrm{~km})$ in the travel scenario.

- The asphalt binder is assumed to be a co-product for use in asphalt pavement mixtures for both the travel and MTU scenarios. 
- The emissions assessment for each pavement mixture type assumed all materials from the batch plant to be delivered and constructed at Michigan Technological University in Houghton, Michigan for the travel scenario.

- The MTU scenario assumed no travel was conducted to deliver aggregates, asphalt binder, or electronic waste plastics or process materials at Michigan Technological University, in Houghton, MI.

- The MTU scenario assumed that e-waste plastics are a co-product of manufactured ABS and HIPS plastics, therefore $\mathrm{CO}_{2}$ emissions would not be included for the initial manufacture of virgin ABS and HIPS plastics.

- E-waste plastics were assumed to be processed before placement in HMA mixture for this model.

The profiles for the SimaPro emissions input were obtained from SimaPro 7.3's ecovent database. Using SimaPro, an inventory of materials, process, and construction scenarios were created as shown in Figure 7.2 below. 


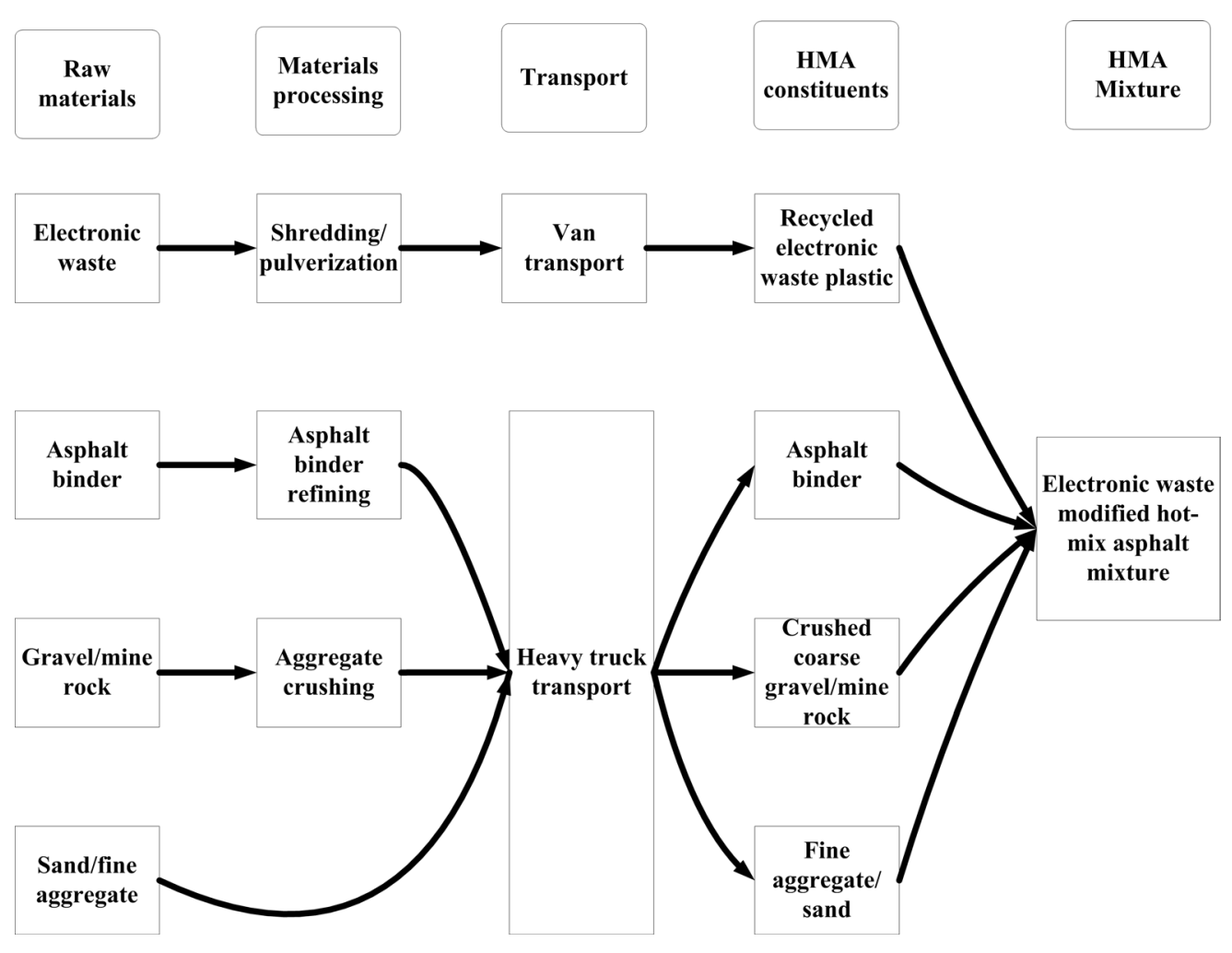

Figure 7.2 SimaPro emissions assessment model for SimaPro carbon emissions analysis

The amount of material used was based on calculations for the assumed pavement design.

The volume of each component was calculated, using assumed specific gravities to approximate the mass of each input. Table 7.1 shows the ABS and HIPS dosage classifications used for this investigation. 
Table 7.1 E-Waste/HMA pavement type dosage classification

\begin{tabular}{ccc}
\hline Mixture type & E-waste addition & $\begin{array}{c}\text { Additive } \\
\text { percentage }\end{array}$ \\
\hline \multirow{2}{*}{ ABS } & $2.5 \%$ ABS & $2.5 \%$ \\
& $5 \%$ ABS & $5.0 \%$ \\
& Control & $0 \%$ \\
\hline \multirow{2}{*}{ HIPS } & $2.5 \%$ HIPS & $2.5 \%$ \\
& $5.0 \%$ HIPS & $5.0 \%$ \\
& Control & $0 \%$ \\
\hline
\end{tabular}

A $2.5 \%$ or $5 \%$ asphalt binder material reduction was applied to the modified e-waste asphalt mixtures calculations to account for the addition of electronic waste modifier. The distances were multiplied by the mass of materials in $\mathrm{kg}$ to calculate units of kilogram kilometers for the transportation values.

\subsection{SimaPro e-waste mixture emissions results}

SimaPro was used to predict $\mathrm{CO}_{2}$ greenhouse emissions and generate a life cycle assessment for the production and disposal for the various asphalt mixtures. Considering the assumptions given previously, SimaPro compared carbon dioxide emissions for the ewaste modified asphalt mixtures based on the IPCC 2007 20a (IPCC) model. Figure 7.3 below displays the IPCC 2007 GWP 20a V1.02 CO2 emissions model results below. This model was used to monitor and predict the carbon dioxide emissions over the time span of a typical pavement life of 20 years from start of construction to reconstruction at the end of 20 years. 


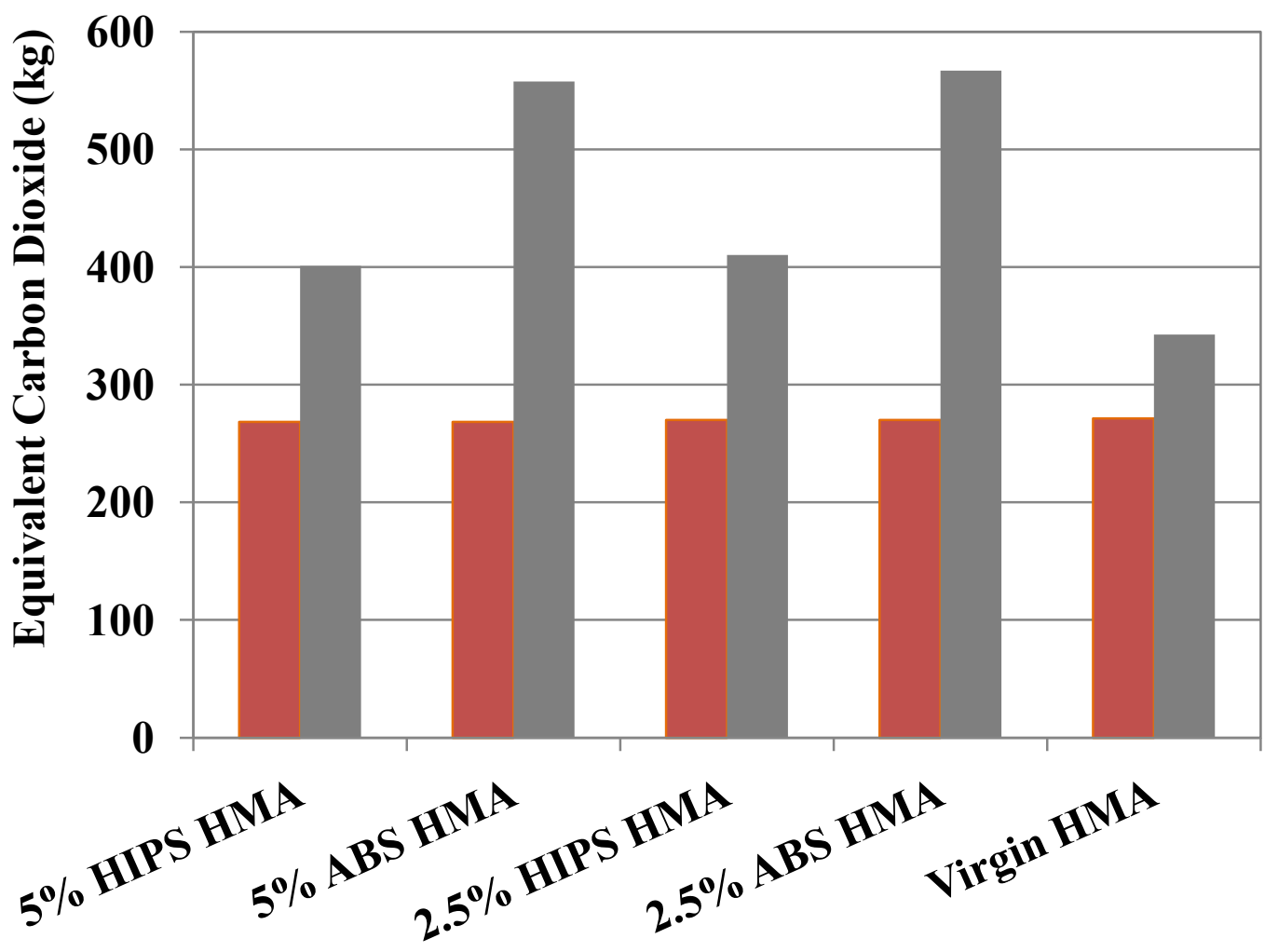

Figure 7.3 IPCC 2007 GWP 20a V1.02 CO2 emissions model comparison after 20 years for e-waste modified asphalt pavement mixtures for a travel and non-travel case (MTU scenario)

The results from Figure 7.3 show that the e-waste mixtures produced a slightly reduced amount of equivalent $\mathrm{CO}_{2}$ emissions levels compared to the Control HMA mixture. Increasing the plastic percentage of ABS and HIPS reduced the projected amount of equivalent $\mathrm{CO}_{2}$ to levels below the $2.5 \% \mathrm{ABS}$ or HIPS mixtures. Travel distance for delivering the e-waste plastics to the Houghton construction site was a factor towards increasing the amount of $\mathrm{CO}_{2}$ produced. The $\mathrm{ABS}$ mixtures produced more $\mathrm{CO}_{2}$ versus the HIPS and control mixtures as the travel distance for material delivery was greater for the ABS particles. 


\subsection{Mixture emissions output ranking}

Based upon the emissions output calculated from the SimaPro software, a comparison between the various e-waste mixtures was made regarding projected emissions output. Table 7.2 displays the ranking for the e-waste modified asphalt mixtures by projected emissions.

Table 7.2 Asphalt mixture $\mathrm{CO}_{2}$ emissions rankings calculated from the SimaPro 20 year IPCC 2007 GWP 20a V1.02 $\mathrm{CO}_{2}$ emissions model-rankings from MTU scenario

\begin{tabular}{cccc}
\hline $\begin{array}{c}\text { Recycled mixture } \\
\text { type }\end{array}$ & $\begin{array}{c}\text { Equivalent } \mathrm{CO}_{2} \\
\text { emitted (kg) travel } \\
\text { scenario }\end{array}$ & $\begin{array}{c}\text { Equivalent } \mathrm{CO}_{2} \\
\text { emitted }(\mathrm{kg}) \\
\text { MTU scenario }\end{array}$ & Rank \\
\hline 5\% HIPS HMA & 400.85 & 268.47 & 1 \\
$5 \%$ ABS HMA & 557.47 & 268.47 & 1 \\
2.5\% HIPS HMA & 410.18 & 269.89 & 3 \\
2.5\% ABS HMA & 566.81 & 269.89 & 3 \\
Control HMA & 342.60 & 271.45 & 5 \\
\hline
\end{tabular}

Table 7.2 shows that the $5 \%$ HIPS and ABS mixtures produced the least amount of $\mathrm{CO}_{2}$. The $2.5 \%$ ABS and HIPS mixtures also outperformed the control mixture which ranked the worst in $\mathrm{CO}_{2}$ output when considering the IPCC $2007 \mathrm{GWP} 20 \mathrm{a}$ V1.02 $\mathrm{CO} 2$ emissions model.

\subsection{MEPDG rutting assessment of e-waste modified pavements}

This assessment compared projected rutting performance of various untreated e-waste mixtures versus the control HMA mixture. The tool used to conduct this initial assessment was MEPDG software. MEPDG was used to simulate a 20 year projected life for a newly construction asphalt concrete road at Michigan Technological University on US-41 in October 2012. This model incorporates assumptions which were used for the MEPDG are as follows: 
- The initial AADTT assumed to be 1880 .

- The Pavement Structure is assumed to have an A-1-a subbase of semi-infinite depth, a crushed stone base layer of 8 ", and a HMA structure of 6" with a 1" surface course, and a base and leveling course of 2.5 " each.

- A level 2 MEPDG analysis was used to determine the properties for the various asphalt mixtures using the RTFO asphalt binder properties for the e-waste and control rutting performance. Figure 7.4 below displays the MEPDG results for the various asphalt mixtures.

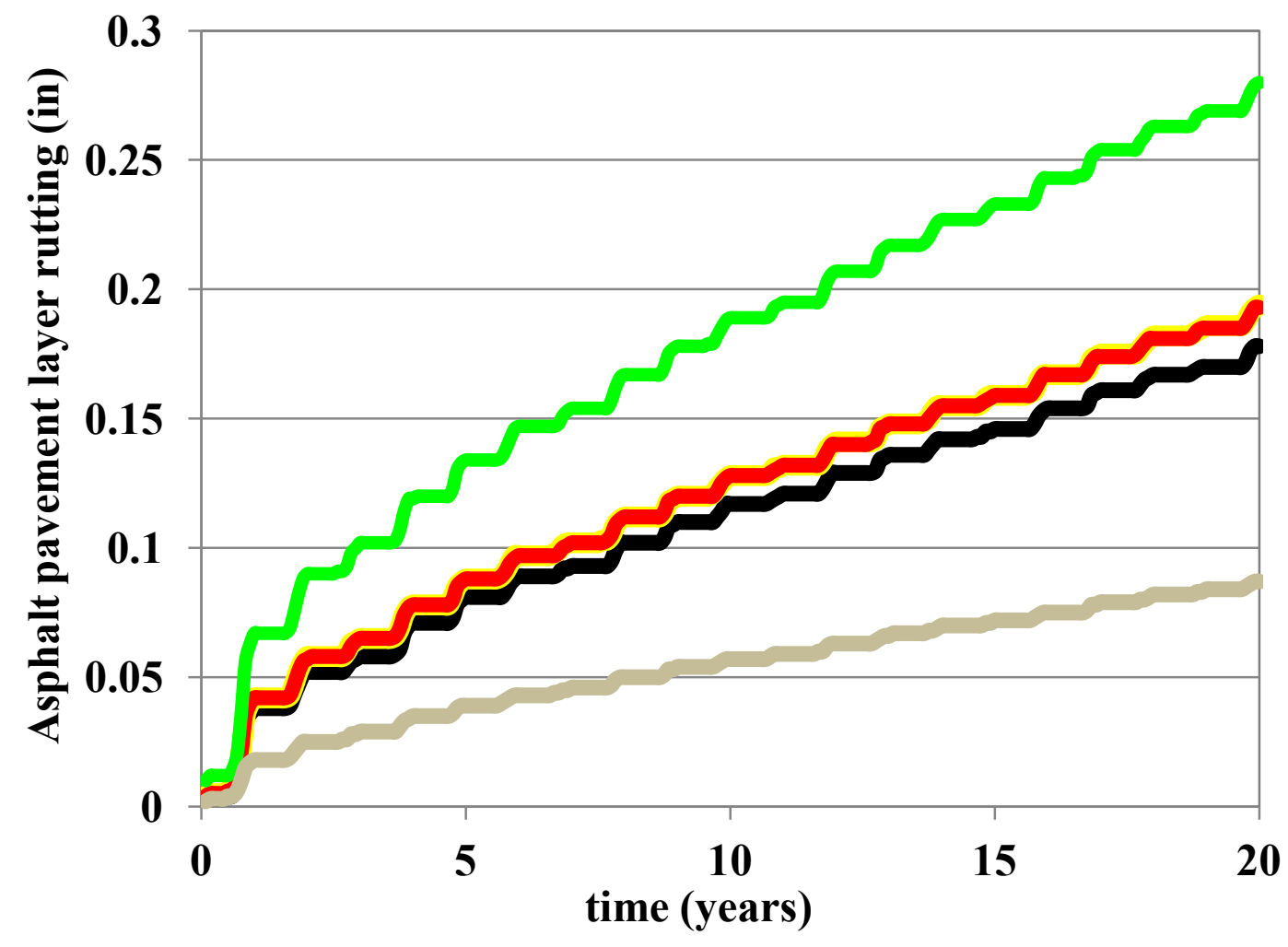

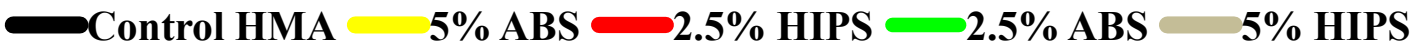

Figure 7.4 MEPDG asphalt pavement rutting prediction rutting structure layers for e-waste modified asphalt mixtures

The results from Figure 7.4 show that the 5\% HIPS mixture outperformed the control mixture. The $2.5 \%$ HIPS and 5\% ABS mixtures had similar performances throughout the 
20 year design life having slightly higher rutting than the control mixture. The $2.5 \%$ ABS mixtures performed worse than all other mixtures over the 20 year design life.

\subsection{MEPDG mixture ranking based upon projected rutting}

Based upon level 2 input parameters, the MEPDG software projected rutting performance for the various e-waste modified asphalt mixtures versus the control mixture. A comparison between the various e-waste mixtures was made regarding projected rutting output from the asphalt layers and the entire pavement structure, Using the MEPDG software. Table 7.3 displays the rankings for the e-waste modified asphalt mixtures based on MEPDG projected rutting performance.

Table 7.3 Asphalt mixture rutting rankings based on MEPDG analysis

\begin{tabular}{cccc}
\hline $\begin{array}{c}\text { Asphalt mixture } \\
\text { type }\end{array}$ & $\begin{array}{c}\text { Asphalt concrete } \\
\text { structural rutting } \\
\text { (in) }\end{array}$ & $\begin{array}{c}\text { Total structural } \\
\text { rutting(in) }\end{array}$ & Rank \\
\hline Control HMA & 0.178 & 0.448 & 2 \\
5\% HIPS HMA & 0.087 & 0.336 & 1 \\
2.5\% HIPS HMA & 0.193 & 0.471 & 3 \\
5\% ABS HMA & 0.194 & 0.472 & 4 \\
2.5\% ABS HMA & 0.28 & 0.58 & 5 \\
\hline
\end{tabular}

Table 7.3 shows that the 5\% HIPS and control mixtures produced the least amount of rutting. The control mixture outperformed the $2.5 \%$ HIPS mixture along with all other ABS mixtures. The $2.5 \%$ ABS mixture ranked the worst in rutting performance within the asphalt concrete and pavement structure layers.

\subsection{Summary}

A limited pavement mixture assessment was conducted to compare carbon dioxide emissions between the various e-waste modified HMA mixtures and the control HMA mixture. SimaPro 7.3 was used to determine projected $\mathrm{CO}_{2}$ emissions between the various mixtures. MEPDG software was used to assess the projected rutting for each of 
the mixtures. This data and resulting conclusions are limited to the given assumptions and only valid as for conditions discussed previously; as future testing may use different assumptions of emissions assessment or MEPDG predicted rutting. The research assessment discussed here is based upon limited lab tests for limited types of electronic waste modified asphalt mixtures, electronic waste plastic types, and modified asphalt binder technologies. 


\section{Chapter 8: Summary, conclusions, and recommendations}

\subsection{Dissertation summary}

Previous investigations into the sustainable use of electronic waste for transportation and building infrastructure has led to the promise of eliminating potential harmful materials from impacting the environment and the use of electronic waste to help to improve the performance of asphalt pavement materials. Although numerous studies and investigations have been conducted concerning potential applications of plastic electronic waste particles and their impact upon the environment, this investigation addresses the mechanical performance of electronic waste plastic modified asphalt pavement materials based on limited laboratory data which may not necessarily directly translate to field performance. The main objectives of this study are as follows:

1. Investigate effects of electronic waste plastics upon the asphalt binder and asphalt mixture mechanical properties in terms of asphalt binder stiffness, rutting susceptibility, and moisture durability properties based upon the Superpave design method.

2. Determine the effect free radical initiation with hydro-peroxide has in improving e-waste plastic performance and compatibility.

3. Develop a framework for evaluating the performance and environmental impact modified electronic waste asphalt materials have for producing sustainable asphalt pavement materials.

Five different asphalt mixture and binder types were investigated: control HMA, untreated ABS, treated ABS, untreated HIPS, and treated HIPS asphalt binder and mixtures were evaluated. Asphalt binder rheological properties, and asphalt mixture testing measures such as: APA rutting, dynamic modulus testing, tensile strength ratio (TSR) testing, and dynamic creep-flow number testing were conducted for this 
investigation. A summary of the findings for the asphalt mixture and binder testing is summarized below in Table 8.1 and 8.2 below. 


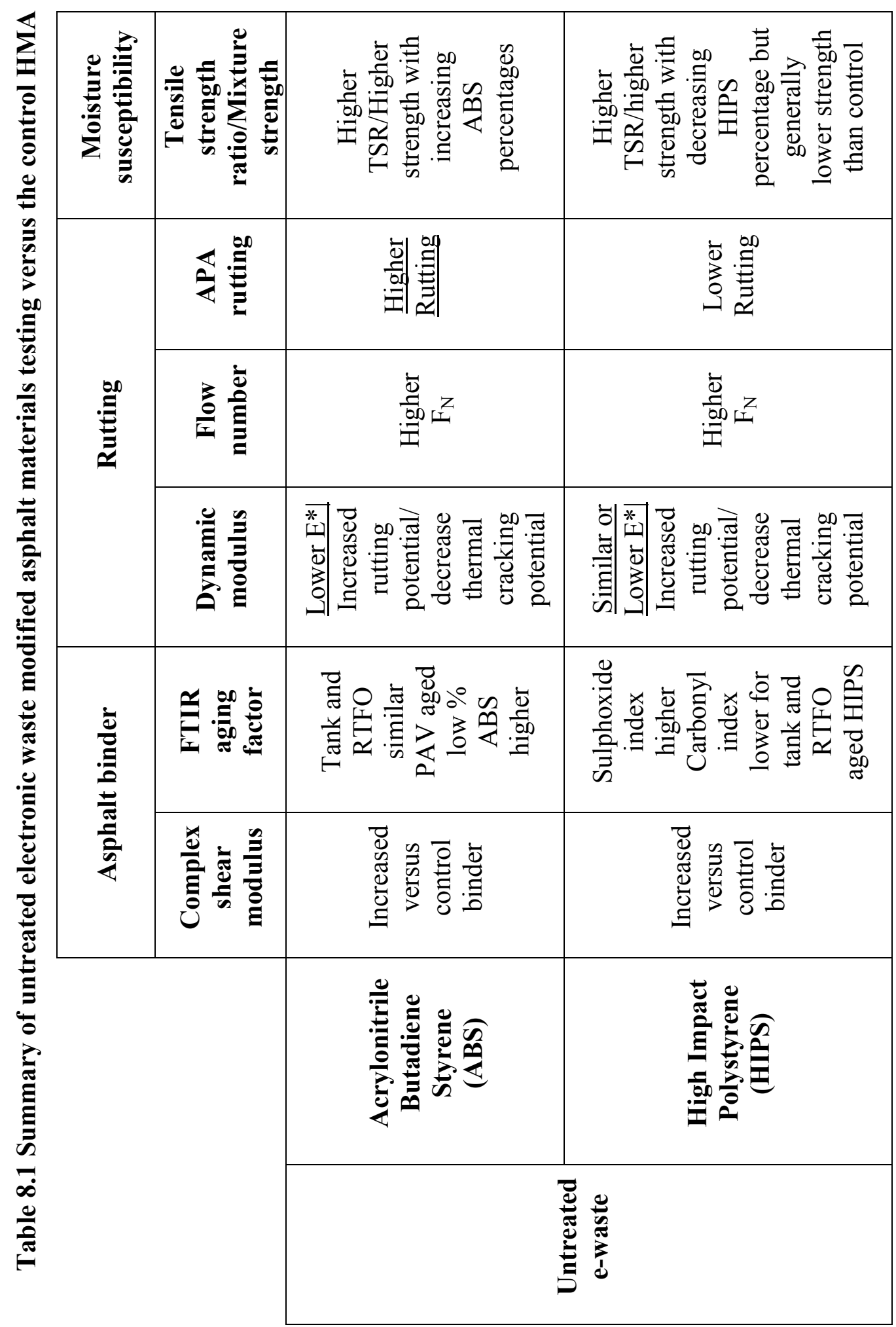




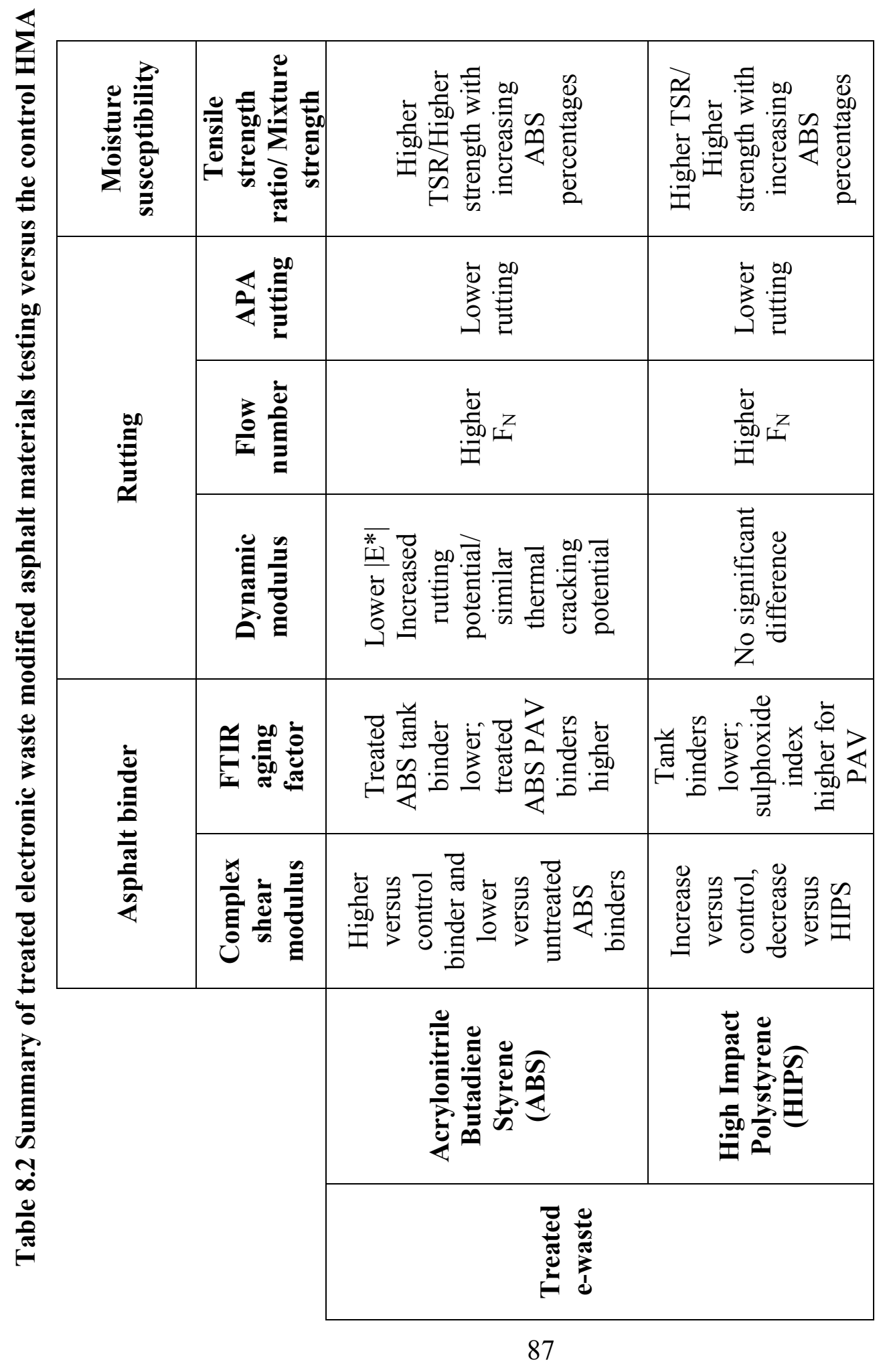


An assessment to address the impact of mixture performance and environmental impact was conducted. The hybrid performance-emissions assessment was presented as an initial step for pavement engineers to decide the optimum performing modified electronic waste mixture. This assessment was used to compare performance, emissions output, and determine mixture performance factors and processes needed to calculate emissions outputs from SimaPro and MEPDG software. The six major sections contain discussions about the use of electronic waste plastics applications in civil engineering infrastructure, the performance of untreated electronic waste modified asphalt binders, the recycling process of bulk electronic waste plastics for integration within asphalt pavement materials, the use of free radical initiators to improve compatibility and bonding strength between e-waste plastics and asphalt binders, and the performance of electronic waste asphalt mixtures.

Treated electronic waste modified asphalt mixtures were studied to determine if chemical modification of e-waste plastics would result in an improved low and high temperature performance for e-waste modified asphalt mixtures. The results from dynamic modulus, moisture susceptibility, and dynamic creep $\mathrm{F}_{\mathrm{N}}$ shows the treating the electronic waste plastics improved the onset of tertiary flow, has slightly improved dynamic modulus results for low temperature $\mathrm{E}^{*}$, and improved TSR values for treated e-waste asphalt mixtures.

This investigation added to the current body of scientific knowledge by discussing three concepts. First this investigation addresses the feasibility of integrating non-metallic components of electronic waste materials within asphalt pavements in terms of high and low temperature performance parameters. In general, thermoplastics are not common modifiers within asphalt binders and pavement mixtures, and this investigation addressed the process of breaking down bulk electronic waste plastics into particle and powder sizes, along with identifying suitable sources electronic waste plastic for conducting and completing various phases of this investigation. Secondly, this investigation addresses the 
compatibility of electronic waste plastic bonding within asphalt binders through the use of a scanning electronic microscope, differential scanning calorimetry, and Fourier Transform Infrared microscopy. These techniques show compatibility between treated electronic waste plastics and asphalt binders. Finally, this investigation discussed and developed a limited performance-emission assessment to determine sustainable e-waste modified asphalt mixtures for optimizing performance and environmental emissions for ranking purposes to choose the optimal e-waste asphalt mixture for construction or rehabilitation.

\subsection{Dissertation recommendations}

Many studies were conducted in this investigation to determine the performance of electronic waste modified asphalt pavement materials feasibility for used in pavement construction and rehabilitation. The primary scope of this investigation is laboratory testing of electronic waste modified asphalt pavement materials and therefore construction, environmental, and economic issues were not fully addressed. The following topics are future research recommendations which would help to address the knowledge gaps found in this study:

1. The performance of electronic waste modified asphalt pavement materials in the laboratory setup compared to the field performance. There are limited field trials which have implemented electronic waste plastic materials within asphalt pavements, therefore the laboratory methods and procedures for introducing ewaste plastics into pavements may have to be adjusted for current practices for HMA batch plants and current polymer modified binder technologies in order to properly simulate the performance in the field.

2. The aging of the e-waste modified asphalt binders in the asphalt plant. It is important to develop a standard procedure to mimic the asphalt binder aging in the asphalt plant and at the time of placement to address concerns of aging after short term and long term aging for e-waste modified asphalt binders. 
3. The thermal cracking potential of e-waste modified mixtures in this study was not thoroughly addressed to assure placement of e-waste asphalt mixtures in cold climates.

4. The environmental impact of e-waste modified asphalt mixtures will need to be thoroughly addressed in terms of leaching and dust generated by raveling.

5. Energy and emission of e-waste modified asphalt mixtures and binders need to be quantified as recycling techniques for e-waste mixtures and powders become more efficient since this would result in a more accurate quantification of the lifecycle inventories of plastic e-waste modified asphalt materials compared with conventional HMA materials.

\subsection{Dissertation conclusions}

Based upon the findings from this investigation the following conclusions can be drawn:

1. Despite the many hazardous materials present within e-waste products, utilizing the nonmetallic plastic components of the e-waste avoids the major heavy metal found within e-waste.

2. Economical recycling procedures must be developed to successfully use the thermoplastic components within e-wastes for use as sizes needed for the modification of asphalt binders and for aggregate replacement.

3. Research indicates that the use of e-waste plastics improved the high temperature properties for asphalt binders and mixtures.

4. Low temperature performance of e-waste plastics for asphalt materials is inconclusive and future research efforts must concentrate on appropriate amounts of e-waste material to implement into pavement materials for maximum performance.

5. Future research efforts need to focus on agents or additives which can effectively provide compatibility between various e-waste plastics and asphalt materials.

6. Electronic waste plastic powders and particles were successfully blended within asphalt binders and mixtures as a modification agent. Compared with 
conventional asphalt binders and mixtures electronic waste modified asphalt binders and mixtures exhibited promise towards improving asphalt pavement material performance.

7. Low percentage ABS asphalt binders were shown to have the best low temperature performance based upon bending beam rheology testing results. High percentage HIPS asphalt binders were shown to have the worst low temperature performance for modified electronic waste asphalt binders.

8. In general electronic waste plastic modified asphalt binders and mixtures stiffen mixtures and binders under low temperature conditions and are stiffer or comparable to the conventional control binder and mixture results.

9. The treated e-waste modified asphalt binder with $5 \%$ e-waste powder within the binder improved high temperature rutting performance by at least one high temperature binder grade for the ABS and HIPS modified asphalt binders. The RTFO aged binder results showed that the modification dramatically improved high temperature performances for the treated HIPS asphalt binder.

10. The treated ABS and HIPS e-waste modified asphalt binders were less viscous than the untreated e-waste modified asphalt binder and were comparable to the control tank asphalt binder viscosity. Low percentages of modified ABS and HIPS e-waste asphalt binders resulted in similar m-values at the specified low temperature grade of the control asphalt binder. In a direct comparison treated ABS modified asphalt binders performed better than treated HIPS modified asphalt binder under Superpave low temperature performance testing. However, treated e-waste modified binder did not appear to improve low temperature performance versus the control asphalt binder.

11. The addition of HIPS reduced viscosity with smaller particles and was shown to easily melt within the asphalt binder. Smaller ABS particles slightly added viscosity to the asphalt binder due to the increased surface area from the smaller ABS particles along with more difficulty melting within the asphalt binder. 
12. Treated ABS and HIPS e-waste modified binders in general are shown to be softer than untreated ABS and HIPS e-waste modified asphalt binders under unaged and post production aged asphalt binders. Long term aged treated e-waste modified asphalt binders from this investigation are shown to significantly stiffen versus conventional and untreated long term aged asphalt binders.

13. Given the property improvements shown through the ABS and HIPS modified asphalt binders, modifications with other waste plastics may be able to give even greater improvements.

14. Treated electronic waste asphalt binders did not exceed low temperature performance of conventional control asphalt binders in bending beam rheometer testing, but considering the improvement in high temperature performance grade, treated electronic waste asphalt binders show potential in extending the range of temperatures which these particular binders can perform.

15. Untreated electronic waste plastic modified asphalt binders generally have a higher viscosity with increasing percentages of e-waste plastic modifier. The use of hydro peroxide reduces viscosity of untreated e-waste plastic modified asphalt binders to viscosities compared to the control asphalt binder.

16. In general the ABS powder particles didn't show significant conglomeration and were dispersed through the asphalt binder matrix.

17. The HIPS particles showed dispersion within the asphalt binder matrix but were in general larger than the ABS particles.

18. It was shown from SEM photos the ABS powder was between 5-20 $\mu$ m while the HIPS powders were between 15 and $90 \mu \mathrm{m}$. E-waste plastic powders were shown to be between dispersed and not conglomerated within the asphalt binder matrix.

19. The DSC testing results showed 1 glass transition temperature with all samples tested and a small change in glass transition temperature for the quenched and unquenched samples. This indicates that the ABS and HIPS plastic particles are compatible with the asphalt binder at the given temperature range. 
20. DSC analysis indicated that there was one single glass transition temperature for all tested ABS and HIPS mixtures with little difference between glass transition temperatures for quenched and unquenched asphalt binder samples.

21. Based upon changes in FTIR spectra between the control binders and treated ewaste modified asphalt binder spectra, a possible chemical change occurred with the e-waste modified asphalt binders based on the change in absorption readings for the e-waste modified binders. This implies that molecular bonding between the asphalt binder and electronic waste plastics occurred.

22. Based on FTIR spectra data the aging indices are reduced or similar for RTFO and unaged e-waste modified asphalt binders based on sulphoxide and carbonyl indices. This implies that there at the tank binder state and for short term aging there is a reduced rate of aging. As the e-waste modified asphalt binders are long term aged, there is a concern with high percentages of PAV aged treated and untreated e-waste binders due to their relatively high sulphoxide and carbonyl indices compared to the other e-waste modified asphalt binders. This indicates that for long term aging states, e-waste modified asphalt binders rapidly age.

23. The 5\% HIPS PAV treated asphalt binder is shown to have the strongest molecular bonding network based on FTIR sulphoxide aging indices.

24. This investigation showed that higher percentages of treated e-waste modified asphalt mixtures improved high temperature performance in terms of rutting susceptibility versus the control mixture. Through the use of hydro-peroxide treatment of e-waste, mixtures containing higher percentages of e-waste modifier improved in rutting performance. Additional percentages of ABS were effective in reducing rutting for untreated ABS mixtures. Overall, chemical treatment of ABS mixtures was effective in reducing rutting than HIPS modified asphalt binders.

25. The use of e-waste modifier for asphalt mixtures was effective in delaying the onset of tertiary flow as show from the flow number tests. ABS mixtures had greater flow numbers versus HIPS mixtures. Additional percentages of ABS or 
HIPS did not translate into improved flow number performance. Treating ABS and HIPS did improve flow number performance for a given percentage of modified mixture.

26. At intermediate temperatures, the $\mathrm{E}^{*}$ results indicated a similar to improved performance compared to the control mixtures. The dynamic modulus results show that at low temperatures the unmodified e-waste mixtures may perform better than the control and treated e-waste mixtures due to the slightly lower $\mathrm{E}^{*}$ values.

27. The addition of e-waste plastics improved TSR in all for all treated e-waste mixtures versus the control mixture. In terms of TSR and strength, it was shown that the chemical treatment was effective for increasing tensile strength for high percentages of ABS or HIPS compared to the control mixture for intermediate temperatures.

28. The ANOVA statistical analysis indicate that for e-waste modified HMA, mixture types are a factor in pavement performance for high temperature and intermediate temperature performance criteria such as flow number, rutting, and intermediate temperature $\mathrm{E}^{*}$ relating to fatigue cracking. There was no evidence that e-waste mixture type was a factor in moisture susceptibility performance based on the ANOVA statistical analysis.

29. The SimaPro emissions calculations resulted in the 5\% HIPS and ABS mixtures producing the least amount of $\mathrm{CO} 2$ emissions, followed by $2.5 \%$ HIPS modified HMA mixture, when distance travel to deliver e-waste plastics for asphalt materials isn't considered. Travel distance to deliver e-waste plastics for use in local asphalt pavement projects is a major obstacle for the reduction of emissions if local recycled ABS and HIPS plastics are not used to modify asphalt pavements.

30. Based on performance testing and emissions model results the recommended optimum mixture determined from the emissions-performance assessment is the 
$5 \%$ HIPS modified asphalt mixture. The 5\% HIPS is the optimum choice due to its relatively low rutting susceptibility compared to the other HMA mixtures, and low carbon dioxide emissions during production compared to the other HMA mixtures. 


\section{Acknowledgements}

I would like to express my sincere gratitude and thanks to my advisor Dr. Zhanping You. He has given of himself to provide constant motivation, leadership, and mentorship; Dr. You has enabled me to achieve my research goals and prepare me for my future endeavors. His advice, temperament, enthusiastic attitude, and financial support have inspired me to achieve my goals and gain confidence for my future pursuit, of which I am truly grateful for. I would like to express my utmost respect and esteem for him.

I would like to acknowledge the assistance of Dr. Julian-Mills Beale of California Baptist University, Dr. Yu Liu of Chang'an University, and Mr. Shu Wei Goh, and Mr. Chris Dedene for their input to this project. I would like to acknowledge the significant contributions in test planning and experimental work, from Su Ting Lau, David Porter, and Kal Johnson from Michigan Technological University. Industry support and advice was provided by Mr. Jerry Cook, Mr. Randy Larson, Dr. Leonard Payls, and Dr. Carissa Mooney. The authors would also like to acknowledge David Wingard from Clemson University for DSC testing and SEM photography and Mr. Owen Mills from Michigan Technological University for providing the SEM photographs. FTIR support and training was provided by Dr. Yoke Kin Yap and Boyi Hao from the Michigan Technological University Physics Department. The experimental work was completed at the Transportation Materials Research Center at Michigan Technological University.

Financial support for the completion of this investigation was made in part by the King Chavez Parks Fellowship Program, National Science Foundation, Michigan Technological University Graduate School, and Michigan Space Grant Consortium. This material is based in part upon work supported by U.S. National Science Foundation under grant 0936726 and the Michigan Space Grant Consortium. Any opinions, findings and conclusions or recommendations expressed in this material are those of the author's and 
do not necessarily reflect the views of the National Science Foundation nor the Michigan Space Grant Consortium.

I would also like to acknowledge Pastor Thomas Griffin and his family along with the congregation of The Lighthouse for their support, prayers, and love. I would finally like to express my deepest gratitude to my wife Karen, for her unconditional love, patience, and support along with my sons and daughters Sharon, Taryn, Baron II, and Darren. 


\section{References}

1. Khan, M.M.K., et al., Flammability Properties of Virgin and Recycled Polycarbonate (PC) and Acrylonitrile-Butadiene-Styrene (ABS) Recovered from End-of-Life Electronics. Journal of Polymers and the Environment, 2007. 15(3): p. 188-194.

2. Nagurney, A. and F. Toyasaki, Reverse supply chain management and electronic waste recycling: a multitiered network equilibrium framework for e-cycling. Transportation Research Part E: Logistics and Transportation Review, 2005. 41(1): p. 1-28.

3. Robinson, B.H., E-waste: An assessment of global production and environmental impacts. Science of the total environment, 2009. 408(2): p. 183-191.

4. Santos, M.C., et al., Determination of toxic elements in plastics from waste electrical and electronic equipment by slurry sampling electrothermal atomic absorption spectrometry. Talanta, 2010. 81(4-5): p. 1781-1787.

5. Dawson, R.B. and S.D. Landry, End-of-life and regulatory issues for flame retardant plastics used in electrical and electronic equipment applications. isee, 2004: p. 46-50.

6. Kang, H.Y. and J.M. Schoenung, Used consumer electronics: a comparative analysis of materials recycling technologies. isee, 2004: p. 226-230.

7. Ladou, J. and S. Lovegrove, Export of electronics equipment waste. International journal of occupational and environmental health, 2008. 14(1): p. 1-10.

8. Achilias, D., et al., Chemical recycling of polymers from Waste Electric and Electronic Equipment. Journal of Applied Polymer Science, 2009. 114(1): p. 212221.

9. Dillon, P.S. Recycling infrastructure for engineering thermoplastics: a supply chain analysis. 1999. IEEE.

10. Das, S.K. and S. Matthew. Characterization of material outputs from an electronics demanufacturing facility. 1999. IEEE. 
11. Masanet, E. and A. Horvath, Assessing the benefits of design for recycling for plastics in electronics: A case study of computer enclosures. Materials \& design, 2007. 28(6): p. 1801-1811.

12. Anandhan, S., et al., Novel thermoplastic elastomers based on acrylonitrilebutadiene-styrene terpolymer (ABS) from waste computer equipment and nitrile Rubber. Rubber chemistry and technology, 2002. 76: p. 1145.

13. Balart, R., et al., Recycling of ABS and PC from electrical and electronic waste. Effect of miscibility and previous degradation on final performance of industrial blends. European polymer journal, 2005. 41(9): p. 2150-2160.

14. Liu, W.Q., et al., Progress in the Preparation of Composites Based on the Nonmetallic Fractions Recycled from Waste Printed Circuit Boards. Advanced Materials Research, 2011. 160: p. 518-523.

15. Liang, R. and R.K. Gupta. Rheological and mechanical properties of recycled polycarbonate. in Proc. Soc. Plast. Eng. Annual Technical Conf. 2000. Orlando, Fl.

16. Liang, R. and R.K. Gupta. Rheological Properties of recycled Polycarbonate and ABS melts. in Proc. XIIIth Int. Congress on Rheology. 2000. Cambridge, U.K.

17. Liang, R. and R.K. Gupta. The effect of residual impurities on the rheological and mechanical properties of engineering polymers separated from mixed plastics. in Proc. Soc. Plast. Eng. Annual Technical Conf. 2001. Dallas, Tx.

18. Mural, P.K.S., et al., Polypropylene/high impact polystyrene blend nanocomposites obtained from E-waste: evaluation of mechanical, thermal and morphological properties. International Journal of Plastics Technology, 2011. 15(1): p. 1-15.

19. Ching, S.K., J.R. Kirby, and O.D. Pitts. Plastics recycling issues for the computer industry: progress and challenges. 1996. IEEE.

20. Morrison, G.R., N.K. Lee, and S.A.M. Hesp. Recycling of plastic and rubber tire waste in asphalt pavements. 1994. 
21. Yokoyama, S. and M. Iji. Recycling of thermosetting plastic waste from electronic component production processes. 1995. IEEE.

22. Aglan, H., Polymeric Additives and Their Role in Asphaltic Pavements. Part I: Effect of Additive Type on the Fracture and Fatigue Behavior. Journal of elastomers and plastics, 1993. 25(4): p. 307.

23. $\mathrm{Li}, \mathrm{Y}$., et al., Improving the aging resistance of styrene butadiene styrene tri block copolymer and application in polymer modified asphalt. Journal of Applied Polymer Science, 2010. 116(2): p. 754-761.

24. Al-Hadidy, A. and T. Yi-qiu, Effect of polyethylene on life of flexible pavements. Construction and Building Materials, 2009. 23(3): p. 1456-1464.

25. Arnold, J., et al., The use of FTIR mapping to assess phase distribution in mixed and recycled WEEE plastics. Polymer Testing, 2010. 29(4): p. 459-470.

26. Schroeder, R.L., The use of recycled materials in highway construction. Public roads, 1994. 58(2): p. 32-41.

27. Hinisliolu, S. and E. Aar, Use of waste high density polyethylene as bitumen modifier in asphalt concrete mix. Materials letters, 2004. 58(3-4): p. 267-271.

28. Othman, A.M., Impact of Polypropylene Application Method on Long-Term Aging of Polypropylene-Modified HMA. Journal of Materials in Civil Engineering, 2010. 22: p. 1012.

29. Jeong, K.D., S.J. Lee, and K.W. Kim, Laboratory evaluation of flexible pavement materials containing waste polyethylene (WPE) film. Construction and Building Materials, 2010.

30. Punith, V.S. and A. Veeraragavan. Laboratory Fatigue Studies on Bituminous Concrete Mixes Utilizing Waste Shredded Plastic Modifier. in Proceedings - 21st ARRB and 11th REAAA Conference, Transport Our Highway to a Sustainable Future, May 18, 2003 - May 23, 2003. 2003. Cairns, QLD, Australia: ARRB Transport Research Ltd. 
31. Punith, V.S. and A. Veeraragavan, Evaluation of reclaimed polyethylenemodified asphalt pavements. Journal of Testing and Evaluation, 2010. 38(Compendex).

32. Punith, V.S., A. Veeraragavan, and S.N. Amirkhanian, Evaluation of reclaimed polyethylene modified asphalt concrete mixtures. International Journal of Pavement Research and Technology, 2011. 4(Compendex): p. 1-10.

33. Colbert, B. and Z. You, Properties of Modified Asphalt Binders Blended with Electronic Waste Powders. Journal of Materials in Civil Engineering, 2012. 24(10): p. 1261-1267.

34. Li, J., et al., Recycle technology for recovering resources and products from waste printed circuit boards. Environmental science \& technology, 2007. 41(6): p. 19952000 .

35. AASHTO, AASHTO T 316-11 Viscosity Determination of Asphalt Binder Using Rotational Viscometer, in AASHTO Standard Specifications for Transportation Materials and Methods of Sampling and Testing.2011, American Association of State Highway and Transportation Officials: Washington D.C.

36. ASTM, ASTM D 4402: Standard Test Method for Viscosity Determination of Asphalt at Elevated Temperatures Using a Rotational Viscometer, 2006, American Society Testing \& Materials: West Conshohocken, PA.

37. ASTM, ASTM D 6521: Standard Practice for Accelerated Aging of Asphalt Binder Using a Pressurized Aging Vessel (PAV), 2008, American Society Testing \& Materials: West Conshohocken, PA.

38. AASHTO, AASHTO T 240-09 Effect of Heat and Air on a Moving Film of Asphalt Binder (Rolling Thin-Film Oven Test), in AASHTO Standard Specifications for Transportation Materials and Methods of Sampling and Testing.2011, American Association of State Highway and Transportation Officials: Washington D.C.

39. AASHTO, AASHTO T 313-10 Determining the Flexural Creep Stiffness of Asphalt Binder Using the Bending Beam Rheometer (BBR), in AASHTO 
Standard Specifications for Transportation Materials and Methods of Sampling and Testing.2011, American Association of State Highway and Transportation Officials: Washington D.C.

40. Guo, J., Asphalt modified with nonmetals separated from pulverized waste printed circuit boards. Environmental science \& technology, 2009. 43(2): p. 503508.

41. Naskar, M., T.K. Chaki, and K.S. Reddy, Effect of waste plastic as modifier on thermal stability and degradation kinetics of bitumen/waste plastics blend. Thermochimica Acta, 2010. 509: p. 128-134.

42. Arkema Inc., Organic Peroxides General Catalog-Americas, A. Inc., Editor 2009, Arkema Inc.: King of Prussia, PA. p. 5.

43. Kim, Y.-C. and B.J. McCoy, Degradation Kinetics Enhancement of Polystyrene by Peroxide Addition. Industrial \& Engineering Chemistry Research, 2000. 39(8): p. 2811-2816.

44. Madras, G. and B.J. McCoy, Oxidative degradation kinetics of polystyrene in solution. Chemical Engineering Science, 1997. 52(16): p. 2707-2713.

45. Scorah, M.J., et al., Peroxide-Controlled Degradation of Polypropylene Using a Tetra-Functional Initiator. Polymer Engineering and Science, 2009. 49: p. 17601766.

46. AASHTO, AASHTO T 315-10 Determining the Rheological Properties of Asphalt Binder Using a Dynamic Shear Rheometer (DSR), in AASHTO Standard Specifications for Transportation Materials and Methods of Sampling and Testing.2011, American Association of State Highway and Transportation Officials: Washington D.C.

47. Naskar, M., T.K. Chaki, and K.S. Reddy, A Novel Approach to Recycle the Waste Plastics by Bitumen Modification for Paving Application. Advanced Materials Research, 2012. 356: p. 1763-1768.

48. Lamontagne, J., Durrieu, F., Planche, J. P., Mouillet, V., Kister, J., Direct and continuous methodological approach to study the ageing of fossil organic material 
by infrared microspectrometry imaging. Anal Chim Acta, 2001. Vol. 444(2): p. pp. 241-50.

49. Michigan Department of Transportation (MDOT), Special Provision for Superpave HMA Mixtures, 2003: Lansing, MI. p. 6.

50. AASHTO, T 340-10 Determining Rutting Susceptibility of Hot Mix Asphalt (HMA) Using the Asphalt Pavement Analyzer (APA) 2012, AASHTO: Washington, DC.

51. Goh, S.W. and Z. You, A simple stepwise method to determine and evaluate the initiation of tertiary flow for asphalt mixtures under dynamic creep test. Construction and Building Materials, 2009. 23(11): p. 3398-3405.

52. Zhanping You, Shu Wei Goh, and R.C. Williams, Development of Specification for the Superpave Simple Performance Tests (SPT), P.E. John W Barak, Editor 2009, Michigan Department of Transportation: Lansing, MI. p. 220.

53. AASHTO, TP 62-09 Developing Dynamic Modulus Master Curves for Hot Mix Asphalt (HMA), 2012, AASHTO: Washington, DC.

54. Goh, S.W. and Z. You. Resilient modulus and dynamic modulus of warm mix asphalt. in GeoCongress 2008: Geosustainability and Geohazard Mitigation, March 9, 2008 - March 12, 2008. 2008. New Orleans, LA, United states: American Society of Civil Engineers.

55. Goh, S.W. and Z. You. Evaluation of warm mix asphalt produced at various temperatures through dynamic modulus testing and four point beam fatigue testing. in 2011 GeoHunan International Conference - Pavements and Materials: Recent Advances in Design, Testing, and Construction, June 9, 2011 - June 11, 2011. 2011. Hunan, China: American Society of Civil Engineers (ASCE).

56. You, Z., et al., Evaluation of low-temperature binder properties of warm-mix asphalt, extracted and recovered rap and ras, and bioasphalt. Journal of Materials in Civil Engineering, 2011. 23(11): p. 1569-1574. 


\section{Appendix A: Copyright clearances}


ARTICLE 1: Copyright Clearance of Journal Paper — Properties of Modified Asphalt Binders Blended with Electronic Waste Powders, 2012, American Society of Civil Engineers (ASCE). The full article has been used in Chapter 3 of this dissertation. The permission to reuse in dissertation is as follows: 
RightslinkB by Copyright Clearance Center - Mozilla Firefox

A https://s100.copyright.com/AppDispatchServlet

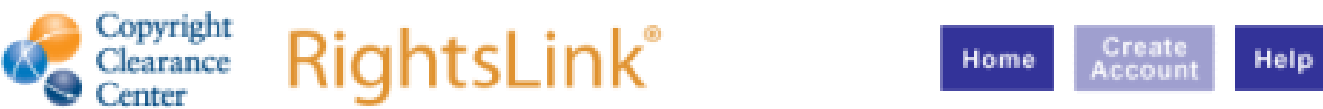

AMERICAN SOCETY OF ONI ENGINEERS
Title:

Author:

Waste Powders

Colbert, B. and You, Z.

Publication: Journal of Materials in Civil Engineering

Publisher: American Society of Civil Engineers

Date: $\quad 10 / 01 / 2012$

Copyright (2) 2012, ASCE. All rights reserved.

\begin{tabular}{l} 
User ID \\
Password \\
\hline Enable Auto Login \\
LoGin \\
Forgot Password/User ID? \\
If you're a copyright.com \\
user, you can login to \\
RightsLink using your \\
copyright.com credentials. \\
Already a RightsLink user or \\
want to learn more?
\end{tabular}

Permissions Request

As an ASCE author, you are permitted to reuse you own content for another ASCE or non-ASCE publication.

Please add the full credit line "With permission from ASCE" to your source citation. Please print this page for your records.

Type of use: Dissertation/Thesis

Portion: full article

Format: print and electronic

Use of this content will make up more than $25 \%$ of the new work: no

Author of this ASCE work or ASCE will publish the new work: yes

\section{BACK CLOSE WINDOW}

Copyright Q 2012 Cepyriaht Clearance Center. Ins. All Rights Reserved. Privacy statement.

Comments? We would like to hear from you. E-mail us at customercare Decopyriaht.com 